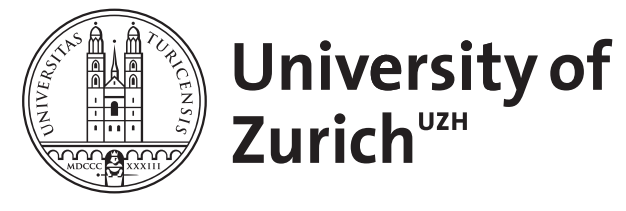

Zurich Open Repository and Archive

University of Zurich

University Library

Strickhofstrasse 39

CH-8057 Zurich

www.zora.uzh.ch

Year: 2007

\title{
Medialität in mediävistischer Perspektive
}

Kiening, Christian

Posted at the Zurich Open Repository and Archive, University of Zurich

ZORA URL: https://doi.org/10.5167/uzh-92944

Journal Article

Published Version

Originally published at:

Kiening, Christian (2007). Medialität in mediävistischer Perspektive. Poetica:285-352. 


\title{
Medialität in mediävistischer Perspektive
}

Kiening, Christian

in: Poetica - 39 | Periodical

68 page(s) ([285] - 352)

\section{Nutzungsbedingungen}

DigiZeitschriften e.V. gewährt ein nicht exklusives, nicht übertragbares, persönliches und beschränktes Recht auf Nutzung dieses Dokuments. Dieses Dokument ist ausschließlich für den persönlichen, nicht kommerziellen Gebrauch bestimmt. Das Copyright bleibt bei den Herausgebern oder sonstigen Rechteinhabern. Als Nutzer sind Sie sind nicht dazu berechtigt, eine Lizenz zu übertragen, zu transferieren oder an Dritte weiter zu geben.

Die Nutzung stellt keine Übertragung des Eigentumsrechts an diesem Dokument dar und gilt vorbehaltlich der folgenden

Einschränkungen:

Sie müssen auf sämtlichen Kopien dieses Dokuments alle Urheberrechtshinweise und sonstigen Hinweise auf gesetzlichen Schutz beibehalten; und Sie dürfen dieses Dokument nicht in irgend einer Weise abändern, noch dürfen Sie dieses Dokument für öffentliche oder kommerzielle Zwecke vervielfältigen, öffentlich ausstellen, aufführen, vertreiben oder anderweitig nutzen; es sei denn, es liegt Ihnen eine schriftliche Genehmigung von DigiZeitschriften e.V. und vom Herausgeber oder sonstigen Rechteinhaber vor.

Mit dem Gebrauch von DigiZeitschriften e.V. und der Verwendung dieses Dokuments erkennen Sie die Nutzungsbedingungen an.

\section{Terms of use}

DigiZeitschriften e.V. grants the non-exclusive, non-transferable, personal and restricted right of using this document. This document is intended for the personal, non-commercial use. The copyright belongs to the publisher or to other copyright holders. You do not have the right to transfer a licence or to give it to a third party.

Use does not represent a transfer of the copyright of this document, and the following restrictions apply:

You must abide by all notices of copyright or other legal protection for all copies taken from this document; and You may not change this document in any way, nor may you duplicate, exhibit, display, distribute or use this document for public or commercial reasons unless you have the written permission of DigiZeitschriften e.V. and the publisher or other copyright holders.

By using DigiZeitschriften e.V. and this document you agree to the conditions of use.

\author{
Kontakt / Contact \\ DigiZeitschriften e.V. \\ Papendiek 14 \\ 37073 Goettingen \\ Email: info@digizeitschriften.de
}


Christian Kiening (Zürich)

\section{MEDIALITÄT IN MEDIÄVISTISCHER PERSPEKTIVE ${ }^{1}$}

\section{Medium und Medien}

Das Verhältnis der mediävistischen Disziplinen zu den in den Geistes-, Kultur- und Sozialwissenschaften zunehmend dominant gewordenen medialen Fragestellungen ist ein janusköpfiges. Einerseits haben sich diese Disziplinen seit längerem mit Dimensionen von Mündlichkeit und Schriftlichkeit, Textualität und (Audio-)Visualität, Kommunikation und Wahrnehmung beschäftigt, Dimensionen, die auch in medialer Perspektive zentrales Gewicht besitzen. Andererseits haben sie sich lange dem expliziten Anschluß an medientheoretische Kategorien oder Modelle verweigert wohl nicht nur aus Reserviertheit gegenüber postmodernen Theoriekapriolen, sondern auch aus Skepsis gegenüber vorschnellen Applikationen, welche die Eigenheit vergangener Gesellschaften, ihrer Strukturen und Imaginationen, auf einige wenige (technische) Parameter verkürzen.

Die Skepsis hat ihren guten Grund, sind doch Ausgangspunkt und Gegenstand der sich im 20. Jahrhundert konstituierenden Medienwissenschaften überwiegend zeitgenössische Phänomene der Kommunikations-, Verbreitungs- oder Massenmedien bzw. der elektronischen oder digitalen Medien. ${ }^{2}$ Auch hat die rasante Eigendynamik der medienwissenschaftlichen

1 Die folgenden Überlegungen kommen aus dem größeren Kontext des seit 1. Oktober 2005 bestehenden Nationalen Forschungsschwerpunkts Medienwandel - Medienwechsel - Medienwissen. Historische Perspektiven (leading house: Universität Zürich); siehe unter www.mediality.ch.

2 Angesichts der kaum überschaubaren englischsprachigen Literatur, die Schwerpunkte im Bereich der Medienanthropologie, der Mediensoziologie und der Massenkommunikationsforschung besitzt, und der enormen Ausdifferenzierung in der deutschen Medienwissenschaft (Medienwirkungsforschung, Medienpsychologie, Medienpädagogik, Mediensoziologie, Medienökonomie, Medienökologie, Medienrecht, Medienethik, Mediendidaktik, Medieninformatik u.a.) beschränke ich mich auf die Nennung einiger theoretisch anspruchsvoller und weiterführender Werke. Den umfangreichsten Überblick bietet: Joachim-Felix Leonhard u. a. (Hg.), Medienwissenschaft. Ein Handbuch zur Entwicklung der Medien und Kommunikationsformen, 3 Bde., Berlin/New York 1999-2002. Außerdem: Rainer Bohn/Eggo Müller/Rainer Ruppert (Hg.), Ansichten einer künftigen Medienwissenschaft, Berlin 1988; Klaus Merten/Siegfried J. 
Entwicklung, samt Ausbreitung in Kulturwissenschaft und Kulturtheorie, zu einer enormen Fülle unterschiedlicher Medienbegriffe und -metaphern geführt. ${ }^{3}$ Nicht nur die traditionellen Formen erscheinen hier als Medien: (1) materielle festkörperhafte Träger (Buch, Tonband, CD-Rom), (2) nachrichtentechnische Übertragungssubstanzen (Luft, Wasser, Elektrizität, Papier), (3) anthropomorphe Übermittlungsfiguren (Boten, Engel, Geister), (4) Komplexe nicht-personaler Kommunikation (Presse, Film, Fernsehen), (5) basale Zeichensysteme oder Äußerungsorgane (Sprache, Stimme), (6) institutionalisierte Ausdrucksformen bzw. soziale Subsysteme (Literatur, Kunst). ${ }^{4}$ Auch der Mensch selbst gilt in bestimmten Zusammenhängen als Medium, ${ }^{5}$ ebenso eine bunte Palette materieller Formen und symbolischer

Schmidt/Siegfried Weischenberg (Hg.), Die Wirklichkeit der Medien. Eine Einführung in die Kommunikationswissenschaft, Opladen 1994; Daniela Kloock/ Angela Spahr (Hg.), Medientheorien. Eine Einführung, München 1997; Peter Ludes, Einfiuhrung in die Medienwissenschaft. Entwicklungen und Theorien, Berlin ${ }^{2} 2003$ ( $\left.{ }^{1} 1998\right)$; Claus Pias u.a. (Hg.), Kursbuch Medienkultur. Die maßgeblichen Theorien von Brecht bis Baudrillard, Stuttgart ${ }^{4} 2004$ ('1999); Helmut Schanze (Hg.), MetzlerLexikon Medientheorie - Medienwissenschaft. Ansätze - Personen - Grundbegriffe, Stuttgart, Weimar 2002; Günter Bentele/Hans-Bernd Brosius/Otfried Jarren (Hg.), Öffentliche Kommunikation. Handbuch Kommunikations- und Medienwissenschaft, Opladen 2003; Stefan Weber (Hg.), Theorien der Medien. Von der Kulturkritik bis zum Konstruktivismus, Konstanz 2003; Alice Lagaay/David Lauer (Hg.), Medientheorien. Eine philosophische Einführung, Frankfurt a. M./New York 2004; Claudia Fraas/Michael Klemm (Hg.), Mediendiskurse, Frankfurt a. M. u. a. 2005; Alexander Roesler/Bernd Stiegler (Hg.), Grundbegriffe der Medientheorie, Paderborn 2005; Dieter Mersch, Medientheorien zur Einfuihrung, Hamburg 2006.

3 Vgl. zum Überblick Jochen Schulte-Sasse, ,Medien/medial“, in: Karlheinz Barck u. a. (Hg.), Ästhetische Grundbegriffe, Bd. 4, Stuttgart/ Weimar 2000, S. 1-38; Georg Christoph Tholen, „Medium/Medien“, in: Roesler/Stiegler (Hg.), Grundbegriffe (wie Anm. 2), S. 150-172; zu den Metaphern schon Klaus Krippendorf, „Der verschwundene Bote. Metaphern und Modelle der Kommunikation“, in: Merten/Schmidt/ Weischenberg (Hg.), Die Wirklichkeit der Medien (wie Anm. 2), S. 79-113.

${ }^{4}$ In abstrakterer wissenschaftssystematischer Form unterscheidet Roland Posner einen biologischen, einen physikalischen, einen technischen, einen soziologischen, einen kulturbezogenen und einen kodebezogenen Medienbegriff: Roland Posner, ,Zur Systematik der Beschreibung verbaler und nonverbaler Kommunikation", in: HansGeorg Bosshardt (Hg.), Perspektiven auf Sprache. Interdisziplinäre Beiträge zum Gedenken an Hans Hörmann, Berlin/New York 1986, S. 267-313, hier S. 293-298; zu Sprache als Medium verschiedene Beiträge von Ludwig Jäger, z. B. „Die Sprachvergessenheit der Medientheorie. Ein Plädoyer für das Medium Sprache“, in: Werner Kallmeyer (Hg.), Sprache und Neue Medien, Berlin/ New York 2000, S. 9-30.

5 Peter Fuchs/ Andreas Göbel (Hg.), Der Mensch - das Medium der Gesellschaft?, Frankfurt a. M. 1994; Stefan Rieger, Die Individualität der Medien. Eine Geschichte der Wissenschaften vom Menschen, Frankfurt a. M. 2001. 
Formationen: ,[...] ein Stuhl, ein Rad, ein Spiegel (McLuhan), eine Schulklasse, ein Fußball, ein Wartezimmer (Flusser), das Wahlsystem, der Generalstreik, die Straße (Baudrillard), ein Pferd, das Dromedar, der Elefant (Virilio), Grammophon, Film, Typewriter (Kittler), Geld, Macht und Einfluß (Parsons), Kunst, Glaube und Liebe (Luhmann)." 6

Die Ausdehnung des Medienbegriffs auf alles nur Denkbare provoziert die Frage, was der Begriff unter solchen Umständen zu leisten vermöge. Eine neuere Medienästhetik fokussiert denn auch besonders die Grenzen des Medialen, seine Inszenierungen und Paradoxierungen. ${ }^{7}$ Eine Medienphilosophie ${ }^{8}$ und eine ,negative' Medientheorie ${ }^{9}$ richten das Augenmerk auf die Konstitutionsbedingungen und blinden Flecke von Medialität. Deutlich wird dabei, daß, selbst wenn man Medialität an Materialität bindet (was nicht alle Modelle tun), die Beobachtbarkeit des Medialen eine konstitutive Kippfigur darstellt: Nicht nur sind Medien nicht als solche gegeben, auch Medienträger , $[\ldots]$ sind für uns nur dann zugänglich, wenn sie gerade nicht als Medienträger fungieren, sondern sich schlicht als Gegenstände der profanen Außenwirklichkeit präsentieren - wobei sich dann wiederum die Frage stellt, von welchen Zeichenträgern diese Geräte ihrerseits präsentiert und getragen werden." ${ }^{\text {10 }}$

Diese ,Unschärferelation“ des Medialen, verbunden mit der Vervielfachung der Medienbegriffe, legt es nahe, sich auf das breite Bedeutungsspektrum von medium zu besinnen, um über die Kommunikations-, Verbreitungs- und Übertragungsmedien hinaus zu einer systematischen Bestimmung des Medialen vorzustoßen. Das lateinische Substantiv medium bezeichnete schon in der Antike in allgemeiner räumlicher wie zeitlicher

6 Alexander Roesler, „Medienphilosophie und Zeichentheorie“, in: Stefan Münker/ Alexander Roesler/Mike Sandbothe (Hg.), Medienphilosophie. Beiträge zur Klärung eines Begriffs, Frankfurt a. M. 2003; S. 34-52, hier S. 34.

7 Zum Beispiel Hans Ulrich Reck (Hg.), Inszenierte Imagination - Beiträge zu einer historischen Anthropologie der Medien, Wien/New York 1996; Sigrid Schade/Georg Christoph Tholen (Hg.), Konfigurationen. Zwischen Kunst und Medien, München 1999; Hans Ulrich Reck, Kunst als Medientheorie. Vom Zeichen zur Handlung, München 2003.

8 Frank Hartmann, Medienphilosophie, Wien 2000; Münker/Roesler/Sandbothe (Hg.), Medienphilosophie (wie Anm. 6), Mike Sandbothe/Ludwig Nagl (Hg.), Systematische Medienphilosophie, Berlin 2005; Reinhard Margreiter, Medienphilosophie, Berlin 2007.

9 Dieter Mersch, „Medialität und Undarstellbarkeit. Einleitung in eine ,negative 'Medientheorie“, in: Sybille Krämer (Hg.), Performativität und Medialität, München 2004, S. 75-95; ders., „Absentia in praesentia. Negative Medialität“, in: Christian Kiening (Hg.), Mediale Gegenwärtigkeit, Zürich 2007, S. 77-90.

10 Boris Groys, Unter Verdacht. Eine Phänomenologie der Medien, München/Wien 2000, S. 21. 
Hinsicht die Mitte, den Mittelpunkt, das Mittlere, das Mittel, das Vermittelnde, ohne daß dabei die spezifisch materiellen Bedingungen von Übertragung, Vermittlung oder Verbreitung im Blick gewesen wären. ${ }^{11}$ Das gilt auch für das Mittelalter. Bei Thomas von Aquin begegnet medium am häufigsten in den Kommentaren $\mathrm{zu}$ den aristotelischen Schriften, wo die M it te l oder Werkzeuge des Schlusses, des Beweises oder der Wahrnehmung (medium demonstrationis, medium cognoscendi) eine zentrale Rolle spielen. ${ }^{12}$ Daneben gibt es unzählige Hinordnungen von zwei Größen auf eine $\mathrm{M}$ it t e hin: das Glied, welches das mittlere eines Syllogismus bildet (medius terminus), der Mensch als medium zwischen utibilia und fruibilia, die auctoritates als medium zwischen Altem und Neuem Testament, die natura als medium zwischen essentia und persona distincta, der intellectus als medium zwischen natura und voluntas, die potentia generandi als medium zwischen absolutum und relatum (alle Beispiele aus dem frühen Scriptum super sententiis). Schließlich aber kann diese Mitte auch eine ontologische Dimension haben, sichtbar dort, wo darüber reflektiert wird, inwieweit der Sohn, indem er von einem anderen Seienden etwas der Person, aber nicht der Substanz nach habe (,habere aliquid ab alio personaliter et non essentialiter"), ${ }^{13}$ ein Medium darstelle zwischen dem Schöpfer und dem Geschaffenen, oder dort, wo die Frage erörtert wird, inwieweit ein Engel den Status des Mittleren überschreite (,Utrum Angelus in suo motu de necessitate transeat medium"). ${ }^{14}$

Sowohl die antike wie die mittelalterliche Theologie, Philosophie und Wissenschaft gingen von einer inneren (substanziellen, genealogischen, logischen) Beziehung zwischen dem Medium und seinen Bezugspunkten aus. Für Aristoteles (De interpretatione I, 16 a 3 ) und andere galt die Stimme als der Seele verwandt: „Als Erzeuger des ersten Signifikanten ist sie nicht bloß ein Signifikant unter anderen. Sie bezeichnet den ,Seelenzustand“, der seinerseits die Dinge in natürlicher Ähnlichkeit widerspiegelt oder reflektiert." ${ }^{15}$ Im Rahmen der Sehtheorien war das platonische Modell einfluß-

1 Vgl. allgemein Kurt Röttgers/Monika Schmitz-Emans (Hg.), Mitte. Philosophische, medientheoretische und ästhetische Konzepte, Essen 2006.

12 Vgl. den Index thomisticum: http://www.corpusthomisticum.org. Zitate im Folgenden nach den ebd. online zugänglichen Opera omnia (hier: S. Thomae Aquinatis Scriptum super Sententiis magistri Petri Lombardi, Bd. 1, hg. von Pierre Mandonnet, Paris 1929).

13 Script. lib.1 d. 20 q. 1 a. 2 arg. 2; http://www.corpusthomisticum.org/snp1019.html.

14 Script. lib. 1 d. 37 q. 4 a. 2; http://www.corpusthomisticum.org/snp1035.html.

15 Jacques Derrida, Grammatologie (1967), übers. von Hans-Jörg Rheinberger und Hanns Zischler, Frankfurt a. M. 1974, S. 24; vgl. auch Karl-Heinz Göttert, Geschichte der Stimme, München 1998. 
reich, demgemäß das Auge oder der Sehstrahl ein Medium ist, welches Substanzen transportiert und Berührungen herstellt: „Wenn der innere Strahl aus dem Auge auftaucht, vermischt er sich mit dem äußeren Licht und dehnt sich bis zum undurchsichtigen Gegenstand aus. Auf Grund seiner natürlichen Beweglichkeit verteilt er sich ganz auf der Oberfläche des Gegenstands und übernimmt seine Gestalt (figura) und Farbe. Auf diese Weise geformt und gefärbt, kehrt der Strahl durch dieselben Öffnungen zur Seele zurück und bringt die Gestalt und Farbe des Gegenstands mit. “16

Noch in der frühneuzeitlichen Naturphilosophie eines Paracelsus, wo der Ausdruck medium ins Deutsche übernommen ist, bezieht er sich überwiegend auf aisthetische, magische oder metaphysische Zusammenhänge. Wenig später aber, im Rahmen der sich entwickelnden Naturwissenschaften, der Optik und der Akustik rücken die Eigenschaften von Trägersubstanzen und die Dimensionen von Übertragung, Vermittlung und Verbreitung ins Zentrum. ${ }^{17}$ Im Gefolge von Keplers Netzhauttheorie etabliert sich eine mechanisierte Vorstellung des Sehaktes, die schließlich auch in den ,technisierten Blicken " von Literatur und Kunst ein Entfaltungsfeld findet. ${ }^{18}$ Seit dem ausgehenden 18. Jahrhundert weitet sich das Bedeutungsspektrum des Ausdrucks in Kunst, Literatur und Ästhetik, Physik und Technik, Magnetismus, Mesmerismus und Spiritismus: ,Medium‘ bezeichnet nun einerseits ideelle Formen der Reflexion als Vermittlungen zwischen Transzendenz und Immanenz sowie den Menschen als Medium, andererseits physikalische Formen der Übertragung (Fluidum, Äther, Kräfte) und den Automaten als ,äußerlich sichtbare[n] Teil einer komplexen Medienanordnung“. ${ }^{19}$

16 David C. Lindberg, Auge und Licht im Mittelalter. Die Entwicklung der Optik von Alkindi bis Kepler (1976), übers. von Matthias Althoff, Frankfurt a. M. 1987, S. 169 in Bezug auf Wilhelm von Conches (12. Jahrhundert).

17 Vgl. Stefan Hoffmann, Geschichte des Medienbegriffs, Hamburg 2002, der das Mittelalter fast völlig übergeht; Material zur Berührung des Begriffs medium mit dem des Milieus bzw. der Umwelt bei Leo Spitzer, ,Milieu and Ambiance“, in: ders., Essays in Historical Semantics, New York ${ }^{2} 1968$ ( $\left.{ }^{1} 1948\right)$, S. 179-316; außerdem begriffsgeschichtlich Jochen Hörisch, „Die Medien der Natur und die Natur der Medien“, in: Joachim Wilke (Hg.), Zum Naturbegriff der Gegenwart, Bd. 2, Stuttgart 1994, S. 122137.

18 Ulrich Stadler, Der technisierte Blick. Optische Instrumente und der Status von Literatur. Ein kulturhistorisches Museum, Würzburg 2003; vgl. auch Harro Segeberg, „Rahmen und Schnitt. Zur Mediengeschichte des Sehens seit der Aufklärung“, in: Wirkendes Wort 43/1993, S. 286-301; Martina Wagner-Egelhaaf, „Gott und die Welt im Perspektiv des Poeten. Zur Medialität der literarischen Wahrnehmung am Beispiel Barthold Hinrich Brockes'“, in: Deutsche Vierteljahrsschrift für Literaturwissenschaft und Geistesgeschichte 71/1997, S. 183-216.

19 Hoffmann, Geschichte des Medienbegriffs (wie Anm. 17), S. 148. 
In diesem Zusammenhang konstituiert sich ein neuartiges Spannungsfeld des Medialen zwischen Materiellem und Immateriellem. In ihm gilt das ,Medium' gegenüber den Gegebenheiten, zwischen denen es ,vermittelt", als neutral und nicht mehr irgendwie gleichartig. Locke begründet eine Zeichentheorie, in der zwischen Bezeichnendem und Bezeichnetem keine Ähnlichkeitsbeziehung mehr herrscht. Empiristen wie Ferguson gehen zwar von ,Mittelursachen' aus, welche die Wahrnehmung der Dinge bewirken, denken sich diese aber ,,auf keine Weise der ersten Ursache oder dem Gegenstand der Wahrnehmung ähnlich“. ${ }^{20}$ Laurence Sterne entwirft in seinem Tristram Shandy (1759-1766) eine Poetik medialer Kontingenz, Friedrich Schiller in seinen Philosophischen Briefen das Bild eines Risses zwischen Gehirn/Bewußtsein und Natur/Wirklichkeit, der allein dadurch gekittet wird, daß das erstere selbst der materiellen Welt angehört. ${ }^{21}$

Eine eigentliche Medientheorie in nuce findet sich bei dem jungen Friedrich Schleiermacher. In seinen Reden Über die Religion (1799) umkreist er die Frage von Vermittlung und Unmittelbarkeit des Göttlichen, ausgehend von der Notwendigkeit, daß es Mittler gebe, die in privilegierter Form das Überirdische im Irdischen gegenwärtig machen. Gemäß christlicher Tradition ist Christus der Mittler schlechthin, doch er ist keineswegs der Einzige. Letztlich schlummert in jedem Einzelnen die Möglichkeit, zum Seher, Propheten, Medium zu werden. Als ein solcher muß er , ,[... nach jedem Ausflug seines Geistes ins Unendliche den Eindruck, den es ihm gegeben hat, hinstellen außer sich als einen mitteilbaren Gegenstand in Bildern oder Worten, um ihn selbst aufs neue in eine andere Gestalt und in eine endliche Größe verwandelt zu genießen, und er muß also auch unwillkürlich und gleichsam begeistert - denn er täte es, wenn auch Niemand da wäre - das, was ihm begegnet ist, für andere darstellen als Dichter oder Seher, als Redner oder als Künstler.“22 Die Mittler übertragen das Unverfügbare in Verfügbares, das Unendliche in Endliches, das Überweltliche in Innerweltli-

20 Adam Ferguson, Grundsätze der Moralphilosophie, Frankfurt a. M./Leipzig 1787, S. 52.

21 Zu Sterne vgl. David E. Wellbery, „Der Zufall der Geburt. Laurence Sternes Poetik der Kontingenz", in: Gerhart von Graevenitz/Odo Marquard (Hg.), Kontingenz, München 1998, S. 291-317; zu Schiller Rüdiger Safranski, Friedrich Schiller oder die Erfindung des Deutschen Idealismus, München/Wien 2004, S. $92 \mathrm{f}$.

22 Friedrich Schleiermacher, Über die Religion. Reden an die Gebildeten unter ihren Verächtern (anonyme Erstausgabe: Berlin 1799), Stuttgart 1969, S. 9 (1. Rede). Eine literarische Spiegelung der Thematik findet sich in der Figur Mittlers in Goethes Wahlverwandtschaften; vgl. Philipp W. Hildmann, „Die Figur Mittler aus Goethes Roman Die Wahlverwandtschaften als Repräsentant der Neologen“, in: Euphorion 97/2003, S. 51-71; Joseph Vogl, „Mittler und Lenker. Goethes Wahlverwandtschaften“, in: ders. (Hg.), Poetologien des Wissens um 1800, München 1999, S. 145-161. 
ches. Sie sind Medien der Darstellung und zugleich Träger von Emphase. Sie folgen einem inneren und keinem äußeren Antrieb und sind doch Ausdruck einer unaufhebbaren Trennung: „Möchte es doch je geschehen, daß dieses Mittleramte aufhörte und das Priestertum der Menschheit eine schönere Bestimmung bekäme! [...] Jeder leuchtete dann in der Stille sich und den Anderen, und die Mitteilung heiliger Gedanken und Gefühle bestünde nur in dem leichten Spiele, die verschiedenen Strahlen dieses Lichts jetzt zu vereinigen, dann wieder zu brechen, jetzt es zu zerstreuen, dann wieder hie und da auf einzelne Gegenstände zu konzentrieren. ${ }^{\text {‘23 }}$

Zwar geht Schleiermacher nach wie von einer inneren Verbundenheit von Medium und Medialisierten aus: Das Vermittelnde könne „unmöglich bloß Endlich sein; es muß Beiden angehören; es muß der göttlichen Natur teilhaftig sein ebenso und in eben dem Sinne, in dem es der endlichen teilhaftig ist". Doch nur utopisch oder eschatologisch sind ein unmittelbares Verstehen und eine unmittelbare Sinnübertragung denkbar. Auch wenn das Religiöse sich im Inneren verströmt, ist seine Mitteilung doch schon wieder gezeichnet durch eine „notwendige Reflexion“, die religiöses Empfinden und religiösen Ausdruck voneinander trennt: ,[...] wer kann über irgend etwas, das zum Bewußtsein gehört, reden, ohne erst durch dieses Medium hindurchzugehen. Nicht nur, wenn wir eine innere Handlung des Gemüts mitteilen, auch wenn wir sie nur in uns zum Stoff der Betrachtung machen und zum deutlichen Bewußtsein erhöhen wollen, geht gleich diese unvermeidliche Scheidung vor sich [...].“24

In dem Maße, in dem damit eine „Realität der Beobachtung zweiter Ordnung" normal wird, ${ }^{25}$ wird auch Kommunikation zum bevorzugten Entfaltungsort des Medialen. Zugleich entstehen soziale Systemstellen des Medialen, die als immanente und neutrale verschieden besetzt werden können - so wie umgekehrt verschiedene ,Medien' nun erst als kategorial gleichartig eingestuft werden können. Das ist die Voraussetzung, unter der Nietzsche in seiner Schrift Ueber Wahrheit und Lüge im außermoralischen Sinne (1873) den Gedanken, Sprache oder andere Medien vermöchten die Wirklichkeit oder die Wahrheit wiederzugeben, als Illusion erweist. Und das ist die Voraussetzung, unter der Wittgenstein in seinem Tractatus feststellt: „Die Grammophonplatte, der musikalische Gedanke, die Notenschrift, die Schallwellen, stehen alle in jener abbildenden internen Beziehung zu einan-

23 Schleiermacher, Über die Religion (wie Anm. 22), S. 10.

24 Ebd., S. 201 (5. Rede); S. 49 (2. Rede).

25 Niklas Luhmann, Die Realität der Massenmedien, ${ }^{3}$ Wiesbaden 2004 ( ${ }^{1}$ Opladen 1995), S. 153. Zur Ausbildung von ,modernen' Beobachtungsverhältnissen im 19. Jahrhundert Jonathan Crary, Techniken des Betrachters. Sehen und Moderne im 19. Jahrhundert (1990), übers. von Anne Vonderstein, Dresden/Basel 1996. 
der, die zwischen Sprache und Welt besteht. Ihnen allen ist der logische Bau gemeinsam.“ ${ }^{26}$ Die Aussage reflektiert die seit dem ausgehenden 19. Jahrhundert medial beschleunigte Technisierung und damit eine Situation, auf die auch die wenig später erprobte Verwendung des Plurals , Me die n ‘ reagiert. Diese Verwendung von Medien im Sinne von Kommunikationsmitteln wird schließlich auf dem Wege über amerikanische Soziologen und Kommunikationstheoretiker (Lasswell, Lazarsfeld) Eingang finden in die zunächst nachrichten- und informationstechnische, dann allgemein kulturwissenschaftliche Diskussion. $^{27}$

$\mathrm{Da}$ indes die vielfältig ausdifferenzierten neueren Medientheorien ihrerseits verschiedenste Kommunikations-, Verbreitungs-, Darstellungs- und Speichermedien und dabei immer wieder auch ältere Verständnisse des Medialen neu zur Geltung bringen, zeigt: Die Medienreflexion begleitet nicht nur die Entwicklung der Medien, sie stellt auch einen Bereich dar, der seine eigenen Dynamiken entfaltet. Das erschwert die Orientierung, eröffnet aber auch die Chance, inter- oder transdisziplinäre Anschlüsse kritisch zu befragen: auf Verschiebungen und Verwerfungen, Inkongruenzen und Anachronismen zwischen verschiedenen disziplinären Epistemen. In diesem Sinne kann der gegenwärtige medienwissenschaftliche, -historische und -theoretische ,Wildwuchs“ aus mediävistischer Sicht dazu dienen, eigene Kernbegriffe wie historische Modelle zu reflektieren und zu differenzieren. Schon die relativ junge Karriere der Begriffe ,Medium‘ und ,Medien“ kann auf die hermeneutische Dimension der Fragestellung aufmerksam machen: Das Instrumentarium, mit dem historische Wissenschaften sich der Vergangenheit nähern, ist immer ein prekäres, ein im Akt der Rekonstruktion selbst zu dekonstruierendes, zu historisierendes und neu zu konturierendes - an autonomie- bzw. geniesemantisch geprägten Leitbegriffen wie Autor und Literatur, Künstler und Kunstwerk wurde dies in den letzten Jahren besonders deutlich. $^{28}$

${ }^{26}$ Ludwig Wittgenstein, Logisch-philosophische Abhandlung (zuerst in den Annalen der Naturphilosophie 14,3-4/1921; als Buch unter dem Titel Tractatus-logico philosophicus, dt.-engl. 1922, ${ }^{2}$ 1933), in: ders., Tractatus logico philosophicus. Tagebücher 1914-1916. Philosophische Untersuchung, neu durchgesehen von Joachim Schulte, Frankfurt a. M. 1984, S. 27 (4.014).

27 Leschke, Einfiuhrung (wie Anm. 2), S. 10 f. mit dem Hinweis auf eine erste, aber folgenlose Begriffsverwendung durch den Publizistikwissenschaftler Emil Dovifat 1928. Zur Dynamisierung der Medien(diskurs)entwicklung vor und nach 1900 vgl. Stefan Andriopoulos/Bernhard Dotzler (Hg.), 1929. Schnittpunkte der Medialität, Frankfurt a. M. 2001; Albert Kümmel/Petra Löffler (Hg.), Medientheorie 1888-1933. Texte und Kommentare, Frankfurt a. M. 2002.

28 Paul Zumthor, La lettre et la voix. De la ,littérature 'médiévale, Paris 1987; Christian Kiening, Zwischen Körper und Schrift. Texte vor dem Zeitalter der Literatur, Frank- 
Für den medial orientierten Zugang zu mittelalterlicher Überlieferung hieße dies: Er stünde immer unter dem Vorzeichen, eine Medialität v o r den als solche bezeichneten Medien und vor den expliziten Mediendiskursen zum Thema zu machen. Und worauf es bei diesem Zugang ankäme, wäre, die mediengeschichtliche Perspektive nicht einfach nach rückwärts zu verlängern, sondern die historischen Eigendynamiken von $\mathrm{Mediali}$ ä t herauszuarbeiten. Es ist keine Frage: Kommunikations-, Überlieferungsund Verbreitungsformen früherer Gesellschaften können, auch wenn in ihrer Zeit nicht als kategorial zusammenhängend erfaßt, als ,Medien“ bezeichnet und in ihren je eigenen historischen Prozessen verfolgt werden. In diesem Sinne ließen sich schon für das Altertum - nicht nur hinsichtlich der griechischen Schriftlichkeit, deren Erforschung mit den Anfängen der Medienwissenschaft eng verbunden ist ${ }^{29}$ - sowohl ein elaborierter Mediengebrauch als auch eine nuancierte Medienreflexion nachzeichnen: anhand der ägyptischen Memorialkultur oder der vorderorientalischen Bildpraxis, der Thematisierung von Stimme und Schrift bei Hesiod und Platon, der Entfal-

furt a. M. 2003. Generell ist für die Reflexion geschichts-, kunst- und literaturwissenschaftlicher Terminologien zu verweisen auf die historisch-semantischen Standardwerke der jüngeren Zeit: Werner Conze/Otto Brunner/Reinhart Koselleck (Hg.), Geschichtliche Grundbegriffe - Historisches Lexikon zur politisch-sozialen Sprache, 7 Bde. und 2 Registerbde., Stuttgart 1972-1997, Studienausg. 2004; Klaus Weimar u. a. (Hg.), Reallexikon der deutschen Literaturwissenschaft. Neubearbeitung des Reallexikons der deutschen Literaturgeschichte, 3 Bde., Berlin/New York 1997-2003; Karlheinz Barck u. a. (Hg.), Ästhetische Grundbegriffe. Historisches Wörterbuch in sieben Bänden, 6 Bde. und 1 Registerbd., Stuttgart/Weimar 2000-2005.

29 Vgl. die Arbeiten von Eric A. Havelock, Preface to Plato, Cambridge (Mass.) 1963; The Literate Revolution in Greece and Its Cultural Consequences, Princeton 1982 (dt. teilweise: Schriftlichkeit. Das griechische Alphabet als kulturelle Revolution. Mit einer Einleitung von Aleida und Jan Assmann [S. 1-36: „Einleitung: Schrift - Kognition - Evolution“], Weinheim 1990); ders., The Muse learns to Write. Reflections on Orality and Literacy from Antiquity to the Present, New Haven 1982 (dt. 1992); siehe auch Wolfgang Kullmann/Michael Reichel (Hg.), Der Übergang von der Mündlichkeit zur Literatur bei den Griechen, Tübingen 1990; Barbara Patzek, Homer und Mykene. Mündliche Dichtung und Geschichtsschreibung, München 1992; Stefan Alkier/Anja Cornils, ,Bibliographie Mündlichkeit - Schriftlichkeit. Eine interdisziplinäre Bibliographie mit Arbeiten aus den Bereichen Theologie, Religionswissenschaften, Geschichtswissenschaft, Altphilologie, Linguistik, Literaturwissenschaft und Philosophie", in: Gerhard Sellin/François Vouga (Hg.), Logos und Buchstabe. Mündlichkeit und Schriftlichkeit im Judentum und Christentum der Antike, Tübingen/Basel 1997, S. 235-265; zusammenfassend Wolfgang Rösler, „Schriftlichkeit - Mündlichkeit“, in: Der Neue Pauly. Enzyklopädie der Antike, Bd. 11, Stuttgart/Weimar 2001, Sp. 241246; Barbara Patzek, „Mündlichkeit und Schriftlichkeit in der Antike“, in: Michael Maurer (Hg.), Aufriß der Historischen Wissenschaften, Bd. 5: Mündliche Überlieferung und Geschichtsschreibung, Stuttgart 2003, S. 14-41. 
tung materieller Form- und Vermittlungsdimensionen bei Aristoteles, der Vorstellung einer beständigen Selbstmitteilung der Welt durch simulacra, figurae oder imagines bei Lukrez. ${ }^{30} \mathrm{Im}$ Begriff der Medialität nun aber wäre dies alles nicht einfach gebündelt. In ihm wäre zugleich die Perspektive mitthematisch, unter der etwas als medial zu betrachten ist. ${ }^{31}$ Die Frage, wie Medialität sich in kulturellen Sinnbildungsleistungen sowohl zum Vorschein bringt wie verbirgt, wäre verbunden mit dem Anspruch, nicht einfach Medientheorien zu historisieren, sondern die historischen wie systemischen Bedingungen der Möglichkeit des Medialen ans Licht zu bringen. Es ginge also um eine mediengeschichtliche und medienwissenschaftliche Alterität, die in kritischer Distanz zu globalhistorischen Mustern operierte und auf das Grundsätzliche des Verhältnisses zwischen historischer Analyse und aktueller Theoriebildung bezogen wäre.

\section{Mediengeschichte der Vormoderne}

Die Schwierigkeiten eines solchen Unternehmens lassen sich exemplarisch verdeutlichen an zwei Büchern, beides Habilitationsschriften, die relativ früh medienhistorisch und -theoretisch argumentierten. Auf der einen Seite ist dies Michael Gieseckes materialreiche, monumentale und ambitiöse Studie zum Buchdruck in der frühen Neuzeit, eines der meistbeachteten medien- und kommunikationsgeschichtlichen Werke der letzten Jahrzehnte. Gie-

30 Jan Assmann, Das kulturelle Gedächtnis. Schrift, Erinnerung und politische Identität in frühen Hochkulturen, München 1992 u. ö.; Hartmut Böhme, „Welt aus Atomen und Körper im Fluß. Gefühl und Leiblichkeit bei Lukrez", in: Michael Großheim/ HansJoachim Waschkies (Hg.), Rehabilitierung des Subjektiven. Festschrift für Hermann Schmitz zum 65. Geburtstag, Bonn 1993, S. 413-439; Christoph Uehlinger, Images as media. Sources for the cultural history of the Ancient Near East and the Eastern Mediterranean (Ist millennium BCE), Fribourg/Göttingen 2000; Lorenz Engell/ Bernhard Siegert/Joseph Vogl (Hg.), Medien der Antike, Weimar 2003 (hier bezogen auf sowohl Basalmedien [Zahl] wie soziale Dispositive [Theater], medial-dingliche Formen [Leuchtfeuer, Botensysteme, öffentliche Post, öffentliche Rede] und symbolisch generalisierte Medien [Geld]); Christian Frevel (Hg.), Medien im antiken Palästina. Materielle Kommunikation und Medialität als Thema der Palästinaarchäologie, Tübingen 2005 (mit einem skeptischen Beitrag bezüglich inadäquater Applikationen von Christoph Uehlinger, ,,,Medien“ in der Lebenswelt des antiken Palästina?“, S. 31-61); Frank Haase, Metaphysik und Medien. Über die Anfänge medialen Denkens bei Hesiod und Platon, München 2005; ders., Die Aristotelische Philosophie der Medien, München 2006.

31 Vgl. Sybille Krämer, „Erfüllen Medien eine Konstitutionsleistung? Thesen über die Rolle medientheoretischer Überlegungen beim Philosophieren“, in: Münker/Roesler/Sandbothe (Hg.), Medienphilosophie (wie Anm. 8), S. 78-90, hier, S. 82. 
secke beschrieb die mit den neuen Druckverfahren einhergehenden kulturellen Veränderungen konsequent als Durchsetzung einer neuen Informations- und Kommunikationstechnologie. ${ }^{32}$ Seine Perspektive war geprägt von dem Eindruck eines gegenwärtigen epochalen medialen Wandels, von dem aus sich der vorausgehende Wandel in und seit der frühen Neuzeit in neuem Licht zeigte. Die Terminologie stammte aus System-, Kommunikations- und Informationstheorie, angereichert durch Elemente aus Technikgeschichte und Anthropologie. Das Ziel war es, die vielfältigen Dimensionen der neuen Reproduktionsweisen in einen globalen Rahmen zu stellen, in der Spannung von Selbst- und Fremdbeschreibungsformen zu entfalten und als umfassende soziale und kulturelle Revolution zu verstehen. Damit brachte Giesecke Bewegung in die oft positivistisch auf Titel, Techniken und Typen fixierte Inkunabel- und Frühdruckforschung. Auch sorgte er dafür, daß das frühe Buchdruckzeitalter einen prägnanteren Platz in den (post-)modernen Mediengeschichten bekam. Vor allem aus kulturwissenschaftlichem und allgemeinem Blickwinkel wurde die Studie, obschon ihre Kombination von Theoriebausteinen Bedenken weckte, emphatisch begrüßt und als Referenzwerk vielfach rezipiert. ${ }^{33}$ Aus fachspezifischerem Blickwinkel hingegen fielen besonders die Ungenauigkeiten, Inkongruenzen und Anachronismen ins Auge; gerade die Betonung des technisch Revolutionären schien angesichts der vielfältigen Übergangszonen zwischen Geschriebenem und Gedrucktem und der erst in der Reformationszeit erreichten gröBeren Breitenwirkung des Druckmediums verfehlt. ${ }^{34}$

32 Michael Giesecke, Der Buchdruck in der frühen Neuzeit. Eine historische Fallstudie über die Durchsetzung neuer Informations- und Kommunikationstechnologien, Frankfurt a. M. 1991.

33 Vgl. die Hinweise in Gieseckes Nachwort zur Taschenbuchausgabe, Frankfurt a. M. 1998. Abwägendes, aber tendenziell positives Urteil bei Jan-Dirk Müller in seiner Besprechung der Arbeit, in: Internationales Archiv für Sozialgeschichte der deutschen Literatur 18.1/1993, S. 168-178; differenzierte Auseinandersetzung mit den Grundlagen bei Georg Jäger, „Die theoretische Grundlegung in Gieseckes Der Buchdruck in der frühen Neuzeit. Kritische Überlegungen zum Verhältnis von Systemtheorie, Medientheorie und Technologie", in: ebd., S. 179-196.

34 Kritisch z.B. die Rezensionen von Gerd Dicke, in: Beiträge zur Geschichte der deutschen Sprache und Literatur 117/1995, S. 188-195; Ulrich Knoop, in: Zeitschrift für deutsches Altertum und deutsche Literatur 124/1995, S. 463-468. Vor allem um die Überbetonung des revolutionären Aspekts geht es Frieder Schanze: „Der Buchdruck eine Medienrevolution?", in: Walter Haug (Hg.), Mittelalter und frühe Neuzeit. Übergänge, Umbrüche und Neuansätze, Tübingen 1999, S. 286-311. Eine differenzierende Perspektive auf der Basis umfangreicher quantifizierender Untersuchungen findet sich bei Uwe Neddermeyer, Von der Handschrift zum gedruckten Buch. Schriftlichkeit und Leseinteresse im Mittelalter und in der frühen Neuzeit. Quantitative und qualitative 
Ebenfalls zwiespältig aufgenommen wurde die andere etwa zeitgleiche Pilotstudie, die komplementär zu Gieseckes Buch gelesen werden kann: Friederike Hassauers Rekonstruktion der Pilgerfahrt nach Santiago de Compostela als eines Paradigmas mittelalterlicher Medialität. ${ }^{35}$ Wo Giesekke vor allem die umstürzenden Veränderungen der Kommunikation durch die Umstellung von Handschrift auf Druck im Auge hatte, zielt Hassauer auf Formen der Kommunikation v or dem Zeitalter mechanischer Reproduktion und auf Mentalitäten einer Gesellschaft, die Sinn (noch) wesentlich an körperliche Vollzüge koppelte. Sie versteht die Pilgerreise als einen sowohl realen wie medialen, mentalen wie symbolischen Komplex der temporalen Mobilität eines ritualisierten Körpers, an dessen Bewegungen sich die Konstitution spezifischer sozialer Räume nachzeichnen läßt. Ihr Interesse gilt dem Verhältnis zwischen dem Körper als Medium und den Medienverbünden, die von der räumlichen Bewegung tangiert werden: Rede und Schrift, Bild, Skulptur und Architektur, Gesten, Riten und Zeremonien. Ihr Ziel ist es, eine Alterität sowohl des Körpers wie des Raums, des Semantischen wie des Medialen ans Licht zu bringen, die als genuines Element der ,Aufbewahrungssysteme' einer Epoche gelten soll. Eine tragfähige Historisierung mittelalterlicher Medialität ergibt sich daraus allerdings noch kaum. Dazu wäre es nötig, die begriffliche Kombinatorik mit analytischer Präzision und die kulturanthropologische Vogelschau mit historischer Tiefenschärfe zu versehen. So bleibt es bei einem Experiment von hohem Reflexionsgrad, aber geringer Anschaulichkeit. Zwar folgt Hassauer nicht wie Czerwinski der Idee einer grundsätzlichen Andersheit mittelalterlicher Wahrnehmungsverhältnisse, ${ }^{36}$ sie bewegt sich vielmehr im Rahmen einer histori-

Aspekte, 2 Bde., Wiesbaden 1998; siehe auch Gerd Dicke/Klaus Grubmüller (Hg.), Die Gleichzeitigkeit von Handschrift und Buchdruck, Wiesbaden 2003.

35 Friederike Hassauer, Santiago. Schrift - Körper - Raum - Reise. Eine medienhistorische Rekonstruktion, München 1993. Einige Rezensionen: L'Homme. Europäische Zeitschrift für Feministische Geschichtswissenschaft 5.1/1994, S. 154-156 (Gabriele Jutz); Mittellateinisches Jahrbuch 29.1/1994, S. 111 f. (Albert Gier); Cahiers de civilisation médiévale 38/1995, S. 37 f. (J. van Herwaarden); Arbitrium 14/1996, S. 37-41 (Bernhard Jahn); siehe auch Christian Kiening, ,Anthropologische Zugänge zur mittelalterlichen Literatur. Konzepte, Ansätze, Perspektiven“, in: Hans-Jochen Schiewer (Hg.), Forschungsberichte zur Germanistischen Mediävistik, Bern u.a. 1996, S. 11129, hier S. 69.

36 Peter Czerwinski, Der Glanz der Abstraktion. Frühe Formen von Reflexivität im Mittelalter. Exempel einer Geschichte der Wahrnehmung, Frankfurt a. M./New York 1989; ders., Gegenwärtigkeit. Simultane Räume und zyklische Zeiten, Formen von Regeneration und Genealogie im Mittelalter. Exempel einer Geschichte der Wahrnehmung II, München 1993; vgl. meine Rezension in Arbitrium 15/1997, S. 150-155, und Peter Strohschneider: „Die Zeichen der Mediävistik. Ein Diskussionsbeitrag zum 
schen Beschreibung der Materialität der Kommunikation. ${ }^{37}$ Doch zentral ist auch für sie der Gedanke einer einschneidenden mediengeschichtlichen Zäsur, der wie bei Giesecke, nur von der anderen Seite her, von zwei Prämissen begleitet wird: der Vorstellung von Medien als ,extensions of man “38 und der Vorstellung einer sich ,zwischen die Körper der Kommunikationspartner" drängenden Druckerpresse. ${ }^{39}$ Beide Prämissen basieren auf einer technisch geprägten Geschichte von Medien, die Evolution in großen Einheiten mißt: als Abfolge (der Dominanz) pri märe r Medien, die auf den Körper bezogen sind und ohne technische Hilfsmittel auskommen, se ku ndär e r Medien, die den Körper erweitern und auf Produzentenseite technische Hilfsmittel voraussetzen (Schrift, Druck), t e r ti ärer Medien, die von Produzenten wie Rezipienten den Einsatz von Technik erfordern (Grammophon, Telephon, Film, Radio, Fernsehen), schließlich qu a r tä re $r$ Medien, die mit den Prinzipien von Digitalisierung und Vernetzung eine Sender und Empfänger neu konfigurierende hybride Integration aller anderen Medien ermöglicht (Computer, Telekommunikation). ${ }^{40}$

So wichtig es ist, die funktionalen Unterschiede zwischen Medien herauszuarbeiten, so wenig ergiebig ist es, zumindest für die älteren Epochen, diese Unterschiede zu einem anthropologisch-technischen Narrativ globalen Charakters zu verknüpfen. Der vielberedete Übergang vom körpergebunde-

Mittelalter-Entwurf in Peter Czerwinskis Gegenwärtigkeit", in: Internationales Archiv für Sozialgeschichte der deutschen Literatur 20.1/1995, S. 173-191.

37 Hans Ulrich Gumbrecht/K. Ludwig Pfeiffer (Hg.), Materialität der Kommunikation, Frankfurt a. M. 1988; vgl. jetzt den Rückblick von Hans Ulrich Gumbrecht, „Materialität der Kommunikation“, in: Roesler/Stiegler, Grundbegriffe (wie Anm. 2), S. 144149.

38 Marshall McLuhan, Understanding Media. The Extensions of Man, London 1964 u. ö.; vgl. zu McLuhan das Kapitel bei Leschke, Einfuihrung (wie Anm. 2), S. 245-257, und den Beitrag von Oliver Lerone Schultz, ,Marshall McLuhan - Medien als Infrastrukturen und Archetypen“, in: Lagaay/Lauer (Hg.), Medientheorien (wie Anm. 2), S. 31-68.

39 Hans Ulrich Gumbrecht, „Beginn von ,Literatur'/ Abschied vom Körper?“, in: Gisela Smolka-Koerdt/Peter M. Spangenberg/Dagmar Tillmann-Bartylla (Hg.), Der Ursprung von Literatur. Medien, Rollen, Kommunikationssituationen zwischen 1450 und 1650, München 1988, S. 15-50.

$40 \mathrm{Zu}$ den ersten dreien: Harry Pross, Medienforschung, Darmstadt 1974; zu den vierten Roland Burkart, Kommunikationswissenschaft. Grundlagen und Problemfelder. Umrisse einer interdisziplinären Sozialwissenschaft, Wien/Köln/Weimar ${ }^{4} 2002\left({ }^{1} 1983\right)$. Es gibt zahlreiche andere in Begriffen und Phasen variierende Einteilungen; die angedeutete stimmt weitgehend überein mit der bei Werner Faulstich, Grundwissen Medien, München 1994 u. ö. in ,Mensch-Medien' (bis ca. 1500), ,Druck-Medien' (ca. 1500 - ca. 1900), ,elektronische Medien' (ca. 1900 - ca. 2000) und ,Substitutionsmedien“ (ab ca. 2000). 
nen Gedächtnis (,brain memory“) zum Schriftgedächtnis (,script memory“), der aus solcher Perspektive das Mittelalter kennzeichnen würde, geht einher mit Verwerfungen und Gemengelagen. Sie teleologisch zu ordnen hieße, auf den Differenzierungsgewinn zu verzichten, der gerade an der, Unsauberkeit' der Übergänge zu gewinnen ist. Zwar gibt es immer noch Tendenzen, eine körpergeprägte charismatische Kultur durch eine scholastischhumanistische abgelöst zu sehen. ${ }^{41}$ Doch gilt schon für Spätantike und Frühmittelalter: Schrift ist nicht schlechterdings ein Medium veräußerlichender Fixierung, sondern auch ein Medium der Selbstkonstitution und der Selbstsorge. ${ }^{42}$ Selbst monumentale Inschriften, in einer literalen Kultur wie der römischen scheinbar Ausdruck von Distanzkommunikation, können einer auf Invokation und Andacht bezogenen Selbstrepräsentation dienen. ${ }^{43}$ Umgekehrt können sich kleinformatige Objektinschriften, etwa diejenigen der Goldbrakteaten, in oral bestimmten Kulturen wie den germanischen statt als primärmagische Texte auch ,schon“ als ,inschriftliche Referate magischen Sprechens in der Götterwelt" erweisen. ${ }^{44}$

Für das hohe Mittelalter hat sich gezeigt: Die Zunahme pragmatischer Schriftlichkeit, die sich seit dem 12. Jahrhundert manifestiert, ${ }^{45}$ führt weder

41 Etwa C. Stephen Jaeger, The Envy of Angels. Cathedral Schools and Social Ideals in Medieval Europe, 950-1200, Philadelphia 1994; Auseinandersetzung damit bei Timo Reuvekamp-Felber, Volkssprache zwischen Stift und Hof. Hofgeistliche in Literatur und Gesellschaft des 12. und 13. Jahrhunderts, Köln/Weimar/Wien 2003, S. 78-101.

42 Das ist jetzt herausgearbeitet in der monumentalen, auf Augustinus zentrierten Arbeit von Christian Moser, Buchgestützte Subjektivität. Literarische Formen der Selbstsorge und Selbsthermeneutik von Platon bis Montaigne, Tübingen 2006; vgl. auch die Rezension von Jörg Dünne, „Subjektgeschichte und Schreibpraktiken. Eine Vorgeschichte der literarischen Autobiographie“, in: IASLonline [16.01.2007].

${ }^{43}$ Géza Alföldy/Silvio Panciera (Hg.), Inschriftliche Denkmäler als Medien der Selbstdarstellung in der römischen Welt, Stuttgart 2001.

44 Sean Nowak, Schrift auf den Goldbrakteaten der Völkerwanderungszeit. Untersuchungen zu den Formen der Schriftzeichen und zu formalen und inhaltlichen Aspekten der Inschriften, Diss. Göttingen 2003 (online unter http://webdoc.sub.gwdg.de/diss/ 2003/nowak), S. 670.

$45 \mathrm{Vgl}$. Michael T. Clanchy, From Memory to Written Record. England 1066-1307, Oxford ${ }^{2} 1993\left({ }^{1} 1979\right)$ u. ö.; Manfred Günther Scholz, Hören und Lesen. Studien zur primären Rezeption der Literatur im 12. und 13. Jahrhundert, Wiesbaden 1980; Brian Stock, The implications of literacy. Written language and models of interpretation in the 11th and 12th centuries, Princeton (N. J.) u. a. 1983; Sylvia Huot, From Song to Book. The Poetics of Writing in Old French Lyric and Lyrical Narrative Poetry, Ithaca/London 1987; Klaus Grubmüller/Hagen Keller/Nikolaus Staubach (Hg.), Pragmatische Schriftlichkeit im Mittelalter. Erscheinungsformen und Entwicklungsstufen, München 1992; Dennis H. Green, Medieval listening and reading. The primary reception of German literature 800-1300, Cambridge 1994; Margit Bihler, Buch und Schrift im mittelalterlichen Gebrauch. Textquellen aus Essens Mittelalter im 
zu einer Abnahme von Mündlichkeit noch zu einer Verminderung der auratischen Dimension von Schriftlichkeit. Sie führt weder zu einer Konkurrenz der ,Künste“ des Wortes und des Bildes ${ }^{46}$ noch zu einer ,Verdrängung ' des Körpers aus dem Kommunikationsprozeß. Vielmehr können alle diese Aspekte Effizienz- und Komplexitätssteigerungen erfahren. Die Vitalität der Stimme und die Präsenz von Körpern bleibt produktions- wie rezeptionsbezogen als Sinnhorizont gültig. ${ }^{47}$ Die Schrift dient nicht nur der Disziplinierung, Vereinheitlichung und Verstetigung, ${ }^{48}$ sie eröffnet, gerade weil sie

Lichte des historischen Funktionswandels der Schrift, Göppingen 1994; Ulrich Ernst, „Formen der Schriftlichkeit im höfischen Roman des hohen und späten Mittelalters“, in: Frühmittelalterliche Studien 31/1997, S. 252-369; Hagen Keller (Hg.), Schriftlichkeit und Lebenspraxis im Mittelalter. Erfassen, Bewahren, Verändern, München 1999; Christel Meier u. a. (Hg.), Pragmatische Dimensionen mittelalterlicher Schriftkultur, München 2002.

46 Vgl. dazu Ekkehard Mai/Kurt Wettengl (Hg.), Wettstreit der Künste. Malerei und Skulptur von Dürer bis Daumier [Ausstellungskatalog], München 2002. Zur LaokoonDiskussion und ihren Konsequenzen Karlheinz Stierle, „Das bequeme Verhältnis. Lessings Laokoon und die Entdeckung des ästhetischen Mediums", in: Gunter Gebauer (Hg.), Laokoon-Projekt. Pläne einer semiotischen Ästhetik, Stuttgart 1984, S. 2358; David E. Wellbery, Lessing's Laocoon. Semiotics and Aesthetics in the Age of Reason, Cambrigde 1984; Inka Mülder-Bach, „Bild und Bewegung. Zur Theorie bildnerischer Illusion in Lessings Laokoon", in: Deutsche Vierteljahrsschrift für Literaturwissenschaft und Geistesgeschichte 66/1992, S. 1-30; dies., Im Zeichen Pygmalions, München 1998; Mathias Mayer, Dialektik der Blindheit und Poetik des Todes. Über literarische Strategien der Erkenntnis, Freiburg/Br. 1997; Horst Althaus, Laokoon. Stoff und Form, Tübingen ${ }^{2} 2000\left({ }^{1} 1968\right)$; Monika Schrader, Laokoon - eine „vollkommene Regel der Kunst“. Ästhetische Theorien der Heuristik in der zweiten Hälfte des 18. Jahrhunderts: Winckelmann, (Mendelssohn), Lessing, Herder, Schiller, Goethe, Hildesheim/Zürich/New York 2005.

47 Paul Zumthor, La poésie et la voix dans la civilisation médiévale, Paris 1984; ders. La lettre (wie Anm. 28); Gregor Vogt-Spira, „Vox et Littera. Der Buchstabe zwischen Mündlichkeit und Schriftlichkeit in der grammatischen Tradition", in: Poetica 23/1991, S. 295-327; Michel Banniard, Viva voce. Communication écrite et communication orale du IV $V^{e}$ au IX siècle, Paris 1992; Clemens M. Kasper/Klaus Schreiner (Hg.), ,Viva vox' und ,ratio scripta'. Mündliche und schriftliche Kommunikationsformen im Mönchtum des Mittelalters, Münster 1997.

48 Gert Melville, „Zur Funktion der Schriftlichkeit im institutionellen Gefüge mittelalterlicher Orden“", in: Frühmittelalterliche Studien 25/1991, S. 391-417; Thomas Lentes/Thomas Scharff, „Schriftlichkeit und Disziplinierung. Die Beispiele Inquisition und Frömmigkeit", in: Frühmittelalterliche Studien 31/1997, S. 233-251; Karl Heidecker (Hg.), Charters and the Use of Writing in Medieval Society, Bruxelles 2000; Walter Pohl/Paul Herold (Hg.), Vom Nutzen des Schreibens. Soziales Gedächtnis, Herrschaft und Besitz im Mittelalter, Wien 2002; Ulrich Ernst, „Standardisiertes Wissen über Schrift und Lektüre, Buch und Druck. Am Beispiel des enzyklopädischen Schrifttums vom Mittelalter zur Frühen Neuzeit", in: Christel Meier (Hg.), Die Enzy- 
Dauerhaftigkeit und Autorität, Latenz, Situationsabstraktheit und Distanzkommunikation ermöglicht, auch der Inszenierung von Mündlichkeit oder dem Ineinander des Auratischen und Semiotischen, des Präsentischen und Reflexiven spezifische Geltungsdimensionen. ${ }^{49}$ Bildlichkeit und Schriftlichkeit stehen in einem vielfältigen Ergänzungsverhältnis. ${ }^{50}$ Dieses Ver-

klopädie im Wandel vom Hochmittelalter bis zur Frühen Neuzeit, München 2002, S. 451-494 und S. 580-585 (Abbildungen).

49 Vgl. Peter Ganz (Hg.), Das Buch als magisches und als Repräsentationsobjekt, Wiesbaden 1992; Barbara Frank/Thomas Haye/Doris Tophinke (Hg.), Gattungen mittelalterlicher Schriftlichkeit, Tübingen 1997; Ernst, „Formen der Schriftlichkeit“ (wie Anm. 45); Horst Wenzel, „Die Schrift und das Heilige“, in: ders./Winfried Seipel/Gotthart Wunberg (Hg.), Die Verschriftlichung der Welt. Bild, Text und Zahl in der Kultur des Mittelalters und der Frühen Neuzeit, Mailand/Wien 2000, S. 15-57; Klaus Schreiner, „Buchstabensymbolik, Bibelorakel, Schriftmagie. Religiöse Bedeutung und lebensweltliche Funktion heiliger Schriften im Mittelalter und in der Frühen Neuzeit“, in: ebd., S. 58-103; ders., „,Göttliche Schreib-Kunst“. Eigenhändige Aufzeichnungen Gottes, Jesu und Mariä. Schriftlichkeit in heilsgeschichtlichen Kontexten“, in: Frühmittelalterliche Studien 36/2002, S. 95-132; ders., „Litterae mysticae. Symbolik und Pragmatik heiliger Buchstaben, Texte und Bücher in Kirche und Gesellschaft des Mittelalters", in: Meier u.a. (Hg.), Pragmatische Dimensionen (wie Anm. 45), S. 277-337; Erika Greber/Konrad Ehlich/Jan-Dirk Müller (Hg.), Materialität und Medialität von Schrift, Bielefeld 2002; Michael Stolz/ Adrian Mettauer (Hg.), Buchkultur im Mittelalter. Schrift - Bild - Kommunikation, Berlin/New York 2006; siehe auch Kiening, Zwischen Körper und Schrift (wie Anm. 28) und ders./Martina Stercken (Hg.), SchriftRäume. Vom Mittelalter zur Moderne, Zürich 2008.

50 Vgl. einige klassische und neuere Arbeiten: Christel Meier/Uwe Ruberg (Hg.), Text und Bild. Aspekte des Zusammenwirkens zweier Künste in Mittelalter und früher Neuzeit, Wiesbaden 1980; Ruth Schmidt-Wiegand (Hg.), Text-Bild-Interpretation. Untersuchungen zu den Bilderhandschriften des Sachsenspiegels, Bd. 1: Textband; Bd. 2: Tafelband, München 1986; Michael Camille, The gothic idol. Ideology and imagemaking in medieval art, Cambridge 1989; Stephan Füssel/Joachim Knape (Hg.), Poesis et pictura. Studien zum Verhältnis von Text und Bild in Handschriften und alten Drucken. Festschrift für Dieter Wuttke zum 60. Geburtstag, Baden-Baden 1989; Wolfgang Harms (Hg.), Text und Bild, Bild und Text, Stuttgart 1990; Jens Wollesen, „,Ut Poesis Pictura'. Problems of Images and Texts in the Early Trecento“, in: Konrad Eisenbichler/Amilcare Iannucci (Hg.), Petrarchs Triumphs. Allegory and Spectacle, Ottawa 1990, S. 183-210; Christine Ratkowitsch, Descriptio Picturae. Die literarische Funktion der Beschreibung von Kunstwerken in der lateinischen Großdichtung des 12. Jahrhunderts, Wien 1991; Ulrich Ernst, Carmen figuratum. Geschichte des Figurengedichts von den antiken Ursprüngen bis zum Ausgang des Mittelalters, Köln/Weimar/Wien 1991; Eckart C. Lutz, ,Verschwiegene Bilder - geordnete Texte. Mediävistische Überlegungen“, in: Deutsche Vierteljahrsschrift für Literaturwissenschaft und Geistesgeschichte 70/1996, S. 3-47; Christel Meier-Staubach, ,Illustration und Textcorpus. Zu kommunikations- und ordnungsfunktionalen Aspekten der Bilder in den mittelalterlichen Enzyklopädiehandschriften", in: Frühmittelalterliche Studien 31/1997, S. 1-31; Jeffrey F. Hamburger, Nuns as artists. The visual culture of a medieval convent, Berkeley u.a. 1997; ders., The visual and the visionary. Art and fe- 
hältnis gewinnt zusätzliche Intensität durch neue genuin auf Wort-BildVerknüpfung angelegte Typen (Biblia pauperum, Speculum humanae salvationis, Ars moriendi, Totentanz etc.), durch den Einsatz neuer mechanischer Vervielfältigungsverfahren (Holzschnitt, Metallschnitt, Teigdruck) und durch das Experiment mit neuen Kombinationsmöglichkeiten (textierte Einblattdrucke, chiro- oder typoxylographische Blockbücher). ${ }^{51}$

Auch für die frühe Neuzeit gilt: Trotz einer Anonymisierung des Verhältnisses von Textproduzenten und -rezipienten, trotz einer Umstellung auf stille, private, häusliche Lektüre und Bildbetrachtung, trotz einer Umbesetzung der im Buchkörper selbst verankerten Sinngarantie zugunsten von Institutionen und Auktorialitäten ${ }^{52}$ - der Körper behält als Medium der Kom-

male spirituality in late medieval Germany, New York 1998; Michael Curschmann, „Wort - Schrift - Bild. Zum Verhältnis von volkssprachigem Schrifttum und bildender Kunst vom 12. bis zum 16. Jahrhundert", in: Haug, Mittelalter und Frühe Neuzeit (wie Anm. 34), S. 378-470; Eckart C. Lutz/Johanna Thali/René Wetzel (Hg.), Literatur und Wandmalerei, Bd. 1: Erscheinungsformen höfischer Kultur und ihre Träger im Mittelalter, Tübingen 2002; Horst Wenzel/Christina Lechtermann, Beweglichkeit der Bilder. Text und Imagination in den illustrierten Handschriften des, Welschen Gastes'von Thomasin von Zerclaere, Köln/Weimar/Wien 2002; Arwed Arnulf, Architektur- und Kunstbeschreibungen von der Antike bis zum 16. Jahrhundert, München 2003; Haiko Wandhoff, Ekphrasis. Kunstbeschreibungen und virtuelle Räume in der Literatur des Mittelalters, Berlin/New York 2003; Lutz/ Thali/Wetzel (Hg.), Literatur und Wandmalerei (siehe oben), Bd. 2: Konventionalität und Konversation, Tübingen 2005; Kathryn Starkey/Horst Wenzel (Hg.), Visual Culture and the German Middle Ages, New York 2005; Horst Wenzel/C. Stephen Jaeger (Hg.), Visualisierungsstrategien in mittelalterlichen Bildern und Texten, Berlin 2006; Johanna Thali, Schauliteratur. Formen und Funktionen literarischer Kommunikation in Text und Bild, Habil.-Schrift Freiburg (Schweiz) 2006.

51 Vgl. Michael Schilling, Bildpublizistik der frühen Neuzeit. Aufgaben und Leistungen des illustrierten Flugblatts in Deutschland bis um 1700, Tübingen 1990; GutenbergGesellschaft/Gutenberg-Museum (Hg.), Blockbïcher des Mittelalters. Bilderfolgen als Lektüren, Mainz 1991; Isa Fleischmann, Metallschnitt und Teigdruck. Technik und Entstehung zur Zeit des frühen Buchdrucks, Mainz 1998; Wolfgang Harms/Michael Schilling (Hg.), Das illustrierte Flugblatt in der Kultur der frühen Neuzeit, Frankfurt a. M. u. a. 1998; Volker Honemann u. a. (Hg.), Einblattdrucke des 15. und frühen 16. Jahrhunderts. Probleme, Perspektiven, Fallstudien, Tübingen 2000; Peter Schmidt, Gedruckte Bilder in handgeschriebenen Büchern. Zum Gebrauch von Druckgraphik im 15. Jahrhundert, Köln 2003.

52 Jan-Dirk Müller, „Der Körper des Buchs. Zum Medienwechsel zwischen Handschrift und Druck“, in: Gumbrecht/Pfeiffer, Materialität (wie Anm. 37), S. 203-217; vgl. auch Dolores Warwick Frese u.a. (Hg.), The book and the body, Notre Dame (Ind.) u. a. 1997; Aleida Assmann, ,Zur Neukonzeption von Schrift an der Medienschwelle um 1500“, in: ZDF-nachtstudio (Hg.), Tausend Jahre Abendland. Die großen Umbrüche 1000, 1500, 2000, Frankfurt a. M. 1999, S. 125-143. 
munikation zentrale Bedeutung. ${ }^{53}$ Weder die Ausbreitung neuer symbolischer Kommunikationsmedien ${ }^{54}$ noch die Verschiebung vom geschriebenen zum gedruckten Wort, die sich seit dem ausgehenden 15. Jahrhundert beobachten läßt, führt allein und in kurzer Zeit zu einem umfassenden gesellschaftlichen Wandel. Zwar verbindet sich diese Verschiebung mit der Reformation und erlaubt die Ausbildung einer öffentlichen Meinung und eines Diskurses des Politischen, ja der politischen Theologie, der , [...] die mediengestützte und dadurch überregional wirkende öffentliche Auseinandersetzung zu einem festen Bestandteil des politischen Prozesses selbst werden ließ. Wie die mediale Multiplikation den Zuschauerraum vor der politischen Bühne europaweit öffnete, so führte die Konfession auf der Bühne unterschiedlichste Interessenlagen der Protagonisten zusammen und ermöglichte auf diese Weise neue Gruppierungen und Formationen. “55 Doch war die frühneuzeitliche Gesellschaft nach wie vor eine (obschon veränderte) Präsenzgesellschaft, in der zwar immer mehr an öffentlicher und politischer Kommunikation im Medium des Drucks erfolgte, diese Kommunikation aber auf Formen der Anwesenheit bezogen blieb: (1) Das, was die mit den neuen Reproduktionsmöglichkeiten hergestellten Flugblätter, Pamphlete und Zeitschriften transportierten, waren zum Teil traditionelle Ideale von legitimer Herrschaft und mündlicher Wahrheitssicherung. ${ }^{56}(2)$ Das, was im

53 Klaus Schreiner/Norbert Schnitzler (Hg.), Gepeinigt, begehrt, vergessen. Symbolik und Sozialbezug des Körpers im späten Mittelalter und in der frühen Neuzeit, München 1992; Burkhardt Krause/ Ulrich Scheck (Hg.), Verleiblichungen. Literatur- und kulturgeschichtliche Studien über Strategien, Formen und Funktionen der Verleiblichung in Texten von der Frühzeit bis zum Cyberspace, St. Ingbert 1996; Johannes Burkhardt/ Christine Werkstetter (Hg.), Kommunikation und Medien in der Frühen Neuzeit, München 2005.

54 Niklas Luhmann, Liebe als Passion. Zur Codierung von Intimität, Frankfurt a. M. 1982; Philipp Wolf, Einheit, Abstraktion und literarisches Bewußtsein. Studien zur Ästhetisierung der Dichtung, zur Semantik des Geldes und anderen symbolischen Medien der frühen Neuzeit Englands, Tübingen 1998.

55 Rudolf Schlögl, „Öffentliche Gottesverehrung und privater Glaube in der Frühen Neuzeit. Beobachtungen zur Bedeutung von Kirchenzucht und Frömmigkeit für die Abgrenzung privater Sozialräume“, in: Gert Melville/Peter von Moos (Hg.), Das Öffentliche und Private in der Vormoderne, Köln/Weimar/Wien 1998, S. 165-209, hier S. 167.

56 Jan-Dirk Müller, „Publizistik unter Maximilian I. Zwischen Buchdruck und mündlicher Verkündigung“, in: Ute Frevert/Wolfgang Braungart (Hg.), Sprachen des Politischen. Medien und Medialität in der Geschichte, Göttingen 2004, S. 95-122; daß später die Publizistik auch mit einem Auraverlust von Herrschaft einhergehen kann, zeigt ebd., S. 123-138, Michael Schilling, „Medienspezifische Modellierung politischer Ereignisse auf Flugblättern des Dreißigjährigen Krieges“. Zum ganzen Komplex auch Wolfgang Harms/Gilbert Heß/Dietmar Peil (Hg.), SinnBilderWelten. Emblematische 
humanistischen, druckorientierten Austausch eine neue res publica litteraria konstituierte, basierte gerade auf der Grenzverwischung von personengebundener und anonymer Adressierung. ${ }^{57}$ (3) Das, was die religiöse Kommunikation auf die allen zugängliche Schrift zu verpflichten schien, operierte zugleich mit einem Vorrang oraler oder interaktioneller Kommunikation. $^{58}$

Insofern ist es zwar berechtigt, die Bedeutung der medialen Neuordnung der frühen Neuzeit herauszustreichen: Mit dem Eindringen der Schrift in viele Bereiche des Sozialen veränderten sich auch die Konzepte von Erkenntnis, Wahrheit und Wirklichkeit, von Nähe und Ferne. Im Gefolge der Reformation erfuhr das quantitativ wie qualitativ reich entfaltete spätmittelalterliche System der Medien des Heils eine massive Umstrukturierung. ${ }^{59}$ Doch erlebten in der gleichen Zeit auch Versuche, Medien in den Dienst einer Vision des Transzendenten zu stellen und zur Darstellung des Undarstellbaren zu nutzen, eine neue Blüte. ${ }^{60}$ Dementsprechend ist ein nuancierteres Raster für die Dynamisierungs- und Pluralisierungsprozesse der Zeit zu entwickeln. ${ }^{61} \mathrm{Zu}$ diesen Prozessen gehören, wie eingangs angedeutet, die

Medien der Frühen Neuzeit, München 1999; Franz Mauelshagen/Benedikt Mauer (Hg.), Medien und Weltbilder im Wandel der Frühen Neuzeit, Augsburg 2000.

57 Jürgen Fohrmann (Hg.), Gelehrte Kommunikation. Wissenschaft und Medium zwischen dem 16. und 20. Jahrhundert, Wien/Köln/Weimar 2005 (bes. der erste Teil von Leander Scholz und Andrea Schütte über Buchdruck und Simulation).

58 Hartmann Tyrell, ,Religiöse Kommunikation. Auge, Ohr und Medienvielfalt“, in: Klaus Schreiner (Hg.), Frömmigkeit im Mittelalter. Politisch-soziale Kontexte, visuelle Praxis, körperliche Ausdrucksformen, München 2002, S. 41-93, hier S. 87. Zur medialen Situation eines spezifischen Narrativs jetzt Johann Anselm Steiger/Ulrich Heinen (Hg.), Isaaks Opferung (Gen 22) in den Konfessionen und Medien der frühen Neuzeit, Berlin/New York 2006.

$59 \mathrm{Zu}$ diesem System vgl. etwa die Arbeiten von Thomas Lentes, „,Andacht' und ,Gebärde‘. Das religiöse Ausdrucksverhalten“, in: Bernhard Jussen/Craig Koslofsky (Hg.), Kulturelle Reformation. Sinnformationen im Umbruch, 1400-1600, Göttingen 1999, S. 29-67; ders., „Auf der Suche nach dem Ort des Gedächtnisses. Thesen zur Umwertung der symbolischen Formen in Abendmahlslehre, Bildtheorie und Bildandacht des 14.-16. Jahrhunderts", in: Klaus Krüger/ Alessandro Nova (Hg.), Imagination und Wirklichkeit. Zum Verhältnis von mentalen und realen Bildern in der frühen Neuzeit, Mainz 2000, S. 21-46; ders., ,Inneres Auge, äußerer Blick und heilige Schau. Ein Diskussionsbeitrag zur visuellen Praxis in Frömmigkeit und Moraldidaxe des späten Mittelalters“, in: Schreiner, Frömmigkeit (wie Anm. 58), S. 179-219. Zur Umstrukturierung Eamon Duffy, The Stripping of the Altars. Traditional Religion in England 1400-1580, New Haven/London ${ }^{2} 2005$ ( $\left.{ }^{1} 1992\right)$.

60 Vgl. Victor I. Stoichita, Das mystische Auge. Vision und Malerei im Spanien des Goldenen Zeitalters, München 1997.

61 Vgl. den SFB 573 „Pluralisierung und Autorität in der Frühen Neuzeit (15. bis 17. Jahrhundert)“" (München). 
Neugewichtung der Augenwahrnehmung, die Entwicklung optischtechnischer Medien oder die Ausbreitung neuer Zirkulationsmodelle und Alphabetisierungsschübe im 17. und 18. Jahrhundert. ${ }^{62} \mathrm{Zu}$ ihnen gehören auch Prozesse einer immer weitere Bereiche der Gesellschaft erfassenden Medialisierung, verbunden mit der Etablierung von Medienvorstellungen, die sich nicht mehr allein an Texten oder Bildern orientierten, sondern die vielfältigen Formen der Übermittlung, Übertragung und Verbreitung systemisch zusammenschlossen.

Vor allem die Zeit um und nach 1800 verdient in dieser Hinsicht Interesse: In ihr wirken alte, teilweise im Gefolge der Empfindsamkeit erneuerte Konzepte körper- und anwesenheitsgeprägter Kommunikation fort - Adam Müller etwa stellt 1816 in seinen Zwölf Reden über die Beredsamkeit die ,natürliche', lebendige, beflügelte Rede über die Schrift und diese wiederum über den Druck. Doch reagiert dies bereits auf eine Technisierung von Aufzeichnungsformen und eine Mechanisierung der Kommunikation, die ihren Anspruch aus der Ausschaltung von Subjektivem und Individualsemantischem gewinnen. Es formieren sich historistische ,Medien der Präsenz', die voraussetzen, daß Medialität gerade aufgrund ihrer Nichtidentität mit dem Ursprünglichen und Wirklichen Präsenz- und Intensitätseffekte produziere. ${ }^{63}$ In den Blick rücken sowohl die Materialitäten wie die Modelle von Kommunikation und Medialität. Theologische Figuren der emphatischen Identität von Bezeichnendem und Bezeichnetem erscheinen nun im Kontext einer sich autonomisierenden Literatur und Kunst, welche die physikalische Erscheinung der Transzendenz kunstreligiös wendet: „Auf ähnliche Weise ist das Kunstgefühl nur ein und derselbe himmlische Lichtstrahl, welcher aber, durch das mannigfach-geschliffene Glas der Sinnlichkeit un-

${ }^{62}$ Friedrich Kittler, Aufschreibesysteme 1800/1900, München ${ }^{4} 2003$ ( $\left.{ }^{1} 1985\right)$; Albrecht Koschorke, Körperströme und Schriftverkehr. Mediologie des 18. Jahrhunderts, München 1999; Martin Jay, „Scopic Regimes of Modernity“, in: Hal Foster (Hg.), Vision and Visuality, Seattle 1988, S. 3-27; Barbara Maria Staffords, Artful Science. Enlightenment, Entertainment, and the Eclipse of Visual Education, Cambridge (Mass.) 1994 (dt. 1998); Ulrike Hick, Geschichte der optischen Medien, München 1999; Friedrich Kittler, Optische Medien. Berliner Vorlesung, Berlin 2002; Nicole Gronemeyer, Optische Magie. Zur Geschichte der visuellen Medien in der Frühen Neuzeit, Bielefeld 2004; Helmar Schramm/Ludger Schwarte/Jan Lazardzig (Hg.), Spektakuläre Experimente. Praktiken der Evidenzproduktion im 17. Jahrhundert, Berlin/ New York 2006.

63 Jürgen Fohrmann/Andrea Schütte/Wilhelm Voßkamp (Hg.), Medien der Präsenz. Museum, Bildung und Wissenschaft im 19. Jahrhundert, Köln 2001. Zur Dimension des Präsentischen grundsätzlich Hans Ulrich Gumbrecht, Diesseits der Hermeneutik. Die Produktion von Präsenz, Frankfurt a. M. 2004; Kiening, Mediale Gegenwärtigkeit (wie Anm. 9). 
ter verschiedenen Zonen sich in tausenderlei verschiedene Farben bricht. “64 Von hier aus läßt sich erst eigentlich die Frage stellen, wie es Medien gelänge, , [...] das Phantasma ihrer Selbstüberschreitung zu erzeugen, so daß beim Rezipienten gegen alle Evidenz [...] suggestive, mitunter sogar halluzinatorische[] Faszinationen hervorgerufen werden."65 Das heißt zwar umgekehrt nicht, das Mittelalter sei allein von der Logik des e in e n Buches und dem Muster der imitatio bestimmt gewesen. ${ }^{66}$ Doch zweifellos spielen neben dem sich universalisierenden Mediengebrauch auch die um und nach 1800 entstehenden mediengeschichtlichen Vorstellungen eine konstitutive Rolle für die Moderne - und damit auch für die Art und Weise, in der diese das Mittelalter bzw. die ,Vormoderne‘ konturiert.

\section{Ansätze der Forschung}

Daraus ergibt sich die Spezifik einer medialen Perspektive auf die Vormoderne: Stehen seit dem 19. Jahrhundert die Entwicklung von neuen technischen Medien und die Entwicklung von Medienbeschreibung, -reflexion und -theorie in einem engen Wechselverhältnis, trifft diese Beschreibung, Reflexion und Theorie in den vorangehenden Epochen auf ein ,Anderes', das sie zwar als Vorgeschichte begreifen und hermeneutisch sich zu eigen machen kann, mit dem sie aber nicht genuin verbunden ist. Dieser ,Mangel besitzt methodologisch einen nicht zu unterschätzenden Vorteil: Er schafft jene Distanz, die es erlaubt, sowohl Modelle des Vergangenen zu bilden als auch die Bedingungen der Modellbildung unter die Lupe zu nehmen. Er fordert dazu auf, die Beschreibungskategorien nicht einfach an diejenigen medienwissenschaftlicher Diskurse anzuschließen, sondern zugleich zu historisieren und zu transformieren.

Geschichtswissenschaftlich zeigt sich zum Beispiel: Die Berührung mit mediengeschichtlichen Fragestellungen erfolgte in den letzten beiden Jahr-

64 Wilhelm Heinrich Wackenroder und Ludwig Tieck, Herzensergießungen eines kunstliebenden Klosterbruders (zuerst Berlin 1797), hg. von Martin Bollacher, Stuttgart 2005, S. 46 (aus dem von Wackenroder stammenden Beitrag „Einige Worte über Allgemeinheit, Toleranz und Menschenliebe in der Kunst“).

65 Martin Andree, Archäologie der Medienwirkung. Faszinationstypen von der Antike bis heute, München 2005, S. 24. Andree unterscheidet fünf verschiedene Grundtypen, die je eigene Phantasmen der Überschreitung ermöglichen und elementare wie spezifisch historisch-semantische Formen der Medienwirkung repräsentieren: Ähnlichkeit, Geheimnis, Unmittelbarkeit, Ursprung, Authentizität.

66 Martin Andree, Wenn Texte töten. Über Werther, Medienwirkung und Mediengewalt, München 2006, S. 213. 
zehnten eher über den Kommunikations- als den Medienbegriff. Der Kommunikationsbegriff schlug eine Brücke zum traditionellen rhetorischen, politischen und theologischen Terminus communicatio ${ }^{67}$ Und er verband sich mit historisch-semantischen Selbstbeschreibungsformen der mittelalterlichen Gesellschaft, bezogen auf politisch-symbolisches, rituell-zeremonielles Handeln, Boten-, Austausch- und Aushandlungsvorgänge, Einsatz von Körperlichkeit, Mündlichkeit und Schriftlichkeit. ${ }^{68}$ Der Medienbegriff

67 Vgl. Martin Kintzinger, ,Communicatio personarum in domo. Begriff und Verständnis einer Mitteilung von Wissen, Rat und Handlungsabsichten“, in: Heinz-Dieter Heimann/Ivan Hlaváček (Hg.), Kommunikationspraxis und Korrespondenzwesen im Mittelalter und in der Renaissance, Paderborn u.a. 1998, S. 139-164; Susanne de Vries/Peter Nitschke, „Consociatio und communicatio: Die politische Gemeinschaft als religiöse Ordnungs- und Rechtseinheit", in: Frederick S. Carney/Heinz Schilling/Dieter Wyduckel (Hg.), Jurisprudenz, Politische Theorie und Politische Theologie, Berlin 2004, S. 103-119; Sophia Menache, The vox Dei. Communication in the Middle Ages, New York/Oxford 1990; Johannes Arnold, ,Perfecta communicatio'. Die Trinitätstheologie Wilhelms von Auxerre, Münster 1995; Barbara Hallensleben, Communicatio. Anthropologie und Gnadenlehre bei Thomas de Vio Cajetan, Münster 1985; vgl. auch die Buchreihe Communicatio. Studien zur europäischen Literaturund Kulturgeschichte (Tübingen $1992 \mathrm{ff}$.) sowie Georg Stanitzek, „Kommunikation (Communicatio \& Apostrophe einbegriffen)“, in: Harro Müller/Jürgen Fohrmann (Hg.), Literaturwissenschaft, München 1995, S. 13-30.

68 Anstelle der vielen Arbeiten aus den letzten Jahrzehnten nenne ich nur den mit einer Bibliographie von fast 1600 Titeln versehenen Band von Marco Mostert (Hg.), New approaches to medieval communication, Turnhout 1999. Seitdem: Werner Rösener (Hg.), Kommunikation in der ländlichen Gesellschaft vom Mittelalter bis zur Moderne, Göttingen 2000; Gerd Althoff (Hg.), Formen und Funktionen öffentlicher Kommunikation im Mittelalter, Stuttgart 2001; Knut Görich, Die Ehre Friedrich Barbarossas. Kommunikation, Konflikt und politisches Handeln im 12. Jahrhundert, Darmstadt 2001; Helmut Bräuer/Elke Schlenkrich (Hg.), Die Stadt als Kommunikationsraum. Beiträge zur Stadtgeschichte vom Mittelalter bis ins 20. Jahrhundert. Festschrift für Karl Czok zum 75. Geburtstag, Leipzig 2001; Hedwig Röckelein (Hg.), Kommunikation, Berlin 2001; dies., Reliquientranslationen nach Sachsen im 9. Jahrhundert. Über Kommunikation, Mobilität und Öffentlichkeit im Frühmittelalter, Stuttgart 2002; Alfred Haverkamp, Gemeinden, Gemeinschaften und Kommunikationsformen im hohen und späten Mittelalter, hg. von Friedhelm Burgard, Lukas Clemens und Michael Matheus, Trier 2002; Wolfgang Huschner, Transalpine Kommunikation im Mittelalter. Diplomatische, kulturelle und politische Wechselwirkungen zwischen Italien und dem nordalpinen Reich (9.-11. Jahrhundert), 3 Bde., Hannover 2003; Barbara StollbergRilinger. „Symbolische Kommunikation in der Vormoderne. Begriffe - Thesen - Forschungsperspektiven“, in: Zeitschrift für Historische Forschung 31/2004, S. 489-527; Michael Jucker, Gesandte, Schreiber, Akten. Politische Kommunikation auf eidgenössischen Tagsatzungen im Spätmittelalter, Zürich 2004; Romy Günthart/Michael Jukker (Hg.), Kommunikation im Spätmittelalter. Spielarten - Wahrnehmungen - Deutungen, Zürich 2005; Thomas Haye, Lateinische Oralität. Gelehrte Sprache in der 
hingegen betraf zunächst eher die modernen und aktuellen Medien, mit denen es die Mediävistik in Universität, Öffentlichkeit und Lebenswelt, in Inszenierungen und Imaginarien $\mathrm{zu}$ tun hat. ${ }^{69}$ Ihn auf die Vergangenheit anzuwenden, hieß sich der grundsätzlichen Frage stellen, die im Zuge des ,linguistic turn' an Bedeutung gewonnen hat: der Frage, wie das Verhältnis historischer Deskription, Rekonstruktion und Narration sowohl zu den materiellen Überlieferungen (der Vergangenheit) als auch $\mathrm{zu}$ den medialen Technologien (der Gegenwart) einzuschätzen sei. ${ }^{70}$

Auch literaturwissenschaftlich wurde mediengeschichtliche Relevanz erst sukzessive durch stärkere Berücksichtigung medienwissenschaftlicher Kategorien hergestellt. Ursula Schaefers wichtige Studie zur altenglischen Dichtung (1992) bezog sich auf die forschungsgeschichtliche Dichotomisierung von Mündlichkeit und Schriftlichkeit und versuchte mit Hilfe der Kategorie der Vokalität über diese Dichotomie und generell über „Medialität als Ordnungskriterium“ hinauszuweisen. ${ }^{71}$ Horst Wenzels Grundlagenwerk (1995) schloß zwar punktuell an Luhmann, Giesecke, Ong oder Leroi-

mündlichen Kommunikation des hohen und späten Mittelalters, Berlin/New York 2005.

69 Hans-Werner Goetz, Moderne Mediävistik. Stand und Perspektiven der Mittelalterforschung, Darmstadt 1999, S. 389; vgl. auch Klaus van Eickels/Ruth Weichselbaumer/Ingrid Bennewitz (Hg.), Mediaevistik und Neue Medien, Ostfildern 2004; Vittoria Borsò/Christoph Kann (Hg.), Geschichtsdarstellung. Medien - Methoden Strategien, Köln/Weimar/Wien 2004. Zur Darstellung materieller Überreste: Bernd Carqué/Daniela Mondini/Matthias Noell (Hg.), Visualisierung und Imagination. Materielle Relikte des Mittelalters in bildlichen Darstellungen der Neuzeit und Moderne, Göttingen 2006. Zum Mittelalterfilm als herausragendem Ort der Epochenimagination Simona Slanicka/Mischa Meier (Hg.), Antike und Mittelalter im Film. Konstruktion - Dokumentation - Projektion, Köln/Weimar/Wien 2006; Christian Kiening/Heinrich Adolf (Hg.), Mittelalter im Film, Berlin/New York 2006.

70 Fabio Crivellari/Marcus Sandl, ,Die Medialität der Geschichte. Forschungsstand und Perspektiven einer interdisziplinären Zusammenarbeit von Geschichts- und Medienwissenschaften“, in: Historische Zeitschrift 277/2003, S. 619-654; Fabio Crivellari u.a. „Einleitung: Die Medialität der Geschichte und die Historizität der Medien“, in: Crivellari/Sandl (Hg.), Die Medien der Geschichte. Historizität und Medialität in interdisziplinärer Perspektive, Konstanz 2004, S. 9-45.

71 Ursula Schaefer, Vokalität. Altenglische Dichtung zwischen Mündlichkeit und Schriftlichkeit, Tübingen 1992, S. 8. Zu den frühmittelalterlichen Konstellationen von Mündlichkeit und Schriftlichkeit auch Stephen N. Tranter/Hildegard L. C. Tristram (Hg.), Early Irish Literature - Media Communication. Mündlichkeit und Schriftlichkeit in der frühen irischen Literatur, Tübingen 1989; Rosamund McKitterick, The Carolingians and the written word, Cambridge/New York 1989; Michael Richter, The oral tradition in the early Middle Ages, Turnhout 1994; Paul Saenger, Space between words. The origins of silent reading, Stanford 1997. 
Gourhan an, zielte aber vor allem auf eine Rekonstruktion mittelalterlicher Memorialkultur, höfischer Kommunikation und Repräsentation. Diese sind konsequent als Erweiterung des Paradigmas der Schrift verstanden: „In einer Gesellschaft, in der die Schrift nur eine sekundäre Rolle spielt, dominieren Augen und Ohren, Gestik, Mimik, Habitus, die Ausstattung der Körper und die Zuordnung der Personen im Raum, die Kommunikation von Angesicht zu Angesicht, die sich darin fortsetzt [...], daß die Terminologie des Sehens und Hörens in den höfischen Texten eine zentrale Bedeutung erhält. “72 Dieses Prinzip wird entfaltet anhand der Funktion der menschlichen Sinne, des Verhältnisses von Partizipation und Mimesis, Repräsentation und Präsenz, Ritual und Inszenierung, der Erfahrung verschiedener Wahrnehmungsräume, der Übergänge zwischen buchliterarischen und körpergeprägten Kommunikationsformen, der Verschränkungen von Textualität und Visualität sowie der Rolle der Tropen. Die Perspektive wechselnd auf die Semantiken wie die Strukturen, die Inszenierungen wie die Reflexionen richtend, entwirft das Buch das Bild eines mediengeschichtlich alteritären Mittelalters, dessen Binnendifferenzen in zeitlicher (frühes/spätes Mittelalter), institutioneller (kirchliche/höfische Räume) und thematischer Hinsicht (weltliche/geistliche Dimensionen) weitgehend offen bleiben. ${ }^{73}$

Auch hier diente zunächst vor allem der Kommunikationsbegriff als funktionale Kategorie zur Beschreibung sowohl intratextueller und intradiegetischer Gegebenheiten als auch sozialer und kontextueller Situationen. ${ }^{74}$

72 Horst Wenzel, Hören und Sehen - Schrift und Bild. Kultur und Gedächtnis im Mittelalter, München 1995, S. 9 f.; vgl. auch ders., ,Imaginatio und Memoria. Medien der Erinnerung im Höfischen Mittelalter", in: Aleida Assmann/Dietrich Harth (Hg.), Mnemosyne. Formen und Funktionen der kulturellen Erinnerung, Frankfurt a. M. 1991, S. 57-82. Voraus ging der Sammelband: Hedda Ragotzky/Horst Wenzel (Hg.), Höfische Repräsentation. Das Zeremoniell und die Zeichen, Tübingen 1990; begleitende Aufsätze sind jetzt gesammelt in: Horst Wenzel, Höfische Repräsentation. Symbolische Kommunikation und Literatur im Mittelalter, Darmstadt 2005.

73 Vgl. demnächst Peter Strohschneider (Hg.), Literarische und religiöse Kommunikation in Mittelalter und Früher Neuzeit, Berlin/New York 2008.

74 Vgl. zum Beispiel Peter Strohschneider, Ritterromantische Versepik im ausgehenden Mittelalter. Studien zu einer funktionsgeschichtlichen Textinterpretation der ,Mörin “ Hermanns von Sachsenheim sowie zu Ulrich Fuetrers, Persibein “ und Maximilians I. ,Theuerdank', Frankfurt/Bern/New York 1986; Beate Kellner/Ludger Lieb/Peter Strohschneider (Hg.), Literarische Kommunikation und soziale Interaktion. Studien zur Institutionalität mittelalterlicher Literatur, Frankfurt a. M. u. a. 2001; Otto Neudeck, „Gefahren allegorischer Kommunikation. Zur prekären Konstituierung adliger Exklusivität in einer Minnerede Hermanns von Sachsenheim (,Die Unminne')"“, in: Beiträge zur Geschichte der deutschen Sprache und Literatur 124/2002, S. 74-91; Andreas Urscheler, Kommunikation in Wolframs, Parzival'. Eine Untersuchung zu Form und Funktion der Dialoge, Bern u. a. 2002; Eckart C. Lutz, ,Modelle der Kom- 
Der Medienbegriff hingegen, im wissenschaftlichen Normalgebrauch an Leitmedien wie ,Sprache“ oder ,Volkssprache', ,Schrift' oder ,Literatur ‘ gebunden, schien stärker auf eine generelle Vermittlungsdimension als eine spezifische Differenzqualität bezogen. ${ }^{75}$ Noch in den repräsentativen literaturwissenschaftlichen Sammelbänden der neunziger Jahre, die an einer Neubestimmung mittelalterlicher Textualität arbeiteten, begegnet er deshalb nur am Rande. ${ }^{76}$ Expliziter wird er erst in den unmittelbar an Wenzels Buch von 1995 anschließenden Arbeiten. ${ }^{77}$ Der Sammelband einer Tagung zu Boten, Briefen und Gesprächen bezieht sich einleitend auf ,ein vermehrtes Nachdenken über die Leistungen einer medientheoretischen Perspektive im weiten Umfang der historisch ausgerichteten Kulturwissenschaften“. Gedacht ist an eine „Übertragung nachrichtentechnischer Modelle auf die hochkomplexe menschliche Kommunikation“, eine Übertragung, die zwar als ,gewiß nicht unproblematisch, aber unter historischer Perspektive auch besonders produktiv“" eingestuft wird. ${ }^{78}$ Die einzelnen Beiträge allerdings

munikation. Zu einigen Autorenbildern des 12. und 13. Jahrhunderts“, in: Christa Bertelsmeier-Kierst/Christopher Young (Hg.), Eine Epoche im Umbruch. Volkssprachliche Literalität 1200-1300, Tübingen 2003, S. 45-72; Sandra Linden, Kundschafter der Kommunikation. Modelle höfischer Kommunikation im ,Frauendienst Ulrichs von Lichtenstein, Tübingen 2004.

75 Vgl. Hugo Kuhn, „Versuch über das 15. Jahrhundert in der deutschen Literatur“, in: ders., Entwürfe zu einer Literatursystematik des Spätmittelalters, Tübingen 1980, S. 77-101, hier S. 78: die „Kulturverhältnisse des ,Mediums“ Sprache werden aber insofern immer komplizierter, als [...] Latein nicht mehr allein im kirchlichen Gebrauch und seinen Derivationen (Kanzleien usw.) die Traditionen, Evolutionen und Revolutionen der Zeit als mittelalterliche Schriftkultur vermittelt, sondern das Humanistenlatein (und -italienisch) sein neues Kultur-Medium dagegensetzt“; S. 79: für Luther ,ist gerade sein Deutsch das Vehikel einer Rückkehr, ad fontes': zum ,reinen Wort“, zur ,reinen Kirche', aber im Medium einer neu statuierten ,Öffentlichkeit', d.h. eben dem der Volkssprache“; S. 80 f.: „Zum Medienwechsel“.

76 Stephen G. Nichols (Hg.), The New Philology, Cambridge (Mass.) 1990 (Speculum 65, Heft 1); Marina S. Brownlee/Kevin Brownlee/Stephen G. Nichols (Hg.), The New Medievalism, Baltimore/London 1991; Gerhard Hahn/Hedda Ragotzky (Hg.), Grundlagen des Verstehens mittelalterlicher Literatur. Literarische Texte und ihr historischer Erkenntniswert, Stuttgart 1992; Joachim Heinzle (Hg.), Modernes Mittelalter. Neue Bilder einer populären Epoche, Frankfurt a. M. 1994; Jan-Dirk Müller (Hg.), ,Aufführung ' und ,Schrift' in Mittelalter und Früher Neuzeit, Stuttgart/Weimar 1996; Helmut Tervooren/Horst Wenzel (Hg.), Philologie als Textwissenschaft. Alte und Neue Horizonte, Berlin 1997 (Zeitschrift für deutsche Philologie 116/1997, Sonderheft); Jan-Dirk Müller/Horst Wenzel (Hg.), Mittelalter. Neue Wege durch einen alten Kontinent, Stuttgart/Leipzig 1999.

77 Die wichtigsten von Horst Wenzel selbst sind jetzt gesammelt in: Mediengeschichte vor und nach Gutenberg, Darmstadt 2007.

78 Horst Wenzel u.a. (Hg.), Gespräche - Boten - Briefe. Körpergedächtnis und Schriftgedächtnis im Mittelalter, Berlin 1997, S. 9 und S. 11. 
lassen sich auf dieses Experiment noch kaum ein. Sie widmen sich überwiegend spezifisch , alteuropäischen' Übertragungsmedien und Kommunikationsformen, ohne auf nachrichtentechnische Modelle Bezug zu nehmen. Die wenigen, die dies doch tun, zeigen, was ein solches Unternehmen ausmacht: hier der Reiz, auf hohem Abstraktionsniveau und in kühner Kombinatorik Verbindungen zwischen ,Vögeln`, ,Engeln` und ,Gesandten` herauszuarbeiten ${ }^{79}$ dort die Gefahr, eine hochkomplexe literarische Inszenierung als „Reflex eines sich dynamisierenden Veränderungsprozesses in den medialen und kommunikativen Programmen der Gesellschaft um 1200“ zu lesen. ${ }^{80}$

Auch die zeitgleiche Studie von Haiko Wandhoff, die kulturanthropologische Zugänge zum Spannungsfeld von Mündlichkeit, Schriftlichkeit und Körperlichkeit mit Ansätzen der Informations- und Medientheorie und Modellen der Systemtheorie verbindet, ist von diesem Problem gezeichnet. ${ }^{81}$ Es

79 Bernhard Siegert, ,Vögel, Engel und Gesandte. Alteuropas Übertragungsmedien“, in: Wenzel u. a. (Hg.), Gespräche (wie Anm. 78), S. 54-62; vgl. auch Sybille Krämer, „Boten, Engel, Geld, Computerviren. Medien als Überträger“, in: Paragrana. Internationale Zeitschrift für Historische Anthropologie 14/2005, S. 15-24. Eher klassisch historisch orientiert ist der Band von Wendelin Knoch (Hg.), Engel und Boten, Berlin 2006, am dezidiertesten mediengeschichtlich argumentiert ebd. Volker Scior, „Veritas und certitudo oder: Warten auf Wissen. Boten in frühmittelalterlichen Informationsprozessen" (S. 110-131, mit weiterer Literatur); siehe außerdem zum Komplex des ,Boten' Jacques Merceron, Le message et sa fiction. La communication par messager dans la littérature française des XII ${ }^{e}$ et XIII ${ }^{e}$ siècle, Berkeley/Los Angeles/London 1998 (in der deutschen Mediävistik kaum beachtet); Stephan Müller, „Datenträger. Zur Morphologie und Funktion der Botenrede in der deutschen Literatur des Mittelalters am Beispiel von ,Nibelungenlied“ und ,Klage““, in: Ludger Lieb/Stephan Müller (Hg.), Situationen des Erzählens. Aspekte narrativer Praxis im Mittelalter, Berlin/New York 2002, S. 89-120; Andreas Wagner (Hg.), Bote und Brief. Sprachliche Systeme der Informationsübermittlung im Spannungsfeld von Mündlichkeit und Schriftlichkeit, Frankfurt u.a. 2003; Horst Wenzel, ,,Vom Körper zur Schrift. Boten, Briefe, Bücher", in: Sybille Krämer (Hg.), Performativität und Medialität, München 2004, S. 269-291; ders., „Botschaften und Briefe. Die Spur des Körpers in der Schrift“, in: Gisela Fehrmann/Erika Linz/Cornelia Epping-Jäger (Hg.), Spuren, Lektüren. Praktiken des Symbolischen, München 2005, S. 259-276; Peter von Moos, „Der Herold: ein Kommunikationsexperte zwischen den Zeiten“, in: ders., Gesammelte Studien zum Mittelalter, Bd. 2: Rhetorik, Kommunikation und Medialität, hg. von Gert Melville, Berlin 2006, S. 153-172.

${ }^{80}$ Hennig Wuth, ,was, strâle unde permint. Mediengeschichtliches zum Eneasroman Heinrichs von Veldeke“, in: Wenzel u. a. (Hg.), Gespräche (wie Anm. 78), S. 63-76, hier S. 76.

81 Haiko Wandhoff, Der epische Blick. Eine mediengeschichtliche Studie zur höfischen Literatur, Berlin 1996; dazu meine Rezension, in: Archiv für das Studium der neueren Sprachen und Literaturen 236/1999, S. 381-385. Weitere thematisch verbundene Arbeiten von Wandhoff: „Aventiure als Nachricht für Augen und Ohren. Zu Hartmanns 
geht ihr um die Vorgeschichte des von Giesecke beschriebenen Medienumbruchs, konkret: um „die Freilegung der informativen Optionen“, die der höfische Adel „mit der Anwendung einer so aufwendigen Informationstechnologie wie der Schrift" verband. ${ }^{82}$ Erst die Schrift vermag ja detaillierte, oral und audiovisuell geprägte höfische Lebenswelten zu erzeugen, Objekte, Bilder und Zeichen als Modelle medialer Sinnbildungsprozesse einzusetzen und Wahrnehmungsformen als Erprobungen kommunikativer Bedingungen zu inszenieren. Wandhoff macht deutlich, in welchem Maße die erzählten Welten der Zeit um 1200 Welten des Sichtbaren und/oder Hörbaren sind. Dabei kleidet er seine Analysen konsequent in eine informations- und medientechnische Terminologie. Sie soll im Sinne Gieseckes eine größtmögliche deskriptive Allgemeinheit sichern und ,eine einheitliche Sichtweise auf [...] ganz unterschiedliche Gegenstände" ermöglichen ${ }^{83}$ Sie suggeriert aber auch, höfische Literatur und Kultur mit ihren ,Schriftanwendern', ,Textbenutzern' und ,Textverarbeitungsprogrammen " lasse sich in spezifisch gegenwärtigen Kategorien der Wissens- und Informationsvernetzung verstehen. Damit wird die historische Eigenart einer Literatur v o r der Literatur, die herauszuarbeiten das neue theoretische Instrumentarium dienen sollte, zumindest teilweise wieder kassiert.

Doch waren die Beobachtungen zum Zusammenhang von Textualität, Medialität und Präsenz zweifellos fruchtbar. Sie fanden Resonanz, etwa bei Christina Lechtermann, die nachzeichnet, wie höfische Texte der Zeit um 1200 Präsenz herstellen - durch ihre spezifische Verfaßtheit und spezifische Wirkungshaftigkeit: „Auf der einen Seite werden die medialen Oberflächen so eingerichtet, $\mathrm{da} ß$ sie einem Präsenzeffekt zuarbeiten, [...] andererseits ist diese Präsenz nie im Text allein realisierbar. Sie braucht einen Rezipienten,

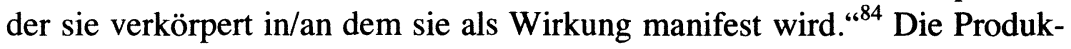
tion von Präsenz zeigt sich an performative Prozesse gekoppelt, die wiederum in den Kommunikations- und Wahrnehmungssituationen der Texte aufscheinen: In ihnen spielen sowohl Imaginationen und Blicke als auch Mo-

von Aue Erec und Iwein", in: Zeitschrift für deutsche Philologie 113/1994, S. 1-22; „Speicher- und Schauräume der Schrift. Die höfische Epik des Mittelalters aus mediengeschichtlicher Sicht", in: Jahrbuch für internationale Germanistik 28/1996, S. 8099; „Gefährliche Blicke und rettende Stimmen. Eine audiovisuelle Choreographie von Minne und Ehe in Hartmanns ,Erec'“, in: Müller (Hg.), ,Aufführung ' und ,Schrift" (wie Anm. 76), S. 170-189; ,velden und visieren, blïemen und florieren. Zur Poetik der Sichtbarkeit in den höfischen Epen des Mittelalters“, in: Zeitschrift für Germanistik N. F. 9/1999, S. 586-597.

82 Wandhoff, Der epische Blick (wie Anm. 81), S. 24.

83 S. 23.

${ }^{84}$ Christina Lechtermann, Berührt werden. Narrative Strategien der Präsenz in der höfischen Literatur um 1200, Berlin 2005, S. 38. 
mente der Stimme und der Verkörperung eine wichtige Rolle - nicht als Momente einer archaischen Präsenz, ${ }^{85}$ sondern als Vermittlungen zwischen den textuellen und visuellen Vergegenwärtigungs s $\mathrm{tr}$ ategi e $\mathrm{n}$ und den lebensweltlichen Vergegenwärtigungs wirkungen. Um allerdings die performative Dynamik medialer Präsenzerzeugung genauer zu erfassen, bedürfte es eines geschärften rezeptionsästhetischen Instrumentariums. Man wird nicht dabei stehenbleiben können, textuelle Sachverhalte rezeptionsbezogen $\mathrm{zu}$ formulieren. ${ }^{86}$ Man wird die Bedeutung von Rahmungen und Wiederholungen, das Verhältnis von intra- und extradiegetischen Aussagen, die Differenz zwischen zeitgenössischen Diskursen der Imagination, der Re-Präsentation oder der Zeichenontologie und literarischen Inszenierungen von Präsenz analytisch und semantisch ausleuchten müssen. Das aber setzt voraus, von verschiedenen Seiten her danach zu fragen, welche Kategorien des Medialen in mittelalterlicher Kultur in welchen Formen verwendet und reflektiert wurden.

Nach gegenwärtigem Forschungsstand zeichnen sich vor allem vier Felder ab, auf denen diese Frage Antworten findet: (1) Formen des Medienwechsels, die das Verhältnis von Mündlichkeit und Schriftlichkeit, von körpergebundener und nicht körpergebundener Kommunikation betreffen, ${ }^{87}$ (2)

85 Vgl. etwa (im Gefolge Czerwinskis) Katharina Philipowski, „Geste und Inszenierung. Wahrheit und Lesbarkeit von Körpern im höfischen Epos", in: Beiträge zur Geschichte der deutschen Sprache und Literatur 122/2000, S. 455-477; kritisch dazu Jan-Dirk Müller, ,Visualität, Geste, Schrift. Zu einem neuen Untersuchungsfeld der Mediävistik“, in: Zeitschrift für deutsche Philologie 122/2003, S. 118-132.

86 Lechtermann, Berührt werden (wie Anm. 84), S. 131: „Der Rezipient soll der erzählten Figur als Begehrender entgegentreten, damit das, was er an sich selbst spürt, als Kontiguität einer Wirkung die Präsenz bestätigt, die der Text nur beschwören, an die er lediglich appellieren kann.“

87 Thomas Cramer, ,Der Buchstabe als Medium des gesprochenen Wortes. Über einige Probleme der Mündlichkeits-Schriftlichkeitsdebatte am Beispiel mittelalterlicher Lyrik". in: Gerhard Sellin u.a. (Hg.), Logos und Buchstabe. Mündlichkeit und Schriftlichkeit im Judentum und Christentum der Antike, Bern 1996, S. 127-152; Christine Ehler/Ursula Schaefer (Hg.), Verschriftung und Verschriftlichung. Aspekte des Medienwechsels in verschiedenen Kulturen und Epochen, Tübingen 1998; Ursula Schaefer (Hg.), ,Artes' im Medienwechsel, Berlin 1998; Wolfgang Raible (Hg.), Medienwechsel. Erträge aus zwölf Jahren Forschung zum Thema „Mündlichkeit" und „Schriftlichkeit“, Tübingen 1998; Horst Wenzel, „Mündlichkeit und Schriftkultur. Zur medialen Transformation körperlicher Wahrnehmung im Mittelalter“, in: Paragrana. Internationale Zeitschrift für Historische Anthropologie 9/2000, S. 175-190; ders., „Die Stimme und die Schrift. Autoritätskonstitution im Medienwechsel von der Mündlichkeit zur Schriftlichkeit“, in: James F. Poag/Claire Baldwin (Hg.), The construction of textual authority in German literature of the medieval and early modern periods, Chapel Hill 2001, S. 49-74; Ludolf Kuchenbuch, „Écriture et oralité. Quelques compléments et approfondissements“, in: Jean-Claude Schmitt/Otto Gerhard 
Formen des Medienverbundes, die mit der wechselseitigen Durchdringung vor allem von Textuellem und Visuellem zu tun haben, ${ }^{88}$ (3) Formen des Medienwandels, die, zum Beispiel in Predigten, Einblattdrucken oder Flugblättern, als frühe Ansätze zur Massenkommunikation begriffen werden, ${ }^{89}$

Oexle (Hg.), Les tendances actuelles de l'histoire du moyen âge en France et en Allemagne, Paris 2002, S. 143-165 (materialreiche Übersicht); Harald Haferland, Mündlichkeit, Gedächtnis und Medialität. Heldendichtung im deutschen Mittelalter, Göttingen 2004; vgl. auch die gesammelten Studien zum Spannungsfeld von Schriftlichkeit und Mündlichkeit von Peter von Moos, Rhetorik, Kommunikation und Medialität (wie Anm. 79).

88 Birgit Franke, ,Tapisserie - ,portable grandeur ' und das Medium der Erzählkunst“, in: dies./Barbara Welzel (Hg.), Die Kunst der burgundischen Niederlande. Eine Einfuihrung, Berlin 1997, S. 121-139; Nikolaus Henkel, „Titulus und Bildkomposition. Beobachtungen zur Medialität in der Buchmalerei anhand des Verhältnisses von Bild und Text im ,Bamberger Psalmenkommentar"“, in: Zeitschrift für Kunstgeschichte 62/1999, S. 449-463; Wolfgang Wegner, ,,Lesen“ und poetische Visualisierung als Medien moralischer lêre im ,Jüngeren Titurel““, in: Euphorion 94/2000, S. 271-292; Silke Tammen, ,Schluß und Genese eines Buches im Zeichen der Apokalypse. Medien der Offenbarung und Lehre auf dem letzten Blatt der Bible moralisée (Codex 1179 der Österreichischen Nationalbibliothek in Wien)“, in: Jan A. Aertsen/Martin Pickavé (Hg.), Ende und Vollendung. Eschatologische Perspektiven im Mittelalter, Berlin 2002, S. 321-347; Stephan Müller, „Erec und Iwein in Bild und Schrift. Entwurf einer medienanthropologischen Überlieferungs- und Textgeschichte ausgehend von den frühesten Zeugnissen der Artusepen Hartmanns von Aue“, in: Beiträge zur Geschichte der deutschen Sprache und Literatur 127/2005, S. 414-435.

89 Hans-Joachim Köhler (Hg.), Flugschriften als Massenmedium der Reformationszeit, Stuttgart 1981; Hartmut Boockmann, ,Über Ablaß-,Medien““, in: Geschichte in Wissenschaft und Unterricht 34/1983, S. 709-721; Georg Steer, „Bettelorden-Predigt als ,Massenmedium““, in: Joachim Heinzle (Hg.), Literarische Interessenbildung im Mittelalter, Stuttgart/Weimar 1993, S. 314-336; Horst Wenzel (Hg.), Gutenberg und die Neue Welt, München 1994; Falk Eisermann, „Medienwechsel - Medienwandel. Geistliche Texte auf Einblattdrucken und anderen Überlieferungsträgern des 15. Jahrhunderts", in: Wolfgang Harms/Michael Schilling (Hg.), Das illustrierte Flugblatt in der Kultur der Frühen Neuzeit, Frankfurt a. M. u. a. 1998, S. 35-58; ders., „Der Ablaß als Medienereignis. Kommunikationswandel durch Einblattdrucke im 15. Jahrhundert. Mit einer Auswahlbibliographie“, in: Rudolf Suntrup/ Jan R. Veenstra (Hg.), Tradition and Innovation in an Era of Change, Frankfurt a. M. u. a. 2001, S. 99-128; Horst Wenzel, „Luthers Briefe im Medienwechsel von der Manuskriptkultur zum Buchdruck“, in: Thomas A. Brady (Hg.), Die deutsche Reformation zwischen Spätmittelalter und früher Neuzeit, München 2001, S. 203-229; Stephanie Altrock/Hans-Joachim Ziegeler, „Vom ,diener der ewigen wisheit' zum Autor Heinrich Seuse. Autorschaft und Medienwandel in den illustrierten Handschriften und Drucken von Heinrich Seuses ,Exemplar"“, in: Ursula Peters (Hg.), Text und Kultur. Mittelalterliche Literatur 1150-1450, Stuttgart/Weimar 2001, S. 150-181; Rudolf Suntrup/Jan R. Veenstra/ Anne Bollmann (Hg.), The Mediation of Symbol in Late Medieval and Early Modern Times - Medien der Symbolik in Spätmittelalter und Früher Neuzeit, Frankfurt a. M. u.a. 2005; Albrecht Hausmann, „Überlieferungsvarianz und Medienwechsel. Die 
(4) Formen des Medienwissens, die aus der Inszenierung, Herausstellung oder Reflexion medialer Aspekte hervorgehen.$^{90}$ Ein interdisziplinärer Konsens über die Dimensionen der jeweils verwendeten Medienbegriffe zeichnet sich allerdings noch kaum ab. Das Themenheft der Zeitschrift Das Mittelalter verweist einleitend auf die „drei großen Medienumbrüche“ und auf das zentrale Interesse, das Mediengeschichte, verstanden als „Geschichte von Zeichensystemen und Informationsträgern“", in den mediävistischen Fächern beanspruchen dürfe. ${ }^{91}$ Doch den meisten der Beiträge bleibt der Medienbegriff äußerlich. Nur in wenigen ist die Analyse in einem Maße medial sensibilisiert, daß sich neue Dimensionen von Texten oder Bildern eröffnen: wenn Schrift- und Wahrnehmungsszenen in der höfischen Epik als raffinierte Störungen und gleichzeitige Neubegründungen kultureller Muster gelesen werden; ${ }^{92}$ wenn an einer illustrierten Chanson-de-geste-Handschrift gezeigt wird, wie das fragile Verhältnis zwischen der „Materialität der adligen Körper und ihre[r] unmittelbare[n] Signifikation" durch eingeschobene Körperzeichen und materielle wie abstrakte Piktogramme Stabilisierung erfährt; ${ }^{93}$ wenn ein spätmittelalterliches Altarretabel sich mit seinen Bild-inBild-Strukturen als facettenreiche mediale Reflexion entpuppt. ${ }^{94}$

deutschen Artes dictandi des 15. Jahrhunderts zwischen Manuskript und Buchdruck“, in: Revue Belge de Philologie et d'Histoire 83/2005, S. 744-768; Sabine Griese, TextBilder und ihre Kontexte. Medialität und Materialität gedruckter Bilder des 15. Jahrhunderts, Habil.-Schrift Zürich 2007.

90 Mireille Schnyder, „Der unfeste Text. Mittelalterliche ,Audiovisualität““, in: Barbara Sabel/André Bucher (Hg.), Der unfeste Text. Perspektiven auf einen literatur- und kulturwissenschaftlichen Leitbegriff, Würzburg 2001, S. 132-153; Klaus Ridder, „Fiktionalität und Medialität. Der höfische Roman zwischen Mündlichkeit und Schriftlichkeit", in: Poetica 34/2002, S. 29-41; Carsten Morsch, ", nû sach er sî an unde sich'. Intermedialität in der literarischen Blickwendung der höfischen Dichtung am Beispiel des Armen Heinrich“, in: Jutta Eming/Annette Jael Lehmann/Irmgard Maassen (Hg.), Mediale Performanzen. Historische Konzepte und Perspektiven, Freiburg/Br. 2002, S. 49-76; Beate Kellner, „Ich grüeze mit gesange. Mediale Formen und Inszenierungen der Überwindung von Distanz im Minnesang", in: Albrecht Hausmann (Hg.), Text und Handeln. Zum kommunikativen Ort von Minnesang und antiker Lyrik, Heidelberg 2004, S. 107-137.

91 Karina Kellermann (Hg.), Medialität im Mittelalter, Berlin 2004, S. 4 (in Zitierung von Volker Depkat).

92 Andrea Sieber, ,,(Un)Erwünschte Effekte. Mediengebrauch, Synergie und Störung im höfischen Roman“, in: Kellermann (Hg.), Medialität (wie Anm. 91), S. 55-63.

93 Silke Winst, „Transmediales Wuchern. Körper - Bilder - Texte am Übergang vom Spätmittelalter zur Frühen Neuzeit (Die ,Ami-et-Amille'-Hs. Arras 696)“, in: Kellermann (Hg.), Medialität (wie Anm. 91), S. 64-76, hier S. 73.

94 Heike Schlie, „Wandlung und Offenbarung. Zur Medialität von Klappretabeln“, in: Kellermann (Hg.), Medialität (wie Anm. 91), S. 23-43. 
Stärker programmatischen Charakter hat ein Sammelband zu Medien der Kommunikation. ${ }^{95}$ Zwar gibt es auch hier Beiträge, die sich einzelnen Formen widmen, ohne daß der Medienbegriff dabei analytische Potenz besäße. Doch in anderen geht es ausdrücklich um ein mediales ,Dazwischen', eine Verschränkung verbaler und nonverbaler Kommunikation, textueller und visueller Repräsentation, ,optischer, akustischer und emotionaler Eindrükke" ${ }^{96}$ Eine sozialwissenschaftliche Einleitung bezieht die Beiträge auf allgemeine Paradigmen der Kommunikationsgeschichte: Luhmanns Modell von Kommunikation als Basisoperation sozialer Systeme, Habermas' Theorie des kommunikativen Handelns und Faulstichs Vorstellung unterschiedlicher Teilöffentlichkeiten. Von ihnen aus ergibt sich ,die wohl reizvollste Aufgabe einer Kommunikationsgeschichte: in der Erprobung moderner Kommunikations- und Gesellschaftstheorien an der Vormoderne die zeitspezifische Eigenart sozialer Kommunikation zu bestimmen und zugleich die (Kommunikations-)Theorien der Moderne im Lichte historischer Befunde zu modifizieren“. ${ }^{97}$ Wie diese beiden Dimensionen aber zu realisieren wären, wird nicht deutlich. Die historisch problematischen Implikationen sozialwissenschaftlicher Theorien scheinen nur kurz auf. Von den Voraussetzungen, die der Systembegriff mit sich bringt, ist nicht die Rede. Der Medienbegriff wird einer „Geschichte der technischen Mittel“ zugeordnet, ${ }^{98}$ die Luhmannsche Unterscheidung von Verbreitungsmedien und symbolisch generalisierten Kommunikationsmedien nicht für die Ausprägungen sozialer Kommunikation fruchtbar gemacht. ${ }^{99}$ Auch die Verkürzungen, die in Faulstichs globaler Medienkulturgeschichte popularisiert wurden, kommen nicht zur Sprache. ${ }^{100}$

${ }^{95}$ Karl-Heinz Spieß (Hg.), Medien der Kommunikation im Mittelalter, Stuttgart 2003.

${ }^{96}$ Nikolaus Henkel, „Mediale Wirkungsstrategien des mittelalterlichen ,Dramas'. Ein Beitrag zur Konstruktion historischer Intermedialität“, in: Spieß (Hg.), Medien (wie Anm. 95), S. 237-263, hier S. 254.

${ }^{97}$ Volker Depkat, „Kommunikationsgeschichte zwischen Mediengeschichte und der Geschichte sozialer Kommunikation. Versuch einer konzeptionellen Klärung“, in: Spieß (Hg.), Medien (wie Anm. 95), S. 9-48, hier S. 32.

${ }^{98}$ S. 9.

${ }^{99}$ S. 23.

${ }^{100}$ Faulstich entwirft das Bild einer in Teilöffentlichkeiten (Hof/Burg, Land/Dorf, Kloster/Universität, Kirchenraum, Stadt) gegliederten Welt, die über zwölf systemspezifische Menschmedien und Schreibmedien verfügt (Hofnarr, Sänger etc.; Blatt, Buch, Glasfenster etc.), von denen die Menschmedien im Zuge „der Auflösung traditioneller Grenzen dieser Teilöffentlichkeiten" zunehmend zerfallen bzw. den Schreibmedien gewichen wären; Werner Faulstich, Medien und Öffentlichkeiten im Mittelalter, 8001400, Göttingen 1996, S. 270 (vgl. die kritische Besprechung von Jan-Dirk Müller, in: Bayerisches Jahrbuch für Volkskunde N. F. 20/1997, S. 203-205); das Buch wird gerahmt und ergänzt durch die Bände: Das Medium als Kult. Von den Anfängen bis zur 


\section{Das Mittelalter der Medienwissenschaft}

Nur bedingt ist also die Herausforderung, die in der medialen Fragestellung liegt, in der Mediävistik schon angekommen. Nur selten haben die mittlerweile zunehmend verwendeten medialen Termini prägnanten und reflektierten Charakter. Häufig transportieren sie vor allem Verheißungen, Verheißungen hinsichtlich der epistemologischen Relevanz historischphilologischer Fächer und ihrer Anschlußfähigkeit an kulturelle und theoretische Paradigmen, Verheißungen, die ihrerseits uneinheitlich sind. ${ }^{101}$ Ist es im Falle der Literaturwissenschaft die kulturwissenschaftliche Öffnung, die sich nicht zuletzt an der Verwendung des Medienbegriffs ablesen läßt, so im Falle der Kunstgeschichte die kunst- oder bildwissenschaftliche Weiterentwicklung: Spielt der Begriff in Beltings großer Studie über den Wandel des Kultbildes noch kaum eine Rolle, ${ }^{102}$ dient er zehn Jahre später, im Rahmen der Bildanthropologie, als , missing link ${ }^{6}$ zwischen Körper und Bild ${ }^{103}$ oder als Ausdruck für die Spezifik der materiellen und kontextuellen Gegebenheit von Bildern, Skulpturen und anderen Formen. ${ }^{104}$

Explizit entdeckt die Geschichtswissenschaft in der Beziehung zur Medienwissenschaft die Möglichkeit, die eigenen Grundlagen zu reflektieren und die Dichotomie von Repräsentation und Wirklichkeit zu vermeiden,

Spätantike (8. Jahrhundert), Göttingen 1997, sowie Medien zwischen Herrschaft und Revolte. Die Medienkultur der frühen Neuzeit (1400-1700), Göttingen 1998; Die bürgerliche Mediengesellschaft (1700-1830), Göttingen 2002; Medienwandel im Industrie- und Massenzeitalter (1830-1900), Göttingen 2004.

101 Vgl. Horst Wenzel, ,Kulturwissenschaft als Medienwissenschaft: Vom Anfang und vom Ende der Gutenberg-Galaxis“, in: Johannes Anderegg/Edith Anna Kunz (Hg.), Kulturwissenschaften. Positionen und Perspektiven, Bielefeld 1999, S. 135-154; ders., „Medien- und Kommunikationstheorie. Ältere deutsche Literatur“, in: Claudia Benthien/Hans Rudolf Velten (Hg.), Germanistik als Kulturwissenschaft. Eine Einführung in neue Theoriekonzepte, Reinbek b. Hamburg 2002, S. 125-151. Vgl. auch Christian Kiening, „Alterität und Methode. Begründungsmöglichkeiten fachlicher Identität", in: Mitteilungen des Deutschen Germanistenverbandes 52/2005 [Germanistische Mediävistik und ,Bologna-Prozess'], S. 150-166.

${ }^{102}$ Hans Belting, Bild und Kult. Eine Geschichte des Bildes vor dem Zeitalter der Kunst, München ${ }^{2} 1991$ ('1990).

${ }^{103}$ Hans Belting, Bild-Anthropologie. Entwürfe für eine Bildwissenschaft, München 2001.

104 Tanja Michalsky (Hg.), Medien der Macht. Kunst zur Zeit der Anjous in Italien, Berlin 2001; Michael Viktor Schwarz, Visuelle Medien im christlichen Kult. Fallstudien aus dem 13. bis 16. Jahrhundert, Wien/Köln/Weimar 2002; Gerhard Wolf, Schleier und Spiegel. Traditionen des Christusbildes und die Bildkonzepte der Renaissance, München 2002; Christiane Kruse, Wozu Menschen malen. Historische Begründungen eines Bildmediums, München 2003. 
aber auch, auf eine sich ihrerseits historisierende Medienwissenschaft zu reagieren: „Eine Theorie und Geschichte der Medien ist [...] eng mit einer Theorie und Geschichte der Geschichte selbst verknüpft und wirft die entsprechenden Fragen auf, die Fragen nach Ereignis und Ereignisserien, nach Epochen und Epochenschwellen, nach Kontinuitäten und Brüchen im $\mathrm{Zu}$ sammenhang der Geschichte. “ ${ }^{105}$ Da Antworten auf diese Fragen bislang eher auf der Ebene einer technischen Ereignisgeschichte gesucht werden, wächst dem genuin historischen Zugriff erhöhte Bedeutung zu: Er kann Momente des Gebrauchs, der Praxis und des Inhalts ins Spiel bringen, die dem medienwissenschaftlichen Zugriff kontingent scheinen. ${ }^{106}$ „Wissensgeschichtlich zu hinterfragen wäre [...] der anhaltende Anspruch an eine Universalgeschichte des Medialen und hier könnte der Dialog mit der Historiographie eben hilfreich sein, um eine Ausdifferenzierung in trennschärfere Technik-, Kultur-, Sozial- und Ästhetikgeschichten des Medialen konstruktiv voranzutreiben." ${ }^{107}$

Konkret erweist sich allerdings der Dialog zwischen den an neueren $\mathrm{Ge}-$ gebenheiten orientierten Medientheorien und den auf den Eigenlogiken der Geschichte insistierenden historischen Fächern nach wie vor als ein asymmetrischer: So sehr die ersteren sich auf die Geschichte einlassen, so wenig können sie sich dem Telos des Digitalen entziehen, von dem sie ausgehen; so sehr die letzteren sich in ihrer Modellbildung auf theoretische Konzeptionen beziehen, so wenig können sie über deren Implikationen hinwegsehen. Für eine historisch sich verstehende Text-, Bild-, Medien- oder Kulturwissenschaft ist es notwendig, zwischen Beschreibungs- und Gegenstandssprache zu unterscheiden, und problematisch, Gegenwärtigkeit in die Vergangenheit zu infiltrieren. Für sie ist wichtig, daß analytische Kategorien in ihrer Modellhaftigkeit bewußt bleiben und nicht als ontologische Sachverhalte der Geschichte unterlegt werden. ${ }^{108}$ Und für sie stellt sich die Frage, ob eine Beschreibung von Prozes se n historischen Wandels sich zum einen von den Determin is me n, die eine technisch geprägte Geschichtsschreibung in den Vordergrund stellt, zum andern von den $\mathrm{Te}$ le ologi en, die sich von der jüngeren Mediendynamik her aufdrängen,

${ }^{105}$ Lorenz Engell/Joseph Vogl, ,Editorial“ zu: Archiv für Mediengeschichte 1/2001 [Mediale Historiographien], S. 7.

${ }^{106}$ Crivellari/Sandl, „Medialität“ (wie Anm. 70), S. 634 f.; vgl. auch Detlev Schöttker (Hg.), Mediengebrauch und Erfahrungswandel. Beiträge zur Kommunikationsgeschichte, Göttingen 2003.

${ }^{107}$ Crivellari u. a., ,Einleitung“" (wie Anm. 70), S. 27.

${ }^{108}$ Vgl. Christian Kiening, „Gegenwärtigkeit. Historische Semantik und mittelalterliche Literatur“, in: Scientia Poetica 10/2006, S. 19-46. 
freimachen kann. ${ }^{109}$ Wo sie dies nicht kann, wird es ihr auch nicht gelingen, historische Eigenlogiken anders denn als rückwärtsgewandte Mystifizierungen zu denken. In diesem letzteren Sinne ordnet Giesecke in einem neueren Buch das Projekt zur Druckrevolution in den Fluchtpunkt einer Medienökologie ein: „Die Ausbreitung alternativer Formen kultureller Informationsverarbeitung und Vernetzung wird gegenwärtig dadurch erschwert, daß wir uns noch immer an den Idealen und Konzepten orientieren, die in der Vergangenheit für die Beschreibung und Propagierung der Buch- und Industriekultur entwickelt wurden. Gerade die Erfolge dieser Epoche haben zu Mystifizierungen geführt. Im Licht der ökologischen Kommunikationstheorie erscheinen die Ambivalenzen der einzelnen Medien und die Wechselwirkungen zwischen ihnen als Quelle der historischen Dynamik." ${ }^{10}$

Wenn wie hier die gegenwärtigen Technologien den Maßstab für die Beschreibung der Geschichte bilden, kann diese kaum anders denn teleologisch konzipiert werden und kann das Mittelalter kaum anders denn als Vorgeschichte erscheinen. Das ist der Fall sowohl in vielen Einzelmediengeschichten wie in Universalmediengeschichten oder deren Schwundstufe: den Medienchroniken. ${ }^{111}$ Während manche ohnehin erst mit der frühen Neuzeit einsetzen, ${ }^{112}$ wiederholen andere unermüdlich die epochalen Muster medialer Inventionen und Revolutionen. ${ }^{113}$ Auch dort, wo bewußt ist, daß Sequenzialität immer im Nachhinein konstruiert wird, und die Perspektive von globalen Dynamiken auf einzelmediale Konstellationen sich verlagert, erscheint das Mittelalter als Epoche, deren Wissenszuwachs ,in letzter Kon-

$109 \mathrm{Zu}$ solchen Teleologien Mersch, Medientheorien (wie Anm. 2), pass.

${ }^{110}$ Michael Giesecke, Von den Mythen der Buchkultur zu den Visionen der Informationsgesellschaft, Frankfurt a. M. 2002.

111 Derrick de Kerckhove, Schriftgeburten. Vom Alphabet zum Computer, München 1995; bei Jochen Hörisch, Der Sinn und die Sinne. Eine Geschichte der Medien, Frankfurt a. M. 2001 (oder in anderer Ausgabe: Eine Geschichte der Medien. Vom Urknall zum Internet, Frankfurt a. M. 2004) gibt es zwar Kapitel zu Ursprüngen und zur Antike, das Mittelalter aber kommt nur im Hinblick auf die Erfindung des Papiers (S. 122), des Spiegels (S. 126) und der Brille (S. 163) vor. Vgl. auch Hans H. Hiebel (Hg.), Kleine Medienchronik. Von den ersten Schriftzeichen zum Mikrochip, München 1997; ders. u.a. (Hg.), Große Medienchronik, München 1999.

${ }^{112}$ René Hirner (Hg.), Vom Holzschnitt zum Internet. Die Kunst und die Geschichte der Bildmedien von 1450 bis heute, Ostfildern-Ruit 1997; Rudolf Stöber, Mediengeschichte. Die Evolution „neuer" Medien von Gutenberg bis Gates. Eine Einfuihrung, Bd. 1: Presse - Telekommunikation und Bd. 2: Film - Rundfunk-Multimedia, Wiesbaden 2003.

${ }^{113}$ Das gilt selbst dort, wo Literatur- oder Kulturwissenschaftler für die Kapitel verantwortlich sind; vgl. etwa Monika Elsner/Hans Ulrich Gumbrecht/Thomas Müller/Peter M. Spangenberg, „Zur Kulturgeschichte der Medien“, in: Merten/ Schmidt/Weischenberg (Hg.), Die Wirklichkeit der Medien (wie Anm. 2), S. 163-187. 
sequenz [...] die Buch- und Wissensproduktion mit beweglichen Lettern als notwendige Entwicklung erscheinen lassen muß.“114 Angesichts solcher Vorgaben differieren dann vor allem die Wertigkeiten, die dem Mittelalter in den jeweiligen globalen Mediengeschichtsverläufen zugeschrieben werden:

(1) überwundene Vorgeschichte: Sie begegnet in vielen globalen oder integralen Mediengeschichten, in denen das Mittelalter als Verkörperung einer spezifischen Konstellation gilt, die durch die technischen Entwicklungen der (frühen) Neuzeit abgelöst oder zumindest in diesen aufgehoben wurde. In einem vielbenutzten Handbuch etwa steht die mittelalterliche Kultur unter dem Signum medienhistorischer Stagnation: Gezeichnet gegenüber der Antike von einem „Verfall der Beredsamkeit“ und einem „Stillstand der Entwicklung von Drama und Theater", bewege sie sich wie jene „[im Übergang] von Mündlichkeit zu Schriftlichkeit“. Die Schriftproduktion verbleibe ,im Kontext des Verbunds von Glaubens- und Herrschaftssicherung der Kirche bis zum Ende des Mittelalters, und dies heißt: bis zur Erfindung der Druckerpresse, die eine Renaissance des antiken Mediensystems bei radikaler Umdefinition des Skriptoriums, der Bibliothek, des Theaters und des Forums auszulösen im Stande ist." “115

(2) le e r e Vorgeschichte: Sie begegnet dort, wo eine Medienarchäologie zwar mediengeschichtliche Diskontinuitäten ins Auge faßt, aber von einem späten Fluchtpunkt geprägt bleibt, demgegenüber das Mittelalter ein unbestimmtes Davor oder Dazwischen repräsentiert, das allenfalls ex negativo von Interesse ist. ${ }^{116}$ Eine Technikgeschichte medialer Dispositive vermißt an mittelalterlicher Kultur das, was in der antiken Philosophie ansatzweise eine Rolle spielt und in der neuzeitlich-modernen Wissenschaft zum Paradigma wird - eine Reflexion über die materiellen Bedingungen von (nachrichten-)technischen Übertragungen: „Seit der Antike zählen dazu beispielsweise die Naturelemente Luft und Wasser, Mineralsteine und Salze, tönende Metallkörper und im Wind rauschende Grashalme, aber auch Linsen und Prismen und Instrumente aus Tierpanzern und -gedärmen.“"117

${ }^{114}$ Manfred Faßler/Wulf Halbach (Hg.), Geschichte der Medien, München 1998, S. 9 f. (Vorwort); zur Sequenzialität S. 18 (Einleitung).

${ }^{115}$ Helmut Schanze (Hg.), Handbuch der Mediengeschichte, Stuttgart 2001, S. 231, S. 229 und S. 223 (Reihenfolge der Zitate).

${ }^{116}$ Vgl. Siegfried Zielinski, Archäologie der Medien. Zur Tiefenzeit des technischen Hörens und Sehens, Reinbek b. Hamburg 2002.

${ }^{117}$ Friedrich Kittler/ Ana Ofak (Hg.), Medien vor den Medien, München 2007 (Zitat aus der Ankündigung zum Workshop „Medien vor den Medien. Übertragung, Störung, Speicherung bis 1700 " am Helmholtz-Zentrum für Kulturtechnik, Berlin, Juni 2004). Anders die Perspektive des Berliner Medienarchäologen Wolfgang Ernst, der in sei- 
(3) e rfüllte bzw. sich erfüllende Vorgeschichte: Sie begegnet dort, wo eine Medienästhetik oder -philosophie die Dynamiken neuer Medien feiert und mittels eines Hindurchgreifens durch das GutenbergZeitalter adelt. Das ist schon der Fall in der frühen Filmtheorie. Béla Balázs preist 1924 das neue Medium als Erfüllung der ,schmerzliche[n] Sehnsucht des Menschen einer verintellektualisierten und abstrakt gewordenen Kultur nach dem Erleben konkreter, unmittelbarer Wirklichkeit" und macht es zur Entelechie einer aus dem Vor-Gutenberg-Zeitalter stammenden Authentizität des Visuellen: „Es war die große Zeit der bildenden Künste, da der Maler und der Bildhauer nicht nur Form und Raumverhältnisse zu abstrakten Gebilden komponierte und der Mensch für ihn nicht nur ein Formproblem war. [...] Die Seele, die unmittelbar zum Körper wurde, konnte in ihrer primären Erscheinungsform gemalt und gemeißelt werden. Doch seit der Buchdruckerei ist das Wort die Hauptbrücke zwischen Mensch und Mensch geworden. In das Wort hat sich die Seele gesammelt und kristallisiert. Der Leib aber ist ihrer bloß geworden: ohne Seele und leer."118 Genau dies aufzuheben ist es, was Balázs als Verheißung dem Film zuschreibt, und genau das ist es wiederum, was später, nun im Kontext der neuen Medien, in Vilém Flussers ,Kommunikologie‘ als konkreter Anschluß der neuen technischen Bilder an die traditionellen Bilder und die Prinzipien der Schrift erscheint: „Die gegenwärtige Kommunikationsrevolution ist im Grunde nichts anderes als die Rückkehr zu einer ursprünglichen Situation, welche durch den Buchdruck und die allgemeine Alphabetisierung durchbrochen und unterbrochen wurde. [...] Diese Rückkehr ins Mittelalter wäre demnach das Charakteristische an den gewaltigen Veränderungen in unseren Kommunikationsstrukturen. “119

nem Vorlesungsskript zu „Mediengeschichte als Medienarchäologie - Mo(nu)mente von Materie, Technik und Logik in der Zeit" (2004-2006) im Blick auf die Präsenz von Handschriften das Mittelalter gerade aufgrund des Unterschieds zwischen moderner Multimedialität und mittelalterlicher Multisensorik für interessant hält; http://www.medienwissenschaft.hu-berlin.de/theorien/skripte/pader3.200406.pdf.

${ }^{118}$ Béla Balázs, Der sichtbare Mensch oder die Kultur des Films (1924). Mit einem Nachwort von Helmut H. Diederichs und zeitgenössischen Rezensionen von Robert Musil, Andor Kraszna-Krausz, Siegfried Kracauer und Erich Kästner, Frankfurt a. M. 2001, S. 104 und S. 16f.

119 Vilém Flusser, Kommunikologie, hg. von Stefan Bollmann und Edith Flusser, Frankfurt a. M. 1998, S. 53; zu Flusser vgl. Elizabeth Neswald, Medien-Theologie. Das Werk Vilém Flussers, Köln/Weimar/Wien 1998 sowie den Beitrag von Gernot Grube, "Vilém Flusser - Mundus ex machina“, in: Lagaay/Lauer (Hg.), Medientheorien (wie Anm. 2), S. 173-199. 
So anachronistisch diese Ansicht sein mag, übt sie doch eine gewaltige Faszination aus. Man spricht von Re-Oralisierung und Re-Visualisierung. ${ }^{120}$ Man entdeckt neue mediale Formen der Nähe. Man bezieht sich auf Balázs und Flusser auch in mediävistischem Kontext. ${ }^{121}$ Und man frönt der Ahnung, daß die uns scheinbar zutiefst prägende Kultur des gedruckten Buches ihrerseits nur Episode in der Entwicklung zu einer von beschleunigten Bildern geprägten Welt sein mag. Diese Ahnung erhält zugleich einen prophetischen Unterton, in dem Gegenwartsdiagnostik und Zukunftsprognostik zusammenklingen und die Suggestion mitschwingt, an einem epochalen medienhistorischen Moment teilzuhaben. ${ }^{122}$ Eben in historischer Hinsicht aber greifen die Analogisierungen zu kurz. Sie übergehen zum Beispiel, daß es schon um 1800, kaum hatte Lessing im Laokoon eine semiotisch-mediale Trennung von Schrift und Bild begründet, Tendenzen gibt, die Einschränkungen der Schrift aufzuheben. Die Romantiker träumen von einer Chiffren- und Hieroglyphenschrift, in der die ursprüngliche Bedeutung der Natur festgehalten wäre. Sie ersehnen eine Transzendierung der Schrift im Bildhaften und Erklingenden, die sich zu einer synästhetischen Gesamtheit

${ }^{120}$ Vgl. Wolfgang Roesler, „Alte und neue Mündlichkeit. Über kulturellen Wandel im antiken Griechenland und heute", in: Der altsprachliche Unterricht 28.4/1985, S. 426; ders., ,,Kulturelle Revolutionen in Antike und Gegenwart: Die Genese der griechischen Schriftkultur und der Anbruch des elektronischen Zeitalters", in: Gymnasium 108/2001, S. 97-112; Hildegard L.C. Tristram (Hg.), (Re)Oralisierung, Tübingen 1996; Johannes Schwitalla, „Medienwandel und Reoralisierung. Phasen sprechsprachlicher Nähe und Ferne in der deutschen Sprachgeschichte“, in: Dorothea Klein u. a. (Hg.), Vom Mittelalter zur Neuzeit. Festschrift für Horst Brunner, Wiesbaden 2000, S. 669-689; Ingo W. Schröder/Stéphane Voell (Hg.), Moderne Oralität. Ethnologische Perspektiven auf die plurimediale Gegenwart, Marburg 2002; Ralf Adelmann/Markus Stauff, ,Ästhetiken der Re-Visualisierung. Zur Selbststilisierung des Fernsehens", in: Oliver Fahle/Lorenz Engell (Hg.), Philosophie des Fernsehens, Paderborn 2006, S. 55-76.

${ }^{121} \mathrm{Zu}$ Balázs vgl. Haiko Wandhoff/Horst Wenzel, „Literatur vor und nach Gutenberg. Perspektiven einer integrativen Mediengeschichte", in: Mitteilungen des Deutschen Germanistenverbandes 44.3/1997, S. 18-29. Die These Flussers ist als ,vielleicht zu prononciert“", aber hinsichtlich der „,Mediävalisierung ' der aktuellen Kommunikationssituation [...] doch bemerkenswert“ zitiert bei Horst Wenzel, „Zum Stand der Germanistischen Mediävistik im Spannungsfeld von Textphilologie und Kulturwissenschaft“, in: Hans-Werner Goetz/ Jörg Jarnut (Hg.), Mediävistik im 21. Jahrhundert. Stand und Perspektiven der internationalen und interdisziplinären Mittelalterforschung, München 2003, S. 149-160, hier S. 159; aufgenommen in Wenzel, Mediengeschichte, Einleitung (wie Anm. 77), S. 10-26, S. 17.

${ }^{122}$ Der Gestus begleitet die Medienwissenschaft von ihren Anfängen an. Er manifestiert sich auch noch bei Faulstich, der in seinem zuerst 1994 erschienenen Buch Grundwissen Medien die vierte Phase der Mediengeschichte, die der Substitutionsmedien, „,a. 2000“ beginnen läßt. 
verbinden. ${ }^{123}$ Schleiermacher hält fest, daß „die religiöse Mitteilung nicht in den Büchern zu suchen“ sei: „Zuviel geht verloren von dem ursprünglichen Eindruck in diesem Medium, worin alles verschluckt wird, was nicht in die einförmigen Zeichen paßt, in denen es wieder hervorgehen soll, wo Alles einer doppelten und dreifachen Darstellung bedürfte, indem das ursprünglich Darstellende wieder müßte dargestellt werden. “124

Nicht in Rechnung gestellt wird darüber hinaus bei der Gegenwartsdiagnostik, daß in der medial bewegten Zeit, in der Balázs schrieb, auch andere Vorstellungen von Epochalität als die des Brückenschlags zwischen Vorund Nach-Gutenberg-Zeitalter kursierten: Der Dramatiker Julius Bab verglich 1925 ,die heutige Situation des Films mit den Anfängen des modernen Dramas im elisabethanischen England kurz vor dem Auftreten Shakespeares"; ${ }^{125}$ der Rundfunk-Direktor Hans Bredow erhob wenig später den Rundfunk zum Medium einer „neue[n] Epoche der Welt- und Kulturgeschichte“, vergleichbar „,er Zeit, in der Gutenberg in Mainz aus dem Buchdruckerhandwerk die Buchdruckerkunst machte, durch die das Vorrecht weniger zum Genuß der Allgemeinheit wurde" ${ }^{126}$ In beiden Fällen geht es um die Frage der Legitimität neuer Medien. In beiden wird eine Antwort gesucht im Blick auf mediale (Massen-)Wirksamkeiten und mediengeschichtliche Analogien, wobei deren Indienstnahme, gemäß der jeweiligen Situation von Film und Rundfunk, diametral verschieden ausfällt: Wo Bab den Film als Medium einstuft, das auch nach zwei bis drei Jahrzehnten überwiegend dem rohen Vergnügen des Pöbels dient und kaum schon die Schwelle zur wahren Kunst überschritten hat, ist für Bredows Lob des Rundfunks dessen Kunstcharakter belanglos - im Vordergrund steht die

${ }^{123}$ Hans-Georg von Arburg/Michael Gamper/Ulrich Stadler (Hg.), ,Wunderliche Figuren". Über die Lesbarkeit von Chiffrenschriften, München 2001; Aleida Assmann/Jan Assmann (Hg.), Hieroglyphen. Stationen einer anderen abendländischen Grammatologie, München 2003; Wilhelm Voßkamp, „,Alles Sichtbare haftet am Unsichtbaren“ . Bilder und Hieroglyphenschrift bei Wilhelm Heinrich Wackenroder, Ludwig Tieck und Friedrich von Hardenberg (Novalis)"“, in: ders./ Brigitte Weingart (Hg.), Sichtbares und Sagbares. Text-Bild-Verhältnisse, Köln 2005, S. 25-45.

${ }^{124}$ Schleiermacher, Über die Religion (wie Anm. 22), S. 120 (4. Rede); vgl. auch Hoffmann, Geschichte des Medienbegriffs (wie Anm. 17), S. 104-106.

125 Julius Bab, „Film und Kunst“, in: Zeitschrift für Ästhetik und allgemeine Kunstwissenschaft 19/1925, S. 181-193; wieder in: Albert Kümmel/Petra Löffler (Hg.), Medientheorie 1888-1933. Texte und Kommentare, Frankfurt a. M. 2002, S. 162-176, hier S. 174.

${ }^{126}$ Hans Bredow, „Eure Aufgaben im Rundfunk!“ (1926); wieder in: Kümmel/Löffler (Hg.), Medientheorie (wie Anm. 125), S. 230-232, hier S. 230. 
Möglichkeit universaler Mitteilbarkeit und Übertragung dank des „Gottesgeschenk[s] der Hertzschen Welle“. ${ }^{127}$

Diese kursorischen Einblicke in die spezifischen medialen Begründungsszenarien der Zwischenkriegszeit wollen nur daran erinnern, wie vielfältig die historischen Rückgriffe ausfallen können und wie wenig sie sich damit als Hintergrund eignen für eine Beschreibung des Verhältnisses von mittelalterlichen und postmodernen Mediensituationen. Zwar ist der Gedanke verführerisch, das mittelalterliche „bi-, ja multi-mediale Denk-, Darstellungs- und Wissensvermittlungs-Modell“ habe ,mit seiner Möglichkeit zur mehrdimensionalen Verknüpfung und in seiner nicht-linearen Struktur vieles vorweggenommen“ von dem, „was als alleinige Errungenschaft der elektronischen Medienkultur der Gegenwart gilt". ${ }^{128}$ Auch ist es faszinierend, ältere und neuere virtuelle Räume, Handschriftenseiten und Benutzeroberflächen, Initialen, Schilder und Computerbildschirme, Flugblätter und Internet, Gotteshand und Datenhandschuh miteinander zu verbinden; ${ }^{29}$

${ }^{127}$ S. 231

${ }^{128}$ Norbert H. Ott, ,,Text und Bild - Schrift und Zahl. Zum mehrdimensionalen Beziehungssystem zwischen Texten und Bildern in mittelalterlichen Handschriften“, in: U1rich Schmitz/Horst Wenzel (Hg.), Wissen und neue Medien. Bilder und Zeichen von 800 bis 2000, Berlin 2003, S. 57-91, hier S. 76. Von einem ,Vorausweisen' spricht Horst Wenzel, ,Ohren und Augen - Schrift und Bild. Zur medialen Transformation körperlicher Wahrnehmung im Mittelalter", in: Faßler/Halbach (Hg.), Geschichte (wie Anm. 114), S. 110-140, hier S. 139: „Der Medienumbruch von der Handschrift zum Buchdruck weist voraus auf das Zeitalter nach Gutenberg.“

${ }^{129}$ Horst Wenzel, ,An den Fingern abgelesen. Zur mittelalterlichen Vorgeschichte digitaler Speicher", in: Ulrich Bosdorf/Heinrich Theodor Grütter (Hg.), Orte der Erinnerung. Denkmal, Gedenkstätte, Museum, Frankfurt a.M./New York 1999, S. 33-58; Haiko Wandhoff, ,Der Schild als Bild-Schirm. Die Anfänge der Heraldik und die Visualisierung der Literatur im 13. und 14. Jahrhundert“, in: Peter Wiesinger u.a. (Hg.), Akten des X. Internationalen Germanistenkongresses Wien 2000 „Zeitenwende - Die Germanistik auf dem Weg vom 20. ins 21. Jahrhundert", Bd. 5: Mediävistik und Kulturwissenschaften/Mediävistik und neue Philologie, Bern u.a. 2002, S. 81-88; ders., Ekphrasis. Kunstbeschreibungen und virtuelle Räume in der Literatur des Mittelalters, Berlin/ New York 2003; ders., „Im virtuellen Raum des Textes. Bild, Schrift und Zahl in Chrétiens de Troyes Erec et Enide“, in: Schmitz/Wenzel (Hg.), Wissen (wie Anm. 128), S. 39-56; Horst Wenzel, „Initialen. Vom Pergament zum Bildschirm“, in: Zeitschrift für Germanistik 13/2003, S. 629-641; ders., „Hand-Zeichen. Zur Mediengeschichte der Hand als Datenträger", in: Moritz Csáky/Peter Stachel (Hg.), Mehrdeutigkeit. Die Ambivalenz von Gedächtnis und Erinnerung, Wien 2003, S. 179-202; ders., ,Von der Gotteshand zum Datenhandschuh. Über den Zusammenhang von Bild, Schrift und Zahl", in: Sybille Krämer/Horst Bredekamp (Hg.), Bild - Schrift - Zahl, München 2003, S. 25-56; Jürgen Fröhlich, ,Meßkram oder ,Die Einwanderung der Null in den modernen Schaltkreislauf über das spätmittelalterliche Rechnungsbuch“", in: Schmitz/Wenzel, Wissen (wie Anm. 128), S. 135-158; ders., „Was aber soelchs himelkorn bedüt/ ist Gott allein zewüssen. Phänomene struktureller Amnesie in me- 
die „Audiovisualität vor und nach Gutenberg“ in ein Spannungsverhältnis zu setzen; ${ }^{130}$ die Beweglichkeit der Bilder zu verfolgen und die Geschichte des ,pre-cinéma' zu schreiben. ${ }^{131}$ Doch ergeben sich daraus vor allem Einsichten in die medialen Dynamisierungen, die im Laufe des 19. und frühen 20. Jahrhunderts die technischen Experimente mit neuen bewegten Bildern vorbereiten und begleiten. ${ }^{132}$ Die historischen Parallelisierungen hingegen bedürften sorgfältiger Kontextualisierung, will man Unterschiede der Formen und Funktionen genauer ermessen, historische Koppelungen und strukturelle Analogien nicht in eins setzen. ${ }^{133}$ Auch wäre die Denkfigur sowohl der ,Vorwegnahme' bzw. des ,Vorausweisens' wie der ,Rückkehr

dialen Umbruchzeiten (Flugblatt und Internet)“, in: Klaus van Eickels/Ruth Weichselbaumer/Ingrid Bennewitz (Hg.), Mediaevistik und Neue Medien, Stuttgart 2004, S. 49-66.

${ }^{130}$ Horst Wenzel/Wilfried Seipel/Gotthart Wunberg (Hg.), Audiovisualität vor und nach Gutenberg. Zur Kulturgeschichte der medialen Umbrüche, Wien/ Mailand 2001; Horst Wenzel, „Vom Anfang und vom Ende der Gutenberg-Galaxis. Historische Medienumbrüche im Für und Wider der Diskussion“, in: Lutz Musner/Gotthart Wunberg (Hg.), Kulturwissenschaften. Forschung - Praxis - Positionen, Wien 2002, S. 339355 .

131 Klaus Bartels, „Proto-kinematische Effekte der Laterna magica in Literatur und Theater des achtzehnten Jahrhunderts“, in: Harro Segeberg (Hg.), Die Mobilisierung des Sehens. Zur Vor- und Frühgeschichte des Films in Literatur und Kunst. Mediengeschichte des Films, Bd. 1, München 1996, S. 113-147; Jörg Jochen Berns, Film vor dem Film. Bewegende und bewegliche Bilder als Mittel der Imaginationssteuerung in Mittelalter und Früher Neuzeit, Marburg 2000; Horst Wenzel/Christina Lechtermann, „Repräsentation und Kinästhetik. Teilhabe am Text oder die Verlebendigung der Worte“, in: Paragrana. Internationale Zeitschrift für Historische Anthropologie 10/2001, S. 191-214; dies. (Hg.), Beweglichkeit der Bilder (wie Anm. 50); Christina Lechtermann/Carsten Morsch (Hg.), Kunst der Bewegung. Kinästhetische Wahrnehmung und Probehandeln in virtuellen Welten, Bern u. a. 2004.

$132 \mathrm{Vgl}$. Jochen Hörisch/Michael Wetzel (Hg.), Armaturen der Sinne. Literarische und technische Medien 1870 bis 1920, München 1990; Hermann Hecht, Pre-Cinema History. An Encyclopaedia and Annotated Bibliography of the Moving Image before 1896, London 1993; Laurent Mannoni/ Donata Pesenti Campagnoni/David Robinson, Light and Movement. Incunabula of the Motion Picture, 1420-1896, London 1996; Stephen Herbert (Hg.), A History of Pre-Cinema. 3 Bde., London/New York 2000; Stefan Andriopoulos, Besessene Körper. Hypnose, Körperschaften und die Erfindung des Kinos, München 2000; Harro Segeberg (Hg.), Die Mobilisierung des Sehens. Zur Vor- und Frühgeschichte des Films. München ${ }^{2} 2001$ ( $\left.{ }^{1} 1996\right) ;$ Sabine Schneider, Verheißung der Bilder. Das andere Medium in der Literatur um 1900, Tübingen 2006; Helmut Pfotenhauer/Sabine Schneider, Nicht völlig wachen und nicht ganz ein Traum. Die Halbschlafbilder in der Literatur, Würzburg 2006.

${ }^{133}$ Vgl. auch die Bedenken bei Jan-Dirk Müller, „Medialität. Frühe Neuzeit und Medienwandel“, in: Kathrin Stegbauer/Herfried Vögel/Michael Waltenberger (Hg.), Kulturwissenschaftliche Frühneuzeitforschung. Beiträge zur Identität der Germanistik, Berlin 2004, S. 49-70, hier S. 50 f. 
kritisch zu befragen: Sie muß ein Ganzes der Geschichte voraussetzen, das als bedeutungshaft erwiesen, nicht aber auf die (materiellen) Bedingungen befragt wird, die eine solche Konstruktion ermöglichen - ein Rückschritt gegenüber dem mediengeschichtlichen Anspruch, (materielle) Bedingungen der Möglichkeit von Kultur freizulegen. Eine Denkfigur, die im Früheren das Spätere entdeckt, tendiert dazu, anachronistische Züge in die historischen Wissensformen einzuführen. ${ }^{134}$ Zugleich stellt sie eine seit längerem gewonnene Einsicht auf den Kopf: daß neue Medien ältere nicht ablösen, sondern ergänzen und deuten, reflektieren und neu funktionalisieren.

In diesem Sinne trifft auch die häufig anzutreffende Aussage, die gegenwärtig intensivierte Mediengeschichte sei Ausdruck der durch Beschleunigungen und Umbrüche gekennzeichneten Situation, ${ }^{135}$ nur die halbe Wahrheit. Unübersehbar ist zwar eine Verbindung zwischen medialen Entwicklungen und medienhistorischen Beschreibungen. Unübersehbar ist aber auch, daß die Auseinandersetzung mit Medialität auch in der Fluchtlinie nicht genuin medienwissenschaftlicher Traditionen steht: der Beschäftigung etwa mit der Materialität der Geschichte, der Alterität vergangener oder fremder Zeichensysteme, der Komplexität von Repräsentation. ${ }^{136}$ Das dekonstruktive Moment beispielsweise, das die Medienphilosophie der auf das Beobachten, Erheben und Quantifizieren versessenen Medienwissenschaft entgegensetzt, reicht als Frage nach den Bedingungen der Möglichkeit des

${ }^{134}$ Vgl. etwa den Satz der Arbeitsgruppe „Medien“, „Über das Zusammenspiel von ,Medialität' und ,Performativität"“, in: Paragrana. Internationale Zeitschrift für Historische Anthropologie 13.1/2004 (Praktiken des Performativen), S. 129-185, hier Kap.: „Intermediale Konfigurationen und der Konstruktcharakter von Einzelmedien“ (Nadja Ghattas und Irina Rajewski), S. 142-151, hier S. 147 zu dem Ineinander von Text und Bild in hochmittelalterlichen Handschriften: „Die integrierenden Darstellungen boten also ein visuelles Programm, das dem aristokratischen, überwiegend analphabetischen Publikum den allmählichen Übergang von einer volkssprachlichen, auf dem mündlichen Vortrag basierenden Kultur zu einer sich zunehmend auf das geschriebene Wort verlassenden Informationskultur erleichterte."

${ }^{135}$ Vgl. etwa Faßler/Halbach (Hg.), Geschichte (wie Anm. 114), S. 15 (Einleitung): „Mediengeschichten entstehen immer dann, wenn mediale Brüche unübersehbar werden."

${ }^{136}$ Claudia Honegger, Schrift und Materie der Geschichte. Vorschläge zur systematischen Aneignung historischer Prozesse, Frankfurt a. M. 1977; James Clifford/George E. Marcus (Hg.), Writing Culture. The Poetics and Politics of Ethnography, Berkeley 1986; Hartmut Eggert/Ulrich Profitlich/Klaus R. Scherpe (Hg.), Geschichte als Literatur. Formen und Grenzen der Repräsentation von Vergangenheit, Stuttgart 1990; Eberhard Berg/Martin Fuchs (Hg.), Kultur, soziale Praxis, Text. Die Krise der ethnographischen Repräsentation. Frankfurt a. M. 1993; Christiaan L. Hart Nibbrig, Was heißt „Darstellen"?, Frankfurt a. M. 1994; Kiening, „Anthropologische Zugänge“ (wie Anm. 35). 
Medialen vor dessen technisch-institutionalisierte Zurichtung zurück. ${ }^{137}$ Insofern , ,[...] ist Medienwissenschaft ein Teilprogramm kulturwissenschaftlicher Forschung. “138

\section{Theoretisches Zwischenspiel}

Aus dem bisher Gesagten dürfte deutlich geworden sein: (1) Ich verstehe die Beschäftigung mit Medialität in mediävistischer Perspektive nicht einfach als Ergänzung einer Mediengeschichte um ihre nicht oder unzureichend erkannte Vorgeschichte. (2) Ich halte die Verwendung des Medienbegriffs, seine Übertragung auf Verhältnisse v o $r$ dem Zeitalter der Medien, nicht schon per se für erkenntnisfördernd, wenn damit nicht ein analytischer wie systematischer Differenzierungsgewinn verbunden ist. (3) Ich sehe diesen Gewinn nicht schon in der Beobachtung medialer Konstellationen, sondern in der Entwicklung einer historisch-mediologischen Perspektive. $^{139}$

Eine solche mediologische Perspektive hat nicht so sehr die technischen Aspekte von Medien im Auge. Sie orientiert sich auch nicht an einem der vielen von Shannon-Weaver abgeleiteten Kommunikationsmodelle, die, wie komplex ihre Einflußbereiche und Wechselwirkungen auch konzipiert sind, verschiedene Einschränkungen aufweisen: eine Schematik von Form und Inhalt, eine Orientierung an Formen des Gelingens bzw. Scheiterns, der Durchführung bzw. Störung von Kommunikation, eine Verengung der Perspektive auf Sender und Empfänger, eine Reduktion von Materialität auf das Substrat der Kommunikation, eine Ausblendung der kulturellen und semantischen Bedingungen, unter denen Kommunikation stattfindet. ${ }^{140}$ Zwar bleibt Kommunikation eine Basiskategorie, um die innermedialen Gegebenheiten und Rahmungen $\mathrm{zu}$ den kontextuellen in eine funktionale Beziehung zu setzen. Doch greift die mediologische Perspektive darüber

${ }^{137}$ Vgl. etwa Derrida, Grammatologie (wie Anm. 15); ders., L'écriture et la différence, Paris 1967.

${ }^{138}$ Müller, ,Medialität“ (wie Anm. 133), S. 61.

${ }^{139}$ Zum Programm einer Mediologie Régis Debray, Introduction à la médiologie, Paris 2000 (dt.: Einfuihrung in die Mediologie, übers. von Susanne Lötscher, Bern 2003); Frank Hartmann, Mediologie. Ansätze einer Medientheorie der Kulturwissenschaften, Wien 2003; außerdem die Reihe Mediologie des Kölner SFB/Forschungskollegs Medien und kulturelle Kommunikation.

${ }^{140}$ Zur Kritik an dem Modell u. a. Wolfram K. Köck, ,Kognition - Semantik - Kommunikation“, in: Siegfried J. Schmidt (Hg.), Der Diskurs des Radikalen Konstruktivismus, Frankfurt a. M. 1987, S. 340-373; Rainer Schützeichel, Soziologische Kommunikationstheorien, Konstanz 2004. 
hinaus, indem sie sich auf die Bedingungen der Möglichkeit von Kommunikation richtet, d.h. auf die Bedingungen, unter denen etwas als Dazwischen, Vermittlung oder Übertragung dienen kann. Sie beschränkt sich dementsprechend weder auf kommunikative Akte noch auf Verbreitungsmedien - so sehr dies naheliegend und forschungspragmatisch sinnvoll sein kann. ${ }^{141}$ Denn wichtig scheint es, die bekannten Figuren medialer Übergänge (von der Mündlichkeit zur Schriftlichkeit, von der Handschrift zum Buchdruck, von der körpernahen zur körperfernen Kommunikation) ihrerseits als Effekte diskursiver und epistemischer Konstellationen zu begreifen. ${ }^{142}$ Das hieße, „Mediengeschichte als Evolution von Beobachterebenen, mithin also aus einem Gesichtspunkt zu konzipieren“ “ ${ }^{143}$ Und das hieße, neben den Formen der Kommunikation auch Prozesse der Wahrnehmung und der Imagination in ihrer medialen Dimension zu bedenken. Einerseits ist mit ihnen eine reiche historische Semantik von Übermittlungsvorgängen verbunden (Theorien der Sprache und Schrift, der Optik und Akustik). Andererseits spielt in verschiedenen Zusammenhängen die Verbindung zwischen den Formen der Vermittlung und denen der Überlieferung bzw. Verbreitung eine Rolle: In narrativen Texten etwa steht mit dem, was Figuren hören, sehen oder kommunizieren, nicht selten auch zur Diskussion, wie überhaupt die Ausbildung und Verstetigung von Sinn zu denken ist. ${ }^{144}$

Ausgangspunkt eines auf mittelalterliche Medialität gerichteten Unternehmens könnte so ein allgemeineres Verständnis des Medialen sein, das es erlaubte, die Fixierung auf die epochalen Umbrüche zu vermeiden. Ein solches Verständnis würde jene elementare Dimension des Medialen beden-

${ }^{141}$ Müller, „Medialität“ (wie Anm. 133), S. 53; vgl. auch ders., „Formen literarischer Kommunikation im Übergang vom Mittelalter zur Neuzeit“, in: Werner Rökke/Marina Münkler (Hg.), Die Literatur im Übergang vom Mittelalter zur Neuzeit, München 2004, S. 21-53.

${ }^{142}$ Vgl. für die Reformation den Ansatz von Jussen/Koslofsky (Hg.), Kulturelle Reformation (wie Anm. 59).

${ }^{143}$ Jäger, „Die theoretische Grundlegung“ (wie Anm. 33), S. 196.

${ }^{144} \mathrm{Zu}$ Neuzeit und Moderne vgl. Götz Grossklaus: Medien-Zeit, Medien-Raum. Zum Wandel der raumzeitlichen Wahrnehmung in der Moderne, Frankfurt a. M. 1997; Ralf Schnell, Medienästhetik. Zu Geschichte und Theorie audiovisueller Wahrnehmungsformen, Stuttgart, Weimar 2000; Erika Fischer-Lichte u.a. (Hg.), Wahrnehmung und Medialität, Tübingen, Basel 2001; zum Mittelalter Wolfgang Harms/C. Stephen Jaeger/Alexandra Stein (Hg.), Fremdes wahrnehmen - fremdes Wahrnehmen. Studien zur Geschichte der Wahrnehmung und zur Begegnung von Kulturen in Mittelalter und früher Neuzeit, Stuttgart/Leipzig 1997; John Greenfield (Hg.), Wahrnehmung im Parzival Wolframs von Eschenbach, Porto 2004; Judith Klinger, „Stimmklang und Erzählraum. Zur performativen Dimension illustrierter Epenhandschriften“, in: Renate Brosch (Hg.), Ikono/Philo/Logie. Wechselspiele von Texten und Bildern, Berlin 2004, S. 103-151; siehe auch die Arbeiten von Wandhoff (wie Anm. 81). 
ken, die beispielsweise Aristoteles in seiner wirkungsreichen Schrift Über die Seele im Blick hatte, wenn er hinsichtlich der Notwendigkeit der Sinneswahrnehmung mittels eines Durchlässigen (Diaphanen) betonte: „Demokrit lehrt also nicht richtig, wenn er meint, man würde ganz genau sehen können, selbst wenn eine Ameise am Himmel wäre, wenn nämlich das Dazwischen (to metaxy) leer würde. Dies ist nämlich unmöglich. Denn das Sehen kommt zustande, indem das Sinnesorgan etwas erleidet. Dies kann aber nicht durch die gesehene Farbe selber geschehen. Also ist es nur durch das Dazwischen möglich, so daß es notwendigerweise ein Dazwischen geben muß.“145

So wie Aristoteles die sich selbst zum Verschwinden bringende passive übertragende Substanz (Licht, Äther) mit aktiven Instanzen, Bewegung der Form einerseits, Gedächtnis, Vorstellung und Phantasia andererseits, zusammendenkt, ${ }^{146}$ so wurde auch in der jüngeren Medienphilosophie die Idee des ,Dazwischen“ von ihrer Beschränkung auf Trägermedien gelöst: „Die grundlegendste Bestimmung des Mediums ist, daß es ein ,Dazwischen' ist. Das Medium steht als drittes zwischen zwei Momenten und nimmt in der Gesamtheit, die sie bilden, bestimmte Aufgaben wahr. Diese Aufgaben kann man vorläufig und unvollständig als Vermittlung, Übertragung, Transport, Ausdruck, Verkörperlichung usw. beschreiben. Das deutet darauf hin, daß es sich bei dem Begriff ,Medium ' um etwas handeln muß, das in einen Prozeß verwickelt ist, das Teil eines Prozesses ist.“' ${ }^{4147}$

Eine solche Bestimmung zielt nicht darauf, verschiedenste Erscheinungsformen allesamt undifferenziert als Medien zu klassifizieren. Sie ist aber geeignet, die nachrichtentechnische Verengung des Medienbegriffs zu überwinden und die Systemstellen zu fokussieren, an denen Mediales beobachtbar und beschreibbar wird. Schon Fritz Heider hatte in einem pionierhaften Aufsatz von 1926 die Differenz zwischen Ding und Medium im Sinne der Differenz von Erkenntnisobjekt und Vermittlung, Innengeschehen und Außengeschehen, Eigenschwingung und aufgezwungener Schwingung herausgearbeitet und gleichzeitig betont, auch Dinge und Spuren könnten

${ }^{145}$ Aristoteles, Vom Himmel. Von der Seele. Von der Dichtkunst, übers. und hg. von Olof Gigon, Zürich 1950, 418b/419a; vgl. auch Anca Vasiliu, Du diaphane. Image, milieu, lumière dans la pensée antique et médiévale, Paris 1997; zur Wirkung im Altertum Andreas Kamp, Philosophiehistorie als Rezeptionsgeschichte. Die Reaktion auf Aristoteles' De Anima-Noetik. Der frühe Hellenismus, Amsterdam/Philadelphia 2001; Peter Adamson, „Vision, Light and Colour in Al-Kindi, Ptolemy and the Ancient Commentators", in: Arabic Sciences and Philosophy 16/2006, S. 207-236.

${ }^{146}$ Frank Haase, Die Aristotelische Philosophie der Medien, München 2006, S. 33-55.

${ }^{147}$ Alexander Roesler, „Medienphilosophie und Zeichentheorie“, in: Münker/Roesler/Sandbothe (Hg.), Medienphilosophie (wie Anm. 8), S. 34-52, hier S. 39. 
Medien sein. ${ }^{148}$ Allgemein gilt: „Alles kann zum Medium werden - sofern es als Medium gebraucht wird." 149 Die Frage ist dann, was in welchen Situationen und Konstellationen als Medium gebraucht und in welcher Weise dieser Gebrauch institutionalisiert und reflektiert wurde. Dabei bieten sich zwei Bezugsgrößen an, um den Charakter von Medium und Medialität zu präzisieren: einerseits Zeichen, andererseits Form, beide elementare Kategorien für jene Analyse des Vorfindlichen, die aus historischer Warte interessiert.

Roland Posner definiert das Medium im Hinblick auf das System der Zeichenvermittlung: „Ein System von Mitteln für die Produktion, Distribution und Rezeption von Zeichen, das dem mit seiner Hilfe ablaufenden Zeichenverhalten bestimmte gleichbleibende Beschränkungen auferlegt, ist ein Medium." ${ }^{150}$ Sybille Krämer sieht das Medium vom Zeichen unterschieden aufgrund seines Spurcharakters, der immer einen (nicht-intendierten) Sinnüberschuß transportiert: „Kraft ihrer medialen Materialität sagen die Zeichen mehr, als ihre Benutzer damit jeweils meinten."151 Alexander Roesler bestimmt das Medium als ,Zeichenmittel“: „Das Zeichen muss zur Erfüllung seiner Aufgabe an etwas konkretem Materiellen festgemacht werden können: Dieses konkrete Materielle, dieser Zeichenträger, diese ,Verkörperung' ist das Medium. “152 In je anderer Weise richten sich die Definitionen auf den Zeichenprozeß, der, wollte man sie kombinieren, (1) zu seiner Realisierung der Materialität bedarf, (2) diese Realisierung immer gemäß bestimmten Bedingungen vollzieht, (3) dabei einen Sinnüberschuß produziert - der wiederum erst aufgrund der medialen V e r kö r per u n g als je und je konkreter beschrieben werden kann. Es geht also um die innere und die äußere Dimension der Medialität des Zeichens, die zusammen jenes ,Feld' eröffnen, auf dem Medialität im Ge bra u ch zu beobachten ist.

${ }^{148}$ Fritz Heider, „Ding und Medium“, in: Symposion: philosophische Zeitschrift für Forschung und Aussprache 1.2/1926, S. 109-157; Neudruck: F. H., Ding und Medium, hg. und mit einem Vorwort versehen von Dirk Baecker, Berlin 2005; zu Heider vgl. Friedrich Bahlke, ,, Mediumvorgänge sind unwichtig'. Zur Affektökonomie des Medialen bei Fritz Heider", in: Annette Keck/ Nicolas Pethes (Hg.), Mediale Anatomien, Bielefeld 2001, S. 401-412.

149 Arbeitsgruppe „Medien“, „Über das Zusammenspiel von ,Medialität“ und ,Performativität““ (wie Anm. 134), Kap.: „Kulturanthropologie der Medien: Thesen zur Einführung“" (Sybille Krämer), S. 130-133, hier S. 130.

${ }^{150}$ Posner, „Beschreibung verbaler und nonverbaler Kommunikation“ (wie Anm. 4), hier S. 302.

${ }^{151}$ Sybille Krämer, „Das Medium als Spur und als Apparat“, in: dies. (Hg.), Medien Computer - Realität. Wirklichkeitsvorstellungen und neue Medien, Frankfurt a. M. 1998, S. 73-94, hier S. 79.

${ }^{152}$ Roesler, ,Medienphilosophie und Zeichentheorie“ (wie Anm. 147), S. 44. 
Verkörperung und Gebrauch meinen hier allerdings nicht etwas, was zum ,Wesen' des Mediums hinzuträte: eine kontingente situative Materialität. Sie meinen vielmehr etwas, was ein Medium zugleich konstituiert und situiert: eine Materialität, die zugleich das Materielle überschreitet, ohne daß aber diese Überschreitung eine zweite ,Welt' (einerseits die materielle, andererseits die immaterielle) ins Spiel brächte. ${ }^{153}$ Um diese nicht-dualistische Spannung zu beschreiben, kann die Kategorie der Form nützlich sein.

Luhmann unterschied bekanntlich zwischen Medium und Form im abstrakten Sinne einer hier losen, dort strikten Koppelung von Elementen. ${ }^{154}$ Diese Unterscheidung ermöglicht es, statt das Medium als ein systemtheoretisch prekäres Drittes, ein ,Dazwischen' zu begreifen, einen neuen Begriff zu bilden, der sich formal der Struktur der Leitdifferenz von System und Umwelt zuordnen läßt. Sie ermöglicht es aber auch, mit einer „systemintern handhabbare[n] Differenz" zu operieren, und zwar dergestalt, daß das Medium die lose gekoppelten Elemente zu strikten Formen bindet, ohne sich dabei selbst zu verbrauchen. Die Unterscheidung ist also eine aspekthafte: Sie betrifft die Differenz von dauerhaftem medialem Substrat auf der einen, zeitlicher Flüchtigkeit der Form auf der anderen Seite. Und sie ist eine autologische: Sie muß die Unterscheidung von Medium und Form als systemkonstitutiv voraussetzen, um sie systemimmanent vornehmen zu können. ${ }^{155}$ Doch liegt die Pointe darin, daß die Unterscheidung nicht gemäß einer schematischen Differenz von Universellem und Partikularem, Idee und Wirklichkeit, Muster und Ausführung gedacht ist. Sie lenkt vielmehr den Blick auf ein zugleich prozessuales und (beobachterbezogen) paradoxales Geschehen: Einerseits schlagen lose und strikt Gekoppeltes beständig ineinander um, andererseits ist das eine jeweils im anderen ,enthalten ' (die Unterscheidung von Medium und Form selbst als Form etc.). Krämer versteht deshalb Form als performativen Vollzug des Medialen. ${ }^{156}$ Khurana begreift Medium als „das Woraus und das Worein einer Form, das als solches nie präsent ist und nicht an sich selbst zu erkennen ist, sondern immer nur an

${ }^{153} \mathrm{Zu}$ dem Problem solcher ,Zwei-Welten-Ontologien“ Sybille Krämer, „Sprache Stimme - Schrift. Sieben Gedanken über Performativität als Medialität", in: Uwe Wirth (Hg.), Performanz. Zwischen Sprachphilosophie und Kulturwissenschaften, Frankfurt a. M. 2002, S. 323-346; dies., „Erfüllen Medien eine Konstitutionsleistung“" (wie Anm. 31), S. 83.

${ }^{154}$ Niklas Luhmann, Die Gesellschaft der Gesellschaft, Frankfurt a. M. 1997, S. 195-202, hier S. 197; siehe auch ders., Die Kunst der Gesellschaft, Frankfurt a. M. 1995, Kap. 3.

${ }^{155}$ Luhmann: Die Gesellschaft (wie Anm. 154), S. 198.

${ }^{156}$ Sybille Krämer, „Form als Vollzug oder: Was gewinnen wir mit Niklas Luhmanns Unterscheidung von Medium und Form?“”, in: Rechtshistorisches Journal 17/1998, S. $558-574$. 
der je aktuellen Form“ ${ }^{157}$ Mersch bezieht die Unterscheidung von Medium und Form auf die konstitutive Dialektik des Medialen zwischen Sichtbarkeit und Unsichtbarkeit, Beobachtbarkeit und Unbeobachtbarkeit: Medium und Form funktionieren als ,[...] Differentiale, die übersetzen, transformieren oder verschieben, die aber als Differentiale nicht hervortreten, sondern nur in ihren Wirkungen ,sind" und als solche beobachtbar werden." ${ }^{158}$ In jedem Fall wird klar: Medialität ist nicht einfach das Prinzip von Vermittlung und Übertragung, sie zeigt sich vielmehr an dem Proze B, der zwei Entitäten aufeinander bezieht. ${ }^{159}$

Die Unterscheidung Medium/Form verweist solchermaßen auf die Notwendigkeit, die Frage „was ist ein Medium?“ umzuformulieren zur Frage „was kann wie als Medium funktionieren?“. Sie macht Prozesse der Koppelung und Entkoppelung ebenso beschreibbar wie konkrete Formen, in denen die Unterscheidung in Gestalt von Zeichenprozessen ihrerseits begegnet und in denen immer auch Selbstüberschreitungen des Gegebenen stattfinden. Unter der heuristischen Annahme, das Medium gehe nicht in der Form auf, sei jedoch nur in dieser beobachtbar, ermöglicht die Unterscheidung sowohl einen reicheren Begriff des Mediums, der Abstraktes und Konkretes aufeinander bezieht, als auch einen reicheren Begriff der Form, der diese als dynamische konzipiert, in und mit der etwas geschieht. ${ }^{160}$ Ein Medium ist ja nicht als solches gegeben, sondern immer nur in Form einer materiellen Verkörperung: als dieses Blatt, dieser Codex, dieses Taufbecken, dieses Glasfenster etc. Genausowenig ist Medialität als solche gegeben, sondern immer nur in Form der Dynamik konkreter Erscheinungen: als Differenz, Spannung, Auffälligkeit, Sich-Zeigen etc. ${ }^{161}$ Die Unterscheidung zwischen

${ }^{157}$ Thomas Khurana, „Was ist ein Medium? Etappen einer Umarbeitung der Ontologie mit Luhmann und Derrida“, in: Sybille Krämer (Hg.), Über Medien. Geistes- und kulturwissenschaftliche Perspektiven, Berlin 1998 (http://userpage.fuberlin.de/ $\sim$ sybkram/medium/inhalt.html), S. 111-142, hier S. 118.

${ }^{158}$ Mersch, Medientheorien (wie Anm. 2), S. 217. Weitere Anschlüsse an Luhmanns Unterscheidung bietet der Band: Jörg Brauns (Hg.), Form und Medium, Weimar 2002.

${ }^{159}$ Vgl. allgemein dazu Sybille Krämer (Hg.), Performativität und Medialität, München 2004.

${ }^{160}$ Vgl. etwa am Beispiel der barocken Emblematik Wilhelm Voßkamp, „Medien Kultur - Kommunikation. Zur Geschichte emblematischer Verhältnisse“, in: Martin Huber/Gerhard Lauer (Hg.), Nach der Sozialgeschichte. Konzepte für eine Literaturwissenschaft zwischen Historischer Anthropologie, Kulturgeschichte und Medientheorie, Tübingen 2000, S. 317-334.

${ }^{161}$ Vgl. Dieter Mersch, Was sich zeigt. Materialität, Präsenz, Ereignis, München 2002; ders., Ereignis und Aura. Untersuchungen zu einer Ästhetik des Performativen, Frankfurt a. M. 2002; außerdem Norbert Bolz, Am Ende der Gutenberg-Galaxis. Die neuen Kommunikationsverhältnisse, München 1993, S. 45: „Die Medialität eines Mediums 
Medium und Form hat insofern grundsätzlichen Charakter. Sie bietet aber auch ein Instrument, um auf historische Situationen zu blicken, in denen eben diese Unterscheidung anders gelagert sein mag: wo eine gegebene Form suggeriert, Ersche in ung s f o rm des (ontologischen) Mediums zu sein, wo Signifikation und Präsentation sich sowohl verschränken wie entkoppeln, Materialität und Medialität sowohl als komplementär wie als gegenläufig fungieren können. ${ }^{162}$

\section{Historische Mediologie}

Ein Grundverständnis des Medialen als eines formalen, dynamischen .Dazwischen' besäße für das Mittelalter nicht zuletzt deshalb besondere Bedeutung, weil hier (lange) eine onto-theologische Grundierung von Medialität vorherrscht, die sich schon in den eingangs angedeuteten Bedeutungsschattierungen des Terminus medium niederschlägt. Ihnen gemäß kann alles und jedes als Medium des Heils, des Göttlichen, des Transzendenten dienen. Das aber heißt: Das ,Dazwischen' ist nicht nur eines, das zwischen zwei Bezugspunkten, sondern eines, das in zwei ,Bezugsachsen" steht: hier derjenigen der Immanenz, dort derjenigen der Transzendenz, zwei ,Achsen', die ihrerseits Verfügbares und Nicht-Verfügbares asymmetrisch verbinden. Zwar kann Transzendentes analytisch immer nur als Transzendentes im Immanenten erfaßt werden. ${ }^{163}$ Doch zielen die mittelalterlichen Selbstbeschreibungsformen gerade auf die Möglichkeit, daß eine Verwandlung des Immanenten ins Transzendente (Visionen, Jenseitsreisen) oder eine Verankerung der Immanenz in der Transzendenz (Sorge Gottes um die Schöpfung) faßbar werde.

Charakteristisch ist demgemäß einerseits ein Partizipationsverhältnis zwischen dem Medium und demjenigen, das oder zwischen dem es vermittelt, und andererseits eine Ursprungsbeziehung: Das Medium kann, so andersartig es erscheinen mag, als Spur seines eigenen Ursprungs, als Teilhabe an seiner eigenen Möglichkeitsbedingung gedacht werden. Es kann nicht nur als Träger von Signifikanten gelten, sondern in die Position des Signifi-

ist unbeobachtbar. Um seine Funktionsweise indirekt zu erkennen, muß man die Formen studieren und die Elemente analysieren."

${ }^{162}$ Peter Strohschneider, „Sternenschrift. Textkonzepte höfischen Erzählens“, in: Wolfram-Studien 19/2006, S. 33-58, hier S. 57. Strohschneider schlägt für die mittelalterliche Identitätslogik im Anschluß an Eric Voegelin den Begriff der ,Kompaktheit“ vor (S. 44).

${ }^{163}$ Niklas Luhmann, Die Religion der Gesellschaft, hg. von André Kieserling, Frankfurt a. M. 2000. 
kats treten - gemäß jener Vorstellung, die zum Beispiel Augustinus in seinen Confessiones vermittelte, die Erscheinungen der Welt, etwa die Himmelskörper, seien Elemente der göttlichen Selbstmitteilung gegenüber dem Menschen: „Haec nobiscum disputas sapientissime, deus noster, in libro tuo, firmamento tuo, ut discernamus omnia contemplatione mirabili, quamvis adhuc in signis et in temporibus et in diebus et in annis." ${ }^{164}$ Zwar stand jene Vorstellung, im 12. Jahrhundert von Hugo von Sankt Viktor auf die griffige Formel gebracht, in der Rede Gottes hätten nicht nur die Wörter, sondern auch die Dinge Bedeutung, ${ }^{165}$ immer (wieder) in Spannung zu der anderen Vorstellung, die Schöpfung sei durch die menschliche Verworfenheit gestört und allenfalls durch Transzendierung oder durch Transformierung vor dem Auge des Geistes als Medium des Göttlichen lesbar. Doch preisgegeben war das ontotheologisch gegründete Modell einer (prinzipiellen) Substanzrelation zwischen Schöpfer, Medium und Geschöpf damit nicht. Was Augustinus theologisch unter Rückgang auf den 2. Korintherbrief bezüglich Christus formuliert, dieser sei ein wahrer Mittler, aber nichts Mittleres, ${ }^{166}$ läßt sich auch von all dem sagen, an dem Unverfügbares sichtbar wird oder sich vollzieht: Dieses ist ein ,Mittel ' und doch mehr als eine bloße ,Mitte' zwischen zwei Einheiten. Das ,Medium‘ ist eine Schnittstelle zwischen verschiedenen Modalitäten der ,Darstellung` und verschiedenen Modalitäten der ,Übertragung'. Es ist ein herausgehobener Ort der Paradoxie, weil es sowohl zwischen Präsenz und Absenz als auch zwischen Immanenz und Transzendenz vermittelt. ${ }^{167}$

164 Augustinus, Confessiones, hg. von Martin Skutella, Leipzig 1934 (verb. Ausg. Stuttgart 1969), XIII, 18,23; zum Kontext Jens Pfeiffer, Contemplatio Caeli. Untersuchungen zum Motiv der Himmelsbetrachtung in lateinischen Texten der Antike und des Mittelalters, Hildesheim 2001, S. 103.

${ }^{165}$ Hugo von Sankt Viktor, Didascalicon de studio legendi. Studienbuch, übers. und eingeleitet von Thilo Offergeld, Freiburg u. a. 1997, S. 322 f. (V, 3): ,[...] in divino eloquio non tantum verba, sed etiam res significare habent [...].“

166 Confessiones X, 43,68: „In quantum enim homo, in tantum $\mathrm{med}$ i a $\mathrm{t}$ or , in quantum autem verbum, n o n $\mathrm{medi}$ u s, quia aequalis deo et deus apud deum et simul unus deus." (Herv. vom Verfasser)

${ }^{167} \mathrm{Da} \beta$ die mittelalterliche Mystik damit auch (medien)theoretisch aufschlußreich ist, haben u. a. Niklas Luhmann und Peter Fuchs, Reden und Schweigen, Frankfurt a. M. 1989, S. 70-100, herauszuarbeiten versucht. Historische Nuancen zwischen verschiedenen Formen mystischen Sprechens und Schreibens drohen dabei allerdings leicht verlorenzugehen. Skeptisch bin ich gegenüber dem Versuch, eine Verbindung zwischen Systemtheorie, Mystik und avancierter Literatur auf einem Verständnis von (1) Medium als blindem Fleck der Systemtheorie, (2) Mystik als Erfahrungsform (im Medium der Nähe oder Liebe) und (3) Avantgarde als Transsubstanzialisierung von Erfahrung zu gründen; Nina Ort, „Versuch über das Medium: das ,was sich zeigt““, in: Oliver Jahraus/Bernd Scheffer (Hg.), Interpretation, Beobachtung, Kommunikati- 
Das gilt nicht nur bezüglich Heil, dem symbolisch generalisierten Kommunikationsmedium des Mittelalters schlechthin. ${ }^{168}$ Allgemein könnte man sagen: Dasjenige, was im Mittelalter als ,Medium' dienen kann, ist gleichzeitig durch Fülle und Mangel charakterisiert. Wo alles in der Welt Mittel sein kann, Transzendentes zum Vorschein zu bringen, kann alles zum einen mehr als ein kommunikatives Mittel sein: nämlich ontisch am Vermittelten teilhaben, zum andern auch weniger als ein ontisches Mittel sein: nämlich kommunikationsbezogen von seinem Ursprung entfernt oder abgeschnitten sein. Medien erscheinen als solche, die sowohl Abwesendes vergegenwärtigen und Distanz überbrücken als auch Aura herstellen und Heil übertragen. Sie sind „Medien der Repräsentation, des Gegenwärtig-Werden-Lassens, In-die-Gegenwart-Rufens". ${ }^{169}$ Doch sie setzen immer auch eine Differenz voraus, die sie als Medium sowohl zu schließen verheißen wie sichtbar machen. Zeichen, Bezeichnetes und Interpret lassen sich dementsprechend nicht einfach als Kategorien einer reinen Verweisbeziehung denken und gehorchen doch einer überaus komplexen Logik von Identität und Differenz.

Ich verdeutliche dies, um es nicht beim Abstrakten zu belassen, an einigen Beispielen, beginnend mit jener berühmten Episode aus Bedas Historia ecclesiastica gentis Anglorum (731), die, von dem Sänger Caedmon berichtend, der Forschung seit längerem als mediale Urszene mittelalterlicher Reflexion über Semi-Oralität gilt. ${ }^{170}$ Die Episode integriert mehrere Perspektiven, zentriert um ein Wunder, das den Einbruch der göttlichen Gnade in die gelehrte Schriftlichkeit bewirkt und diese zugleich verwandelt. Erzählt wird zum einen von dem ins Kloster eingetretenen Hirten Caedmon, der sich just in dem Moment als Medium des Gotteslobes erweist, da er sich von der institutionalisierten Medialität der Gemeinschaft abwendet: Nicht die monastische Öffentlichkeit bringt Caedmon zum Gesang, sondern die Traumerscheinung eines Engels im Viehstall, auf die hin er einen Hymnus über den Ursprung der Geschöpfe vorträgt. Erzählt wird zum andern von der Klostergemeinschaft, die sich nach sorgfältiger Prüfung der Ereignisse in Caedmon ihr eigenes Medium schafft, das im Folgenden das ganze

on. Avancierte Literatur und Kunst im Rahmen von Konstruktivismus, Dekonstruktion und Systemtheorie, Tübingen 1999, S. 147-170.

${ }^{168}$ Vgl. Jochen Hörisch, Brot und Wein. Die Poesie des Abendmahls, Frankfurt a.M. 1992, S. 106 bezogen auf die Eucharistie.

${ }^{169}$ Wenzel, Hören und Sehen (wie Anm. 72), S. 306.

${ }^{170}$ Vgl. zuletzt Beate Kellner, „Wort Gottes - Stimme des Menschen. Textstatus und Profile von Autorschaft in Otfrids von Weißenburg ,Evangelienbuch““, in: dies./Peter Strohschneider/Franziska Wenzel (Hg.), Geltung der Literatur. Formen ihrer Autorisierung und Legitimierung im Mittelalter, Berlin 2005, S. 139-162, hier S. 139-144. 
Spektrum der Heilsgeschichte in liedhafte Form bringt und das Heilsgeschehen im Kloster in medialer Auratik präsent macht.

Verschiedene Vorgänge der Übertragung (transferre, convertere) erweisen sich als ineinander verschränkt: die Übertragung von Himmlischem in Irdisches (in Form unerhörter Gesänge), die Übertragung von Schriftlichem in Mündliches (die Mönche lesen Caedmon Heilsgeschichtliches vor, das er in Gesang transformiert), die Übertragung von Latein in Volkssprache (die eine Ausbreitung der Lieder und deren allgemeine Anerkennung ermöglicht). Zugleich zeigen sich diese Übertragungen als solche, die ihrerseits das gegebene Medium der Schrift überschreiten. Beda teilt den Schöpfungshymnus nicht volkssprachig, sondern lateinisch mit und markiert damit die Differenz zwischen dem, was sich sagen, und dem, auf das sich verweisen läßt: , ,[...] neque enim possunt carmina, quamuis optime conposita, ex alia in aliam linguam ad uerbum sine detrimento sui decoris ac dignitatis transferri.“'171 Auch präsentiert er keine stringente Chronologie, sondern eine Verschränkung von vorausgesetztem Ergebnis und hergestelltem Vollzug. Die Narratio überblendet vom Ende der Geschichte auf das Gastmahl, das als Anfang die Finalität schon in sich trägt. Sie verwebt Ergebnis und Ablauf der Geschichte. Sie bringt das Paradoxon religiöser Kommunikation zum Vorschein, das darin besteht, daß vom Einbrechen der Gnade immer nur zugleich in und über der Zeit erzählt werden kann. Sie stellt damit ein Muster bereit, auf das andere Inspirationsgeschichten (z.B. in den Praefationen des altsächsischen Heliand) zurückgreifen konnten.

Bedas Caedmon-Episode gibt beispielhaft zu erkennen, wie vielschichtig das Verhältnis zwischen mündlichen und schriftlichen, korporalen und skripturalen, sanglichen und prosaischen, laikalen und klerikalen Formen im Mittelalter gedacht wurde. Sie gibt auch zu erkennen, daß performative (die semiotische Differenz überspielende) Vollzüge und reflexive (die semiotische Differenz bewußt machende) Fokussierungen nicht als gegensätzlich aufzufassen sind. Diese wirken zusammen und ermöglichen Steigerungseffekte, die sich nicht zuletzt aus der gleichzeitigen Selbstausstellung und Selbstüberschreitung des Medialen ergeben. In diesem Sinne widmet beispielsweise die bronzene Tür des Hildesheimer Domes (1015), die am Anfang einer Tradition steht und ihrerseits Teil eines komplexen Ausstattungsprogramms ist, in ihrer Erzählung der menschlichen (Un-)Heilsgeschichte

${ }^{171}$ Beda der Ehrwürdige, Kirchengeschichte des englischen Volkes, übers. von Günter Spitzbart, Darmstadt ${ }^{2} 1997$ ( $\left.{ }^{1} 1982\right)$, S. 398. 
medialen Aspekten besonderen Raum. ${ }^{172}$ Die beiden Flügel, links nach unten von der Erschaffung des Menschen bis zum Tod Abels, rechts nach oben von der Verkündigung bis zur Auferstehung Christi führend, zeigen verschiedene göttliche und humane Medien des Heils: (1) das Buch Gottvaters und die Bücher der Evangelisten unter dem Kreuz, (2) die schaffende, urteilende oder richtende Hand Gottes, die aufnehmenden Hände Christi und der Engel, die Hände Adams und Evas sowie Kains und Abels - sie alle bezogen auf das die Darstellung überschreitende performative Moment der konkreten Handhabung der Tür, das in den großen Türklopfern manifest wird. Dieses Moment erfährt eine weitere Reflexion durch (3) die Darstellung von verschlossenen, offenen oder halboffenen Pforten und Durchgängen auf der Tür selbst - eine Bezugsstiftung zwischen intra- und extradiegetischer Situation. Kirchenbesucher und Betrachter werden eben an der Schwelle zum Raum des Heils mit der Repräsentation einer Schwelle konfrontiert, die das Räumliche mit dem Überräumlichen und das Zeitliche (linker Flügel: AT, rechter Flügel: NT) mit dem Überzeitlichen verbindet. An genau der Stelle, an der die Türen sich öffnen und als Türen zurücktreten, erscheinen sie selbst als Medium - zwischen Außen und Innen, Greifbarkeit (durch extreme Plastizität) und Ungreifbarkeit (aufgrund der Bewegung der neutestamentlichen Heilsgeschichte nach oben hin, vom Betrachter weg), Sinnfülle des Gegenwärtigen und Verheißung des erst Kommenden, Materialität (Schöpfung, Logos) und Immaterialität (Noli me tangere), Konkretheit und Abstraktheit, Darstellung und Vollzug des Medialen.

Auch andere mediale Schwellenobjekte sind von solchen einerseits symbolisierenden, andererseits desymbolisierenden Bewegungen geprägt. Taufbecken etwa markieren den Eintritt in die Gemeinschaft des Heils und die Institution der Kirche in Form eines materiellen Objekts, das seinerseits eine figurativ-symbolische Repräsentation enthalten kann. Sie bewahren das Heilsmedium des geweihten Wassers und sind Teil eines Rituals, in dem sich ein Ur-Ritual (die Taufe Christi im Jordan) wiederholt. Sie situieren sich somit im Schnittpunkt zwischen historia (Geschichtlichkeit der Taufe als Begründungsinstitut christlicher Gemeinschaft) und veritas (Fülle der Wahrheit in der endzeitlich-überzeitlichen Gemeinschaft). Gleichzeitig thematisieren sie diesen Schnittpunkt in den Szenen, die sie zeigen. So zumindest in einem der frühesten und spektakulärsten Beispiele des Genres: dem Reiner von Huy zugeschriebenen Taufbecken der Kapelle „Unsere Liebe Frau am Taufbecken“ zu Lüttich (vermutlich zwischen 1107 und

${ }^{172}$ Vgl. Steffen Bogen, ,,Türen auf Bildertüren. Zum Ort, Medium und Selbstverständnis christlicher Bilderzählung“, in: Crivellari u.a. (Hg.), Die Medien der Geschichte (wie Anm. 70), S. 239-261. 
1118). ${ }^{173}$ Es ruht auf (ursprünglich) zwölf Bronzerindern, die metonymisch an das im Buch der Könige 7,23 in Zusammenhang mit dem Tempelbau Salomons beschriebene eherne Meer erinnern. Es steht damit im wahrsten Sinne des Wortes auf einem figurativen Vorbild, das es zugleich übertrifft und überbietet, das es realisiert und reflektiert, das es als Schrift präsent hält und über die Schrift hinaus ,erfülltt ${ }^{174}$

An seinen vier Seitenwänden zeigt das Lütticher Becken fünf chronologisch aufeinander folgende Szenen, allesamt auf das Taufgeschehen bezogen: (1) die Predigt Johannes des Täufers in der Wüste von Judäa; (2) die (Buß-)Taufe der Neubekehrten als Ankündigung der Taufe im Geiste durch Christus; (3) die Taufe Christi als zentrale Hauptszene; (4) die Taufe des Zenturio Cornelius durch Petrus und (5) die Taufe des Philosophen (Krato). Mit dieser Folge vergegenwärtigt und vermittelt das Becken ein zentrales (Ursprungs-)Moment christologischer Heilsstiftung: die Taufe Christi, die Verkündigung seiner Göttlichkeit durch Gott den Vater, die Offenbarung des Heiligen Geistes, die Heiligung der Welt, der jüdischen wie der griechisch-römischen, der weltlichen wie der geistlichen. Dieses Moment ist ein historisch-zeitliches wie heilsgeschichtlich-überzeitliches, greifbar in der Plastizität des Geschehens, das aus der Wand des Beckens heraustritt, und zugleich überhöht in der Aura der Schrift, die die Figuren umgibt: Schriftstücke erweisen Petrus (Schriftrolle) und Johannes (Evangelienbuch) als autoritative Zeugen des göttlichen Wortes. Inschriften in den Bildfeldern und auf den Beckenrändern machen das Wort der Evangelisten gegenwärtig und die performativen Akte des Heilsvollzugs nachvollziehbar (facite ergo, ego vos baptizo, ego a te debeo baptizari, ego te baptizo). Das Becken bezieht sich auf ein vergangenes Kunstwerk/Heilswerk, einen berühmten Heilsort (den Tempel Salomons, in dem das ,erzene Meer" seinen Ort hatte) und heilsstiftende Akte, die allesamt in einen Sinnvollzug integriert werden, der seine mediale Dimension sowohl ostendiert wie transzendiert. Über die horizontale und die vertikale Achse entfaltet sich die irdische Ausbreitung des göttlichen Logos als Engführung symbolisch generalisierter Medien (Taufe, Wasser, Geist) und verbreitungsbezogener Medien (Predigt, Schriftrolle, Buch). Zugleich wird im Hin und Her zwischen Materialisierung und Symbolisierung die Hoffnung genährt, das Becken selbst als Medium vermöge nicht nur die Heilsstiftung zu zeigen, sondern die Gläubigen an ihr partizipieren zu lassen.

${ }^{173}$ Grundsätzlich dazu: Bruno Reudenbach, Das Taufbecken des Reiner von Huy in Lüttich, Wiesbaden 1984.

${ }^{174}$ Vgl. Bernd Mohnhaupt, Beziehungsgeflechte. Typologische Kunst des Mittelalters, Bern u. a. 2000 
Das Mediale stiftet solchermaßen Identitäten wie Differenzen - und dies keineswegs nur dort, wo die christliche Heilsgeschichte im Zentrum steht. Ontologische Denk- und Sprachfiguren spielen in vielen Bereichen der mittelalterlichen Gesellschaft eine Rolle: In Recht, Herrschaft, Kunst und Literatur tragen sie dazu bei, Legitimitäten zu stiften, aber auch Komplexitäten der Inszenierung zu erzeugen. Wolfram von Eschenbach verknüpft in seinem Parzival das Geheimnis der Herkunft der Erzählung mit dem Mysterium der Botschaften des Grals, beide bezogen auf Formen der Schrift. ${ }^{175}$ Skizziert wird eine Quellenkette, in der ein gewisser Kyot das Bindeglied darstellt zwischen einer ins Heidnisch-Alttestamentliche und auf die Sterne zurückreichenden Schrift und der gegenwärtigen, , vorliegenden', in christlichen Kontext versetzten Geschichte. Kyot habe in Toledo ein heidnisches Buch gefunden, das die von Flegetanis in den Sternen gelesene und niedergeschriebene Geschichte des Grals bot. Er habe in lateinischen Büchern/Chroniken nach der Geschichte des Gralsgeschlechts gesucht (und diese in Anschouwe gefunden), aber dem Erzähler aufgetragen, die Geschichte zunächst noch zu verheimlichen, weil ihm selbst die âventiure dies gebot. Damit ist eine Figur besonderer Authentizität geschaffen, die sowohl heidnische, in Chiffren (karacter; 453,15) geschriebene Bücher wie französische und britannische Chroniken zu verstehen vermag, ein Gewährsmann, in dem sich das Schriftliche ins Mündliche (zurück)verwandelt, ein Medium zur Auratisierung der Geschichte im Hinblick sowohl auf überirdische Ursprünge wie auf geheimnisumwitterte Übertragungen. Zwar sind die Prinzipien der Transkription und Translation schriftliterarische, doch überschreiten sie die schriftliterarischen Praktiken ebenso wie sie sie verwischen: Wie das Verhältnis zwischen dem gegebenen Text und seinem numinosen Ursprung genau zu denken wäre, bleibt offen.

Humane und mediale Genealogien überlagern sich, und dies nicht zuletzt deshalb, weil das Gralsgeschlecht selbst eine mediale Beziehung zu jener Transzendenz besitzt, die auch den Ursprung der Geschichte verkörpert. Der Gral wird in doppelter Weise vom Überirdischen genährt bzw. mit transzendenter Energie aufgeladen: einerseits in Form der Taube, die jeden Karfreitag eine weiße Oblate (Hostie) auf den Stein legt und diesem damit die Wunderkraft verleiht, köstliche Getränke und Speisen aller Art hervorzubringen; andererseits in Form einer am Rand des Steins erscheinenden Chiffrenschrift (,von karacten ein epitafum“; 470,25), die die jeweils zum Gral

${ }^{175}$ Vgl. zuletzt Strohschneider: „Sternenschrift“ (wie Anm. 162). Zitate nach: Wolfram von Eschenbach, Parzival, nach der Ausgabe Karl Lachmanns, revidiert und kommentiert von Eberhard Nellmann, übertragen von Dieter Kühn, 2 Bde., Frankfurt a. M. 1994, V. $453,15$. 
berufenen Jungen und Mädchen nennt und von selber wieder verschwindet. In dieser übermateriellen Verkündungsschrift sind dauerhafter Beschreibstoff und flüchtige Präsenz paradox vereint. Und in ihr seien der Gralsgesellschaft, so heißt es, sowohl die Bedingungen der Erlösung ihres leidenden Gralskönigs (durch die Mitleidsfrage) als auch die Bedingungen des Aufenthalts der Gralsritter in fremden Ländern (Verbot der Frage nach ihrer Herkunft) mitgeteilt worden. Das irdische Geschehen wird solchermaßen zwar unter das Zeichen des Überirdischen gestellt, nicht aber in jenem aufgehoben. Vielmehr erweist sich die Gralsschrift als eine Umschaltstelle, die Dinge eher in Bewegung versetzt als festschreibt. Das Programm, das sie enthält, weist über sie selbst hinaus: Die mündliche Frage an den Leidenden vollzieht sich diesseits der Transzendenz, in der sich die Schrift gründet. Indem am Ende das nunmehrige Frageverbot auf das vorherige Fragegebot reagiert, schreibt sich die immanente Logik der Gralsgesellschaft in die transzendente Logik der Gralsursprünge ein. Indem mit dem in der Schrift erscheinenden Nicht-Fragen-Dürfen auch das Erzählen vom Geschehenen scheinbar unmöglich gemacht wird (tatsächlich ist es ja gerade jetzt an sein Ziel gekommen), wird die Paradoxie der Schrift als eines immer nur in der Verschiebung, Verlagerung und Verzögerung Sinn erzeugenden Mediums sichtbar.

Die knapp gestreiften Beispiele mögen andeuten, daß der mediävistische Blick auf Medialität keiner sein muß, der einfach bekannte Phänomene in neue Terminologie kleidet. Diesem Blick kann vielmehr eine genuin erschließende Kraft innewohnen - wenn er sich auf Situationen richtet, in denen (verschiedene) materielle Formen auf mediale Prinzipien hin transzendiert werden, ontologische und epistemologische mit kommunikativen Aspekten in ein Verhältnis treten oder generell mediale Gegebenheiten ostendiert, inszeniert oder reflektiert werden. Gegenüber der meist privilegierten Konzentration auf Phänomene des Medien wa nde ls oder des Medien we c h s e ls rückt damit ein anderer Bereich in den Fokus: der des Medien wis s e n s. Dieses Wissen - als ein Wissen sowohl um den elementaren Charakter (,knowing that') wie die vielfältigen Formen (,knowing how') des Medialen - betrifft weniger die äußeren medialen Bedingungen von Kommunikation, Überlieferung und Sinnbildung als die inneren, in denen jene äußeren ihrerseits ausgestellt oder dargestellt werden können. Die Ausstellung manifestiert sich in der Art und Weise, in der Texte, Bilder und Objekte, indem sie etwas sagen oder zeigen, ihr eigenes Sagen oder Zeigen mit in den Blick rücken: zum Beispiel in der Fülle von Möglichkeiten, durch Schrift und Mise-en-page, Sprache und Rhetorik, Metrum und Rhythmus Hervorhebungen zu schaffen. Die Darstellung manifestiert sich als Beobachtungssituation zweiter Ordnung in all jenen Formen, die me- 
diale Ursprünge, Strukturen, Konstellationen, Funktionen und Entwicklungen in den Blick rücken. ${ }^{176}$ Es genügt, an die verschiedenen Diskussionen $\mathrm{zu}$ Arten und Funktionen von Bildern zu erinnern oder an die verschiedenen Theorien und Reflexionen von Gebet und Andacht (im ausgehenden 15. Jahrhundert z. B. Berthold, Zeitglöcklein; Fridolin, Schatzbehalter).

An diesen Typen wird zugleich sichtbar, daß Medialität als Kategorie der Beobachtung und als Dynamik eines ,Dazwischen' eng mit Intermedialität, ${ }^{177}$ aber auch mit Meta- und Transmedialität verknüpft ist: Nur an den Beziehungen und Rahmungen ist zu greifen, wie in historischen Sinnwelten Medialität und Mediales konzipiert, reflektiert und funktionalisiert wurden. Es geht damit um weit mehr als um Text-Bild-Relationen, die in der Mediävistik lange im Vordergrund standen. Es geht um die Profilierung der Medialität einer Form durch das, was diese aufnehmen oder darstellen oder auf das sie (ver-)weisen kann. Zu berücksichtigen ist dabei zum ersten das ganze Spektrum materieller Typen (Schriftstücke, Druckwerke, Objekte, Wand-, Glas- und Tafelgemälde etc.) und medialer Konstellationen (Texte, Bilder, Diagramme, Karten etc.). ${ }^{178}$ Zum zweiten das ganze Inventar der Formen, die zwischen einzelnen Text- oder Bildelementen multiple Beziehungen stiften: syntagmatische wie paradigmatische, semantische wie klangliche oder graphische. Zum dritten die ganze Reichweite sowohl medialer Selbstbeschreibungen wie medialer Selbstüberschreitungen, die beide zusammen die epistemische wie performative Dimension des Medialen ausmachen. Beispielsweise in Texten: eine Beschreibung von Objekten, Malereien und Räumen, von Gegebenheiten des Erzählens, Dichtens, Schreibens, Singens oder allgemein Kommunizierens; eine Thematisierung

176 Vgl. Claudia Liebrand/ Irmela Schneider (Hg.), Medien in Medien, Köln 2002.

177 Die theoretische Diskussion entwickelt sich vor allem an Phänomenen der Moderne und Postmoderne; vgl. aus jüngster Zeit Mathias Mertens (Hg.), Forschungsüberblick Intermedialität. Kommentierungen und Bibliographie, 3 Bde., Hannover 2000; Beate Ochsner/Charles Grivel (Hg.), Intermediale. Kommunikative Konstellationen zwischen Medien, Tübingen 2001; Jörg Helbig, Intermedialität. Eine Einfuihrung, Frankfurt a. M. 2001; Irina O. Rajewsky, Intermedialität, Tübingen 2002; Ulrich Ernst, Intermedialität im europäischen Kulturzusammenhang. Beiträge zur Theorie und Geschichte der visuellen Lyrik, Berlin 2002; Andreas Böhn (Hg.), Formzitat und Intermedialität, St. Ingbert 2003.

${ }^{178} \mathrm{Zu}$ Diagrammen vgl. Alexander Patschovsky (Hg.), Die Bildwelt der Diagramme Joachims von Fiore. Zur Medialität religiös-politischer Programme im Mittelalter, Ostfildern 2003; Kathrin Müller, Visuelle Weltaneignung. Astronomische und kosmologische Diagramme in lateinischen Handschriften des 11. bis frühen 14. Jahrhunderts, Göttingen 2008). Zu Karten jetzt Jürg Glauser/Christian Kiening (Hg.), Text Bild - Karte. Kartographien der Vormoderne, Freiburg/ Br. 2007. 
der Formen, Intentionen und Funktionen von Texten, zum Beispiel des Verhältnisses von Vers und Prosa; eine Potenzierung durch Reflexion der (Grenzen der) Schrift in der Schrift. ${ }^{179}$ In Bildern: ein Spiel mit Nischen, Fenstern, Türen und Rahmen, Gemälden, Karten und Spiegeln, Bildern, Materialien und Spolien, eine Spannung von Sichtbarem und Unsichtbarem, von äußeren und inneren, realen und mentalen Formen. ${ }^{180}$ Das Refle-

${ }^{179}$ Für die lateinische Literatur ist dies vor allem im Hinblick auf die Poetiken aufgearbeitet worden; andere Perspektiven eröffnet Peter von Moos, „Was galt im lateinischen Mittelalter als das Literarische an der Literatur? Eine theologisch-rhetorische Antwort des 12. Jahrhunderts“, in: Joachim Heinzle (Hg.), Literarische Interessenbildung im Mittelalter, Stuttgart/Weimar 1993, S. 431-451; aus jüngerer Zeit Frank Bezner, „Vela Veritatis“. Hermeneutik, Wissen und Sprache in der Intellectual History des 12. Jahrhunderts, Leiden/Köln 2005; ders., „Latet Omne Verum? Mittelalterliche ,Literatur'-Theorie interpretieren“, in: Peters (Hg.), Text und Kultur (wie Anm. 89), S. 575-611; ders., ,, Omnes excludendi sunt praeter domesticos.' Eine mittelalterliche Reflexion über die sozialen und kommunikativen Bedingungen des Wissens“, in: Cora Dietl/Dörte Helschinger (Hg.), Ars und Scientia im Mittelalter und in der Neuen Frühzeit. Ergebnisse interdisziplinärer Forschung. Georg Wieland zum 65. Geburtstag, Tübingen/Basel 2002, S. 57-76. Für die deutschsprachige Literatur vgl. die Arbeiten von Wandhoff (wie Anm. 81); außerdem Harald Haferland/Michael Mecklenburg (Hg.), Erzählungen in Erzählungen. Phänomene der Narration in Mittelalter und Früher Neuzeit, München 1996; Bruno Quast, ,Vera icon. Über das Verhältnis von Kulttext und Erzählkunst in der Veronika des Wilden Mannes“, in: Müller/Wenzel, Mittelalter (wie Anm. 76), S. 197-216; Ludger Lieb/Stephan Müller (Hg.), Situationen des Erzählens. Aspekte narrativer Praxis im Mittelalter, Berlin, New York 2002; Timo Reuvekamp-Felber, „Briefe als Kommunikations- und Strukturelemente in der Virginal. Reflexionen mittelalterlicher Schriftkultur in der Dietrichepik", in: Beiträge zur Geschichte der deutschen Sprache und Literatur 125/2003, S. 57-81; Peter Strohschneider, „Textheiligung. Geltungsstrategien legendarischen Erzählens im Mittelalter am Beispiel von Konrads von Würzburg Alexius", in: Gert Melville/Hans Vorländer (Hg.), Geltungsgeschichten. Über die Stabilisierung und Legitimierung institutioneller Ordnungen, Köln/Weimar/Wien 2002, S. 109-147; ders., ,,Reden und Schreiben. Interpretationen zu Konrad von Heimesfurt im Problemfeld vormoderner Textualität“, in: Joachim Bumke/ Ursula Peters (Hg.), Retextualisierung in der mittelalterlichen Literatur, Berlin 2005 (Zeitschrift für deutsche Philologie 124/2005, Sonderheft), S. 309-344; ders., „Sternenschrift“" (wie Anm. 162); Christian Kiening, „Zeitenraum und mise en abyme. Zum ,Kern“ der Melusinegeschichte“, in: Deutsche Vierteljahrsschrift für Literaturwissenschaft und Geistesgeschichte 79/2005, S. 3-28.

${ }^{180}$ Zur autoreflexiven Dimension Victor I. Stoichita, Das selbstbewußte Bild. Vom Ursprung der Metamalerei (1993), übers. von Heinz Jatho, München 1998; vgl. auch Louis Marin, Opacité de la peinture. Essais sur la représentation au Quattrocento, Paris 1989; Klaus Krüger, Das Bild als Schleier des Unsichtbaren. Ästhetische Illusion in der Kunst der frühen Neuzeit in Italien, München 2001; Valeska von Rosen/Klaus Krüge/Rudolf Preimesberger (Hg.), Der stumme Diskurs der Bilder. Reflexionsformen des Ästhetischen in der Kunst der Frühen Neuzeit, Berlin/München 
xionspotential solcher Formen ist nicht schon im neuzeitlichen Sinne von Autoreflexivität und Fiktionalität zu verstehen. Es bleibt bezogen einerseits auf Nah-, andererseits auf Transzendenzkommunikation. Es arbeitet aber, indem es deren Bedingungen mitausstellt, daran, die Rahmungen solcher Kommunikation gleichzeitig zu sichern und zur Verhandlung zu stellen.

\section{Felder und Perspektiven}

Eine historische Mediologie kann solchermaßen anschließen an die in jüngerer Zeit intensivierten Bemühungen um die Eigenheit vormoderner Texte, Bilder und Objekte. Sie greift andererseits über diese hinaus, indem sie die Bestimmung dessen, was jeweils als Text, Bild oder Objekt fungiert, vom Ensemble aller Formen her vornimmt und auf die Strukturen ihres vermittelnden Dazwischen bezieht. An die Stelle einer Fixierung auf die bekannten Konstanten mediengeschichtlicher Umbrüche tritt dabei eine Fokussierung von Prozessen, Situationen und Semantiken, aus denen partiellere, aber auch tiefenschärfere Bilder vormoderner Medialität hervorgehen können weniger geeignet für das Narrativ einer ins Digitale mündenden Medienteleologie, dafür interessanter für eine Beschreibung der historischen Bedingungen der Möglichkeit des Medialen.

2003. Zur Inserierung und Inszenierung von Schrift Hartmut Boockmann, „Über Schrifttafeln in spätmittelalterlichen deutschen Kirchen“, in: Deutsches Archiv 40/1984, S. 210-224; ders., „Belehrung durch Bilder? Ein unbekannter Typus spätmittelalterlicher Tafelbilder", in: Zeitschrift für Kunstgeschichte 57/1994, S. 1-22; Arwed Arnulf, Versus ad picturas. Studien zur Titulusdichtung als Quellengattung der Kunstgeschichte von der Antike bis zum Hochmittelalter, München u.a. 1997; Ruth Slenczka, Lehrhafte Bildtafeln in spätmittelalterlichen Kirchen, Köln/Weimar/Wien 1998; Bruno Reudenbach, Das Godescalc-Evangelistar. Ein Buch für die Reformpolitik Karls des Großen, Frankfurt a. M. 1998; Heinz Herbert Mann, Wörter und Texte in den Bildkünsten. Vier Studien zum Verhältnis von Sprache und bildender Kunst, München 1999; Jens T. Wollesen, „Spoken Words and Images in Late Medieval Italian Painting", in: Gerhard Jaritz/Michael Richter (Hg.), Oral History of the Middle Ages. The Spoken Word in Context, Krems/Budapest 2001, S. 257-276. Zu realen und mentalen Bildern Klaus Krüger/Alessandro Nova (Hg.), Imagination und Wirklichkeit. Zum Verhältnis von mentalen und realen Bildern in der Kunst der frühen Neuzeit, Mainz 2000; Klaus Krüger, ,Medium and Imagination. Aesthetic Aspects of Trecento Panel Painting“, in: Victor M. Schmidt (Hg.), Italian Panel Painting of the Duecento and Trecento, Washington 2002, S. 57-81; ders., „Bild und Bühne. Dispositive des imaginären Blicks“, in: Ingrid Kasten/Erika Fischer-Lichte (Hg.), Transformationen des Religiösen. Performativität und Textualität im geistlichen Spiel, Berlin/ New York 2007, S. 218-248. 
Prozesse - damit sind Dynamiken gemeint, die sich ,unterhalb“ der Ebene abspielen, auf der man makrohistorisch die epochalen medialen Umbrüche verortet. Der Prozeßbegriff setzt eine Zeitdifferenz voraus, wobei aber die verschiedenen Momente nicht durch kausale Determination verbunden sind. Zugleich impliziert er eine Abkehr von einem Denken, demgemäß Gegenstände abgelöst betrachtet werden können von der Zeit und dem Raum, in dem sie begegnen. ${ }^{181}$ Prozesse haben es damit zu tun, daß „konkrete selektive Ereignisse zeitlich aufeinander aufbauen, aneinander anschließen", ${ }^{182}$ ohne daß aber die Sequenz entweder strikt notwendig oder gänzlich zufällig wäre. Sie betreffen eine Gerichtetheit, die makro- und mikrohistorisch durchaus nicht die gleiche sein muß. Prozesse wie die Veränderung der Rolle des Körpers, der Gewohnheiten des Lesens oder der Präsenzmodelle des Heils lassen sich in Bezug setzen zur makrohistorischen Ereignisfolge im Zuge der Ausbreitung von Schriftlichkeit oder der Einführung des Buchdrucks. Doch dieser Bezug löst sich bei genauerem Blick in eine Fülle von Bezugsmöglichkeiten auf, führen doch die genannten Prozesse weniger zu schlichten Umstrukturierungen denn zu unübersichtlichen Komplexitätssteigerungen: zu Differenzierungen im Verhältnis medialer Formen zueinander, zu Umbesetzungen in deren Funktionen, zu Pluralisierungen im Sinne einer Vermehrung von Möglichkeiten unter den Bedingungen unsicherer oder nur partiell greifender Hierarchisierungen. ${ }^{183}$

Versucht man dementsprechend mediale Prozesse auf einer Ebene zu beschreiben, auf der noch nicht vorausgesetzt ist, was die entscheidenden diskursiven Ereignisse gewesen seien, bieten sich andere Begriffe und andere Typen von Unterschieden an. Zum Beispiel Materialisierung/Dematerialisierung. Dieses Begriffspaar bringt in den Blick, wie mittelalterliche Überlieferung damit experimentiert, Materielles als auratisch zu erweisen und zugleich auf ein Nicht-(nur)-Materielles hin zu übersteigen. Im Spätmittelalter kreisen die vielfältigen Formen der Verkörperlichung und Entkörperlichung darum, Transzendentes darstellbar und übertragbar zu machen. Es entwickelt sich eine dialektische Steigerung von Innerlichkeit und Äußerlichkeit, welche die Gegenwärtigkeit des Heils an seine medial immer wei-

${ }^{181}$ Grundlegend Alfred North Whitehead, Prozeß und Realität. Entwurf einer Kosmologie (1929), übers. von Hans Günter Holl, Frankfurt a. M. 1979.

${ }^{182}$ Niklas Luhmann, Soziale Systeme. Grundriß einer allgemeinen Theorie, Frankfurt a. M. 1984, S. 74. In historischer Hinsicht ders., „Geschichte als Prozeß und die Theorie sozio-kultureller Evolution“, in: ders., Soziologische Aufklärung, Bd. 3: Soziales System, Gesellschaft, Organisation, Opladen 1981, S. 178-197.

${ }^{183} \mathrm{Vgl}$. Christian Kiening, „Zwischen Mittelalter und Neuzeit? Aspekte der Epochenschwellenkonzeption", in: Mitteilungen des Deutschen Germanistenverbandes 49/2002, S. 264-277. 
tere Verbreitung knüpft und zugleich noch im Modus mechanischer Vervielfältigung $\mathrm{zu}$ intensivieren sucht.

Ein anderes Paar wäre das von Symbolisierung und Desymbolisierung. Mit ihm ließe sich beschreiben, wie mediale Formen im Mittelalter je neu Anwesenheit und Gegenwärtigkeit herstellen und zugleich den Akt der Herstellung ausstellen - oder sogar explizit zum Thema machen: An der Diskussion des mental-realen Status von Repräsentation oder des Status des Wandlungsgeschehens in der Eucharistie wird auf theoretischer Ebene ein intensives Nachdenken über mediale, materielle und symbolische Handlungen und (Zeichen-)Prozesse deutlich. ${ }^{184}$ Von ihm her erscheint die reformatorische Wende als Umcodierung eines semiotischen und sakramentalen Realismus: Man solle nicht behaupten, so Zwingli, ,[...] sacramenta sygind zeichen, die ouch das sygind, das sy bedütend. Denn wären sy, das sy bedütend, so wärend sy nit zeichen; denn zeichen und das, so verzeichnet ist, könnend ie nit ein ding sin. ${ }^{، 185}$ Eben diese Wende hin zur semiotischen und medialen Differenz zwischen Bezeichnendem und Bezeichnetem geht einher mit sozialen, ökonomischen und politischen Veränderungen, die jeweils nur im Geflecht konkreter Situationen beschreibbar sind.

Situatione n - mit diesem Stichwort ist eine historische Eigentümlichkeit aufgerufen, die in den letzten Jahren deutlicher bewußt geworden ist: die Tatsache, daß mittelalterliche Überlieferung in geringerem Maße situationsabstrakt ist als neuzeitliche und in höherem Maße Bekanntes auf je neue Aktualität und Geltung hin perspektiviert. Das bedeutet auch: Die Gegebenheiten, unter denen sich Überlieferung ausbildet, verstetigt und verändert, hinterlassen in besonderer Weise ihre Spuren im Überlieferten, seinen kommunikativen Strukturen wie materiellen Formen. ${ }^{186}$ Schon im Mittelal-

${ }^{184}$ Brian Stock, The Implications of Literacy. Written Language and Models of Interpretation in the Eleventh and Twelfth Centuries, Princeton, N.J. 1983, S. 252-315; Gary Macy, The Theologies of the Eucharist in the Early Scholastic Period. A Study of the Salvific Function of the Sacrament According to the Theologians c. 1080-c. 1220, Oxford 1984; Miri Rubin, Corpus Christi. The Eucharist in Late Medieval Culture, Cambridge u.a. 1991; Gary Macy, Treasures from the Storeroom. Medieval Religion and the Eucharist, Collegeville (Minn.) 1999; Heike Schlie, Bilder des Corpus Christi. Sakramentaler Realismus von Jan van Eyck bis Hieronymus Bosch, Berlin 2002; Esther Wipfler, ,Corpus Christi in Liturgie und Kunst der Zisterzienser im Mittelalter, Münster 2003.

${ }^{185}$ Ulrich Zwingli, „Von dem touff“ (1525), in: ders., Sämtliche Werke, hg. von Emil Egli u. a., Bd. 4, Leipzig 1927, S. 218.

${ }^{186}$ Zum Begriff der ,Situationalität' Peter Strohschneider, ,Situationen des Textes. Okkasionelle Bemerkungen zur ,New Philology““, in: Tervooren/Wenzel (Hg.), Philologie als Textwissenschaft (wie Anm. 76), S. 62-86; ders., „Textualität der mittelalterli- 
ter war zwar Überlieferung stets auch mit einem Absehen vom reinen Hier und Jetzt, mit der Möglichkeit des Überdauerns und der Latenz verbunden. Sie war aber zugleich bezogen auf Bedingungen, die ein je neues Hier und Jetzt herzustellen erlauben. Dementsprechend gilt es, Texte, Bilder und Objekte selbst als komplexe Situationen oder Figurationen zu begreifen, deren Medialität nicht einfach an isolierten Punkten, sondern in der Gesamtheit der materiellen Erscheinungen wie der zeichenhaften Gefüge erfaßbar ist.

Da ist zum Beispiel die Medialität textueller Selbstausstellungsformen: Textursprungsgeschichten reflektieren orale Situationen und beziehen zugleich aus ihnen ihre eigenen (in Handschrift und Druck unterschiedlichen) Geltungsansprüche; ${ }^{187}$ Rechtsaufzeichnungen konstruieren eine vergangene mündliche Rechtskultur, um durch sie ,das Vordringen differenzierter Formen des administrativen und rechtlichen Schriftgebrauchs“ zu stützen. ${ }^{188}$ Oder die Medialität des geistlichen Spiels: Dieses schließt an die Liturgie an, in der Zeitliches und Räumliches, Architekturelemente und Objekte, Körper und Gesten, Bewegungen und Prozessionen, Worte und Gesänge kombiniert sind. Auch das Spiel vergegenwärtigt das Heilsgeschehen und verschafft zugleich den es deutenden Institutionen Geltung. Doch es führt zugleich Biblisches und Theologisches, Legendarisches und Erbauliches, Kirchliches und Außer-Kirchliches, Bildliches und Klangliches in einer Weise zusammen, die über die klerikal-sakralen Räume und die liturgischfestlichen Zeiten hinausgreift und symbolische und indexikalische Formen der Evidenz verknüpft. ${ }^{189}$ Oder die komplexe Medialität von Reliquien: Sie

chen Literatur. Eine Problemskizze am Beispiel des ,Wartburgkrieges““, in: Müller/Wenzel (Hg.), Mittelalter (wie Anm. 76), S. 19-41.

${ }^{187}$ Stephan Müller, „Alte Medien. Einmaligkeit und Mehrmaligkeit von Stimme und Schrift im Prolog des Wolfdietrich D in Handschrift und Druck“, in: Scientia Poetica 10/2006, S. 1-18.

${ }^{188}$ Simon Teuscher, „Notiz, Weisung, Glosse. Zur Entstehung ,mündlicher Rechtstexte“ im spätmittelalterlichen Lausanne“, in: Ludolf Kuchenbuch/Uta Kleine (Hg.), ,Textus' im Mittelalter. Komponenten und Situationen des Wortgebrauchs im schriftsemantischen Feld, Göttingen 2006, S. 253-284, hier S. 284; siehe auch ders., „Textualising Peasant Enquiries: German ,Weistümer' between Orality and Literacy“, in: Karl Heidecker (Hg.), Charters and the Use of Writing in Medieval Society, Bruxelles 2000, S. 239-254; ders., Erzähltes Recht. Lokale Herrschaft, Verschriftlichung und Traditionsbildung im Spätmittelalter, Frankfurt a. M. 2007; für einen anderen Bereich Jan-Dirk Müller, ,Zwischen mündlicher Anweisung und schriftlicher Sicherung von Tradition. Zur Kommunikationsstruktur spätmittelalterlicher Fechtbücher", in: Helmut Hundsbichler (Hg.), Kommunikation und Alltag in Spätmittelalter und Früher Neuzeit, Wien 1992, S. 379-400.

${ }^{189}$ Zur medialen Differenz von Passionsspiel und Passionsliteratur Jan-Dirk Müller, „Mimesis und Ritual. Zum geistlichen Spiel des Mittelalters“, in: Andreas Kab- 
fungieren zugleich als Metonymien, Verkörperungen und symbolische Formen, als Träger- und Übertragungsmedien. Sie sind machtvolle und zugleich fragile Gebilde, überformt durch Gefäße und Imitate, Schreine und Aufbauten, versehen mit sprachlichen und bildlichen Zeichen, eingebettet in kultische Handlungen wie diskursive Prozesse. Sie sind Austragsort der Spannung zwischen Sichtbarkeit und Unsichtbarkeit, Zeitlichkeit und Überzeitlichkeit, Materialität, Semiotizität und Ästhetizität. Sie bedürfen der Sicherung und der Kennzeichnung und verbinden sich deshalb mit Umkleidungen und Rahmungen, Zeichen und Figuren, Namen und Geschichten, die kontextualisieren, was die Objekte nur zeigen, und sich ihrerseits im Bezug auf die Objekte als nicht nur Zeichengefüge, sondern auch Materialitäten und Handlungsformen erweisen. ${ }^{190}$

In jedem dieser Fälle erweist sich Medialität nicht so sehr als der äußerliche Aspekt der Sinngefüge (das, was diese vermittelt), sondern als der konstitutive Aspekt, von dem der Sinn nicht abzulösen ist (das, was diese vermittelnd zur Erscheinung bringt). Dementsprechend sind Schrift, Bild oder Objekt nicht einfach Teile eines multimedialen Verbundes, sondern je eigene Formen komplexer Medialität, denen ihr Rahmen in Gestalt von Transgredierungen und Transzendierungen eingeschrieben ist. Den Blick auf Situationen und Figurationen zu richten heißt damit auch, die Vielfalt kontextueller Möglichkeiten zu rekonstruieren und von ihnen her verschiedene Dimensionen der Medialität der Überlieferung zu konturieren. ${ }^{191}$ Besonders

litz/Gerhard Neumann (Hg.), Mimesis und Simulation, Freiburg/Br. 1998, S. 541-571. Zum ganzen Komplex zuletzt Hans-Joachim Ziegeler (Hg.), Ritual und Inszenierung: Geistliches und weltliches Drama des Mittelalters und der frühen Neuzeit, Tübingen 2004; Christel Meier/Heinz Meyer/Claudia Spanily (Hg.), Das Theater des Mittelalters und der frühen Neuzeit als Ort und Medium sozialer und symbolischer Kommunikation, Münster 2004; Christoph Petersen, Ritual und Theater. Meßallegorese, Osterfeier und Osterspiel im Mittelalter, Tübingen 2004; Christian Kiening, „Präsenz Memoria - Performativität. Überlegungen im Blick auf das Innsbrucker Fronleichnamsspiel“, in: Kasten/Fischer-Lichte (Hg.), Transformationen des Religiösen (wie Anm. 180), S. 139-168; Cornelia Herberichs, „Lektüren des Performativen. Zur Medialität geistlicher Spiele des Mittelalters“, in: Kasten/Fischer-Lichte (Hg.), Transformationen des Religiösen (wie Anm. 180), S. 169-185.

$190 \mathrm{Vgl}$. Uwe Geese, Reliquienverehrung und Herrschaftsvermittlung. Die mediale Beschaffenheit der Reliquien im frühen Elisabethkult, Darmstadt 1984; Anton Legner, Reliquien in Kunst und Kult zwischen Antike und Aufklärung, Darmstadt 1995; Christof L. Diedrichs, Vom Glauben zum Sehen. Die Sichtbarkeit der Reliquie im Reliquiar. Ein Beitrag zur Geschichte des Sehens, Berlin 2001; Luigi Canetti, Frammenti di eternità. Corpi e reliquie tra Antichità e Medioevo, Rom 2002; Bruno Reudenbach/ Gia Toussaint (Hg.), Reliquiare im Mittelalter, Berlin 2005.

${ }^{191}$ Vgl. Ursula Peters, ,Text und Kontext. Die Mittelalter-Philologie zwischen Gesellschaftsgeschichte und Kulturanthropologie“ (2000), wieder in: dies., Von der Sozial- 
ergiebig sind jene historischen Verdichtungen, bei denen entweder eine Fülle von Formen auf das gleiche Ereignis reagieren oder einzelne Formen ein Ereignis in der Fülle der medialen Aspekte entfalten: Das franziskanische Ringen um die Authentizität der Stigmata tangiert in exemplarischer Weise Fragen von Körper, Schrift und Bild, von Urbild und Wiederholung, von Transzendenz und Immanenz, von Öffentlichkeit und Heimlichkeit. ${ }^{192}$ Inthronisationen, Weihen, Erhebungen, Konzilien, Festakte, Hochzeiten, Begräbnisse, Translationen, Wallfahrten, Heiltumsweisungen etc. bringen multimediale Inszenierungen mit sich. ${ }^{193}$ Begleitende Texte und Bilder reflektieren die zum Einsatz kommenden Rituale, Prozessionen und Ostentationen - die Chronik des Anonimo Romano über die Ereignisse der kurzen Regentschaft des Cola de Rienzo bietet ein markantes Einzelbeispiel. ${ }^{194}$ An ihnen allen lassen sich die historischen Kategorien und Semantiken beob-

geschichte zur Kulturwissenschaft. Aufsätze 1973-2000, hg. von Susanne Bürkle, Lorenz Deutsch und Timo Reuvekamp-Felber, Tübingen/Basel 2004, S. 301-334; dies. (Hg.), Text und Kultur (wie Anm. 89); Jan-Dirk Müller (Hg.), Text und Kontext. Fallstudien und theoretische Begründungen einer kulturwissenschaftlich angeleiteten Mediävistik, München 2007.

${ }^{192}$ Vgl. Klaus Krüger, Der frühe Bildkult des Franziskus in Italien. Gestalt- und Funktionswandel des Tafelbildes im 13. und 14. Jahrhundert, Berlin 1992; Bettine Menke/Barbara Vinken (Hg.), Stigmata. Poetik der Körperinschrift, München u. a. 2004; Michael F. Cusato/Jacques Dalarun/Carla Salvati, The Stigmata of Francis. New Studies, New Perspectives, St. Bonaventure (N.Y.) 2006.

${ }^{193}$ Vgl. etwa Peter Johanek: „Geschichtsüberlieferung und ihre Medien in der Gesellschaft des späten Mittelalters", in: Meier u. a. (Hg.), Pragmatische Dimensionen (wie Anm. 45), S. 339-357; Hiram Kümper, ,,,Groth gethone“ schallt ins Reich. Ein Versuch über Königswahl und -krönung Maximilians I. als vormodernes Medienereignis an der Schwelle zur Neuzeit“, in: Ludolf Pelizaeus (Hg.), Wahl und Krönung im Umbruch, Frankfurt a. M. u.a. 2008 (im Druck); Hartmut Kühne, Ostensio reliquiarum. Untersuchungen über Entstehung, Ausbreitung, Gestalt und Funktion der Heiltumsweisungen im römisch-deutschen Regnum, Berlin/New York 2000; Bernhard Schneider (Hg.), Wallfahrt und Kommunikation. Kommunikation über Wallfahrt, Mainz 2004; Christian Kiening, „Hybriden des Heils. Reliquie und Text des ,Grauen Rocks“ um 1512“, in: Peter Strohschneider (Hg.), Literarische und religiöse Kommunikation in Mittelalter und Früher Neuzeit, Berlin/New York 2008 (im Druck). Zum berühmten Beispiel der Hl. Fides von Conques Kathleen Ashley/Pamela Sheingorn, Writing Faith. Text, Sign, and History in the Miracles of Sainte Foy, Chicago 1999; Beate Fricke, Cultura veterum Deorum. Die heilige Fides von Conques und die Bildkultur des Okzidents, München 2007 (im Druck).

${ }^{194}$ Hans Belting/Dieter Blume (Hg.), Malerei und Stadtkultur in der Dantezeit. Die Argumentation der Bilder, München 1989; speziell zum Fall Rienzos Serena Romano, „L'immagine di Roma, Cola di Rienzo e la fine del Medioevo“, in: Maria Andaloro/Serena Romano (Hg.), Arte e iconografia a Roma. Da Costantino a Cola di Rienzo, Mailand 2000, S. 227-256. 
achten, die Mediales im Spannungsfeld von Präsenz/Absenz und Immanenz/Transzendenz zur Erscheinung bringen.

Semantiken - sie betreffen zunächst einmal die Fülle an Möglichkeiten, Mediales als solches zu charakterisieren oder zu markieren. ${ }^{195}$ Onomasiologisch wäre hier, wie eingangs skizziert, am Wortfeld von medium und seinen Umgebungen selbst anzusetzen, semasiologisch das Spektrum möglicher Felder des Medialen zu entfalten. Jeweils geht es um kulturelle Selbstbeschreibungsformen, die nicht nur aus Terminologischem oder metasprachlich Explizitem bestehen, sondern aus allem, das bedeutungstragend sein kann: der Buchstabe, das Wort, die diagrammatische Figur, das Bildelement, der Knochensplitter etc. Wo alles zum Zeichen und Medium werden kann, finden Semantiken des Medialen Ausprägung ebenso in theologischen wie in philosophischen, in logischen wie in musikalischen, in textuellen wie in visuellen Diskursen. Eine Beschränkung auf Verbreitungsmedien würde dieses Spektrum vorschnell verengen. Sie würde überdies verdekken, inwieweit diese Medien selbst im Mittelalter hinsichtlich ihrer Medialität bedacht wurden oder nicht.

Zum Beispiel führt die Geschichte der Verwendungszusammenhänge des Ausdrucks textus und verwandter Termini auf eine Spannung einerseits zwischen Materiellem und Immateriellem, andererseits zwischen Transzendenz und Immanenz. Diese Spannung tangiert eben jenes Dazwischen, das für die Bedingungen kultureller Überlieferung charakteristisch ist. Durchgängig verbindet sich mit dem Ausdruck die Vorstellung materiell verkörperter Schriftmacht (textus evangelii), andere Dimensionen hingegen (schrifttragendes Ding, sinntragender Körper, geschriebener Wortlaut) wurden nur fallweise aktualisiert und lassen erst längerfristig, im Gefolge der Scholastik, eine „Verschiebung der Wahrnehmung des Geschriebenen vom Hörensagen zum sehenden Verstehen (autonomes Lesen)“ erkennen. „Der vokative, aus sich selbst sprechende Textus fügt sich diesem Organwechsel des Verfügens und Verstehens. Er verstummt und gewinnt an literaler und paginaler Klarheit, wird zum sichtbaren Herzstück der Seite, umgeben von den klärenden Glossen, durchflochten und geordnet mit Hilfe von Absätzen, Ziffern, Titeln in bedeutungstragenden Farben, veranschaulicht und gedeutet von Figuren und Szenen, erschlossen durch Register. Es sind diese visuellen Ergänzungsmittel, die helfen, das ordnungsmetaphorische Potential des textus zu entfalten (textus vel ordo, textus et capitulum), ihn für andere

${ }^{195}$ Vgl. auch Ludwig Jäger (Hg.), Semantik der Medien, Paderborn 2002. 
Schriftwerke als die sacra pagina verfügbar zu machen und als abstrakte Standardform visualisierten Sinns im Bewußtsein zu verankern.“196

An der Geschichte von Ausdruck und Begriff ,Textus“ kann also ein Stück weit auch eine Geschichte von Textualität als Medialität sichtbar werden. Gleiches gälte für andere Termini, die ebenfalls zwischen einer aisthetischen, einer epistemologischen und einer onto-theologischen Bedeutungsdimension vermitteln. Beispielweise der Begriff figura. Er changiert zwischen Darstellung und Vollzug. Er verknüpft das Moment der Körperund Gestalthaftigkeit, der Bildhaftigkeit und Anschaulichkeit mit dem Moment der rhetorischen Trope und der christlich-figuralen Realprophetie. $\mathrm{Fi}$ gura markiert damit einerseits die Differenz sowohl zu phantasma wie zu veritas, partizipiert andererseits an veritas. Changierend zwischen Eigentlichkeit und Uneigentlichkeit hat der Begriff eine sowohl substanzielle wie epistemische Komponente. Er verweist sowohl auf den Schatten des Wahren (umbra) wie auf das Abbild des Urbilds (imago). Zugleich repräsentiert er das Mittel, veritas sinnlich erscheinen zu lassen und ein Ereignis ,in die Perspektive der Jederzeitlichkeit und Ewigkeit“ zu versetzen. ${ }^{197}$ Figuren sind sowohl Schöpfungszeichen, ,eingerichtet vom göttlichen Willen, um die unsichtbare Weisheit Gottes sichtbar zu machen“, als auch Bildzeichen, in denen der Ungelehrte, der im aufgeschlagenen Buch der Schöpfung zu lesen versucht, Gestalten, aber keine Buchstaben, äußere Erscheinungen, aber nicht ihre innere Vernunft erkennt. ${ }^{198}$ Greifbar wird hier die oben angesprochene Beziehung zwischen Medium und Form als eine zwischen Medialität im abstrakten Sinne (Prinzip von Vermittlung und Vermitteltheit) und im konkreten Sinne (konkrete Mittel, in denen Heilsgeschehen kommuniziert werden kann). Demgemäß kann auch Schrift als figura gelten: als konkrete Form, die in ihrer präsentischen und auratischen Dimension an dem partizipiert, das sie überträgt, und die in ihrer semiotischen Dimension

${ }^{196}$ Kuchenbuch/Kleine (Hg.), Textus (wie Anm. 188), S. 417-453, hier S. 452 (Nachbetrachtung der Herausgeber).

${ }^{197}$ Erich Auerbach, ,Figura“, in: Archivum Romanicum 22/1938, S. 436-489; wieder in: ders., Neue Dantestudien, Istanbul 1944, S. 11-71, hier S. 37.

${ }^{198}$ So in der berühmten Stelle bei Hugo von St. Viktor, Didascalicon VII, 3 (De tribus diebus); vgl. Hugo von St. Viktor, De tribus diebus, hg. von Dominique Poirel, Turnhout 2002: „Vniuersus enim mundus iste sensilis quasi quidam liber est scriptus digito Dei, hoc est uirtute diuina creatus, et singulae creaturae quasi figurae quaedam sunt, non humano placito inuentae, sed diuino arbitrio institutae ad manifestandam et quasi quodammodo significandam inuisibilem Dei sapientiam. Quemadmodum autem si illiteratus quis apertum librum uideat, figuras aspicit, litteras non cognoscit, ita stultus et animalis homo qui non percipit ea quae Dei sunt, in uisibilibus istis creaturis foris uidet speciem, sed non intelligit rationem [...].“ (S. 9, Z. 94-101); vgl. dazu Pfeiffer, Contemplatio Caeli (wie Anm. 164), S. 168 f. 
zugleich eine Vorläufigkeit transportiert, die nach mittelalterlichem Verständnis allen irdischen Formen eignet.

In diesen Formen kann das selbst Formgebende zur Erscheinung kommen: als ostensio oder, in stärkerem Maße inszeniert, ostentatio. Bewegt sich schon die ostensio zwischen einer göttlich gewährten Enthüllung und Offenbarung und einer menschlich unterstützten Zeigung und Demonstration, so kommen in der ostentatio, die im späten Mittelalter bei Messen, Prozessionen und Weisungen multimediale Züge annimmt, selbstreflexive Züge dazu. Beide aber haben es mit einer mehrfachen Spannung zu tun: von Sagen und Zeigen, von Notwendigkeit und Überschüssigkeit, von (auf das Auge bezogenen) Äußerem und (auf den Geist bezogenen) Innerem, von Zur-Erscheinung-Kommen und Zur-Erscheinung-Bringen. Jeweils geht es um das Entstehen von etwas, das als vorhanden vorausgesetzt (ontologische Dimension), gleichzeitig aber mittels bestimmter Strategien im Zeigen konstituiert bzw. re-präsentiert wird (epistemologische Dimension). Das späte Mittelalter läßt erkennen, wie das, was als grundlegend für die religiöse, politische und juridische Kommunikation der mittelalterlichen Gesellschaften angesehen werden kann (Sichtbarkeit, Hörbarkeit, metonymische Präsenz, performativ hergestellte Geltung) Steigerung und Zuspitzung, aber Verschiebung und Veränderung erfährt. ${ }^{199}$ Es bilden sich eigene visuelle Muster des Ostentativen: Ecce homo, Vera icon, Ostensio vulnerum, Auferstehung Christi. Es kommt aber auch zu Distanznahmen gegenüber den Exzessen der Veranschaulichung und Veräußerlichung. Ausgestaltet werden die Semantiken des Inneren und Innerlichen, erprobt Sicherungen von Sinn unabhängig von seiner Zur-Schau-Stellung. Ostension und Ostentation können somit einerseits als Basiselemente von Medialität gelten, insofern diese neben dem Dazwischen und der Vermittlung immer auch die genuine Leistung einer Konstitution von Wirklichkeit umfaßt. Sie begegnen andererseits in historisch spezifischen Profilierungen - in der Präsenzkultur des Mittelalters nicht anders als in der Medienkultur der Moderne, wo in Existenz- und Sprachphilosophie, Ästhetik und Semiotik gegen die Dualismen der Repräsentation und die Dominanzen des Logos das Phänomen des Zeigens wieder zur Geltung gebracht wurde. ${ }^{200}$

${ }^{199}$ Vgl. Kühne, Ostensio reliquiarum (wie Anm. 193); Horst Wenzel, „Wahrnehmung und Deixis. Zur Poetik der Sichtbarkeit in der höfischen Literatur“, in: Wenzel/ Jaeger (Hg.), Visualisierungsstrategien (wie Anm. 50), S. 17-43; Horst Wenzel/Ludwig Jäger (Hg.), Deixis und Evidenz, Freiburg/Br. 2007 (im Druck).

${ }^{200}$ Vgl. Sybille Krämer, ,Sagen und Zeigen. Sechs Perspektiven, in denen das Diskursive und das Ikonische in der Sprache konvergieren", in: Zeitschrift für Germanistik N. F. 3/2003, S. 509-519; außerdem Wirth, Performanz (wie Anm. 153), S. 36 (Einleitung), 
Die mediale Perspektive findet dergestalt in den mittelalterlichen Eigenlogiken und -semantiken sowohl historische Untersuchungsfelder wie modellhafte Konstellationen. Sie bietet die Möglichkeit, neue Blicke auf die Überlieferung mit einer Reflexion der Bedingungen von Überlieferung und ihrer Erschließung zu verknüpfen. Tatsächlich handelt es sich ja bei Medialität, wie bei Materialität, Performativität oder Semiotizität, zuallererst um eine methodologische Kategorie, die zwar am Gegenstand sich zeigt, doch dies nur gemäß der spezifischen Perspektive, die sich auf diesen richtet. Mit jeder der Kategorien verbindet sich die Entscheidung für eine be st immte Fokussierung von Geschichte und Überlieferung und die Möglichkeit, bestimmte Differenzierungen zu gewinnen. Performativität das beträfe die Vollzugsdimensionen eines Objekts und einer Situation, die durch Rahmungen und Wiederholungen konstituiert wird. Materialität - das beträfe die Gegebenheiten des Objekts oder der Situation, die für jeden Sinnvollzug benötigt und zugleich von diesem überschritten wird. Semiotizität - das beträfe die Zeichenhaftigkeit der Überlieferung, die auch dort gegeben ist, wo eine Präsenz von Objekt oder Situation zu dominieren scheint. Medialität - das könnte als jene Größe begriffen werden, die sich materiell in den performativen Vollzügen semiotischer Gefüge zeigt und zwar sich dergestalt zeigt, daß ein Mittleres zugleich als Vermittelndes erscheint. Mit ihm wären Möglichkeiten des Bedeutens gesetzt, die weder einfach im Materiellen fundiert und im Zeichenhaften codiert wären, sondern jeweils aus einer Bewegung $\mathrm{zw}$ is $\mathrm{ch}$ e $\mathrm{n}$ beiden hervorgehen und in Wiederholung und Abweichung sich realisieren.

Mit den Stichworten Wiederholung und Abweichung sind zugleich zentrale Aspekte mittelalterlicher Kultur genannt ${ }^{201}$ An ihr läßt sich exemplarisch beobachten, wie Medien nicht nur der Übermittlung (von Information und Wissen), sondern auch der Übertragung (von Energie) dienen und wie beides, Übermittlung und Übertragung, auf Vorgegebenes und Ursprüngliches bezogen ist, das im Hier und Jetzt zu vergegenwärtigen die Geltung des je Gegenwärtigen sichert. Dies bedenkend, wäre der Übergang zum Zeitalter des Buchdrucks und einer medialisierten Öffentlichkeit nicht einfach als Durchsetzung neuer technischer und kommunikativer Standards zu beschreiben. Er wäre im größeren Rahmen epistemischer Pluralisierungen, institutioneller Differenzierungen und semantischer Umbesetzungen zu se-

S. 267 (Eco); Mersch, Was sich zeigt (wie Anm. 161); ders., Medientheorien (wie Anm. 2), S. 224.

${ }^{201}$ Vgl. zuletzt Monique Goullet, Écriture et réécriture hagiographiques. Essai sur les réécritures de Vies de saints dans l'Occident latin médiéval (VIIf-XIII s.), Turnhout 2005. 
hen. Dann könnte auch deutlich werden, inwieweit das im 19. Jahrhundert geläufig werdende Verständnis des Medialen als eines universalen Apriori mit einer Verschiebung der onto-theologischen und transzendenzbezogenen Grundierung von Medialität zusammenhängt: Erst dort, wo Medien zu Formen werden, unähnlich dem, was sie übermitteln, bilden sie jene formale kommunikationslogische Struktur, die jeden Welt- und Wirklichkeitszugang zu bestimmen scheint und für jeden eigene Formen bereithält: Medien der Kunst, der Religion, der Politik, der Geschichte etc. Erst diese umfassende Medialisierung bringt wiederum jene Frage nach dem Realen oder dem Nicht-Medialen hervor, die Mediendiskurse und -gebrauch seit einiger Zeit durchzieht. ${ }^{202}$ Auch im Hinblick auf diese Frage kann der Blick auf die im Mittelalter anders laufenden Grenzziehungen zwischen Medialem und Realem, Texthermeneutik und Welthermeneutik, semiotischem und ontologischem Zeichenverständnis erhellend sein.

${ }^{202}$ Vgl. Benjamin Jörissen, Beobachtungen der Realität. Die Frage nach der Wirklichkeit im Zeitalter der Neuen Medien, Bielefeld 2007. 